\title{
Baseline household survey: Dadu district
}

Pakistan Initiative for Mothers and Newborns (PAIMAN)

Follow this and additional works at: https://knowledgecommons.popcouncil.org/departments_sbsr-rh

Part of the Family, Life Course, and Society Commons, and the Maternal and Child Health Commons How does access to this work benefit you? Let us know!

\section{Recommended Citation}

Pakistan Initiative for Mothers and Newborns (PAIMAN). 2006. "Baseline household survey: Dadu district." Islamabad: Population Council. 


\section{Baseline Household Survey Dadu DISTRICT}





\section{Pakistan Initiative for Mothers and Newborns (PAIMAN)}

\section{Dadu \\ Baseline Household Survey}




\section{(1) Population Council}

The Population Council, an international, non-profit, non-governmental organization established in 1952, seeks to improve the well-being and reproductive health of current and future generations around the world and to help achieve a humane, equitable, and sustainable balance between people and resources.

The Council analyzes population issues and trends; conducts research in the reproductive sciences; develops new contraceptives; works with public and private agencies to improve the quality and outreach of family planning and reproductive health services; helps governments design and implement effective population policies; communicates the results of research in the population field to diverse audiences; and helps strengthen professional resources in developing countries through collaborative research and programs, technical exchanges, awards, and fellowships.

\section{For inquiries, please contact:}

Population Council

\#7, Street 62, F-6/3, Islamabad, Pakistan

Tel: 92512277439

Fax: 92512821401

Email: info@pcpak.org

web: http://www.popcouncil.org

Layout \& Design : Ali Ammad

Printed by: Crystal Printers, Islamabad

Disclaimer:

"This study/report is made possible by the generous support of the American people through the United States Agency for International Development (USAID). The contents are the responsibility of JSI Research \& Training Institute, Inc. and do not necessarily reflect the views of USAID or the United States Government." 


\section{Contents}

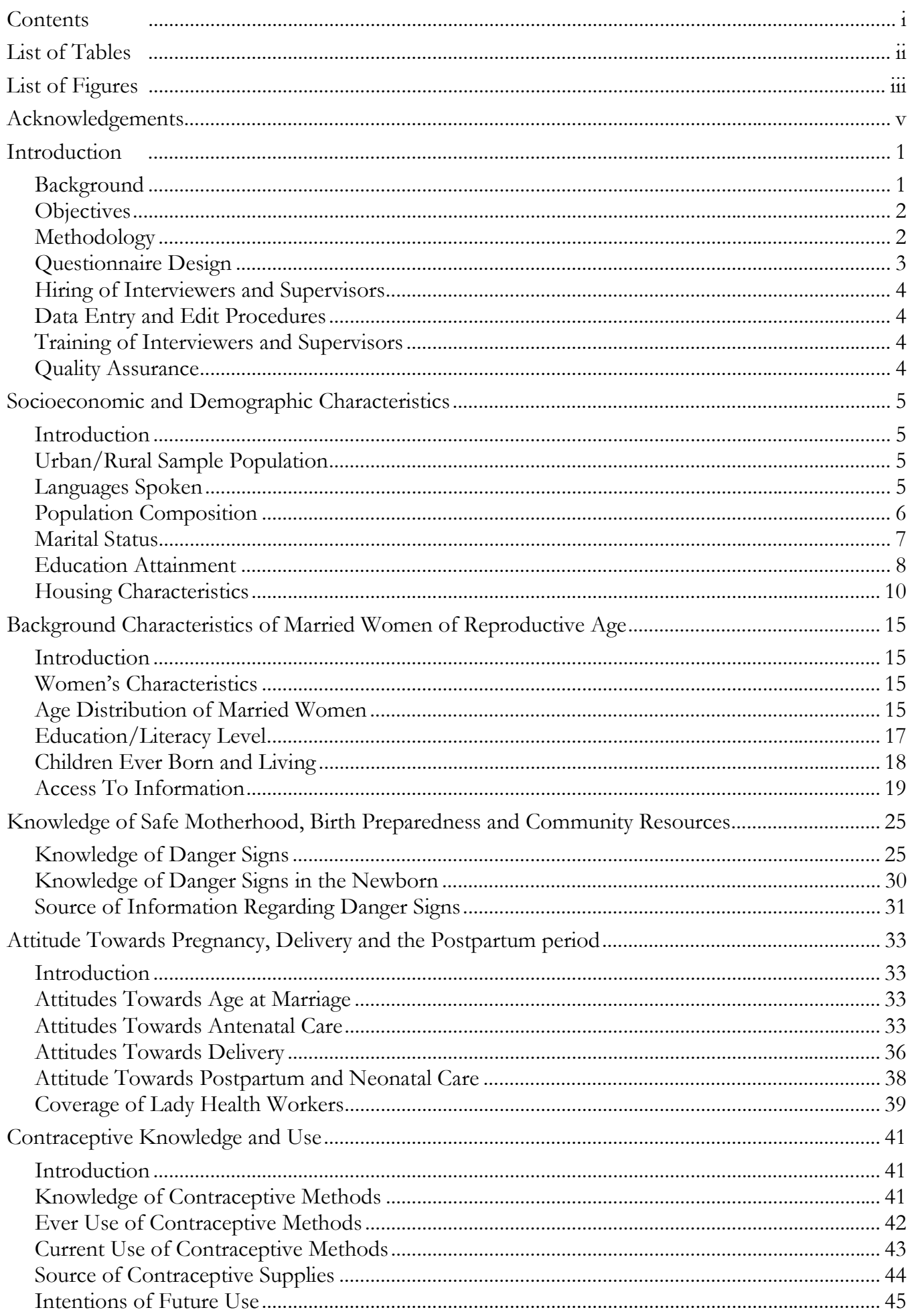




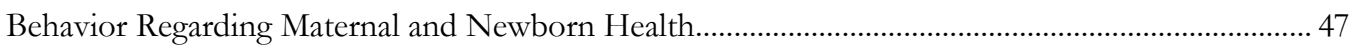

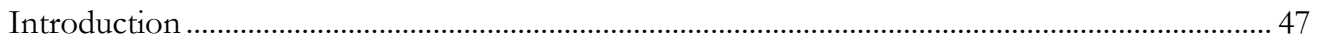

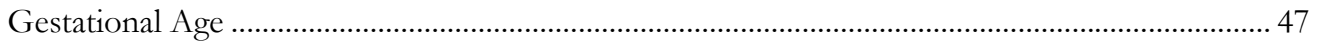

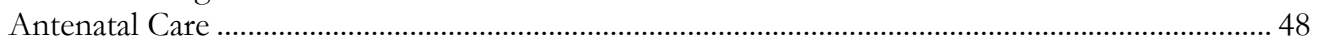

Tetanus Toxoid Injections and Iron/Folate Supplements .......................................................... 51

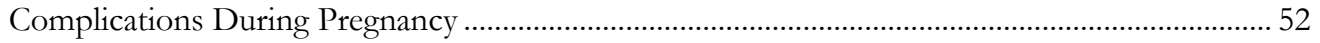

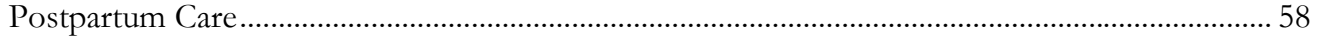

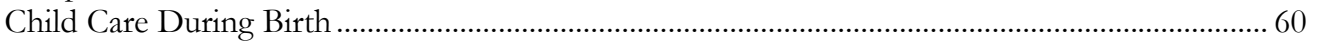

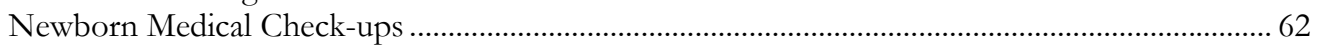

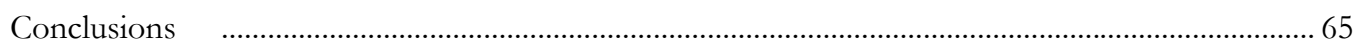

References

\section{List of Tables}

Table 1.1: Number of blocks/villages and households selected for the sample population .......... 2

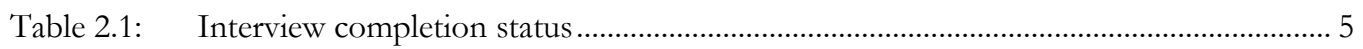

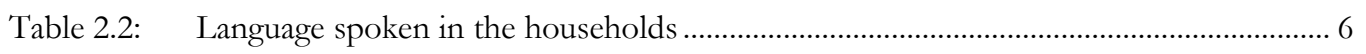

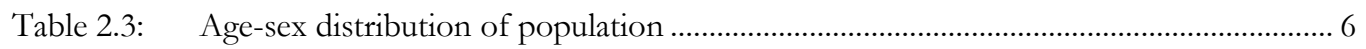

Table 2.4: Household population by age (15 years and above), sex and marital status.................. 8

Table 2.5: Household population by age (10 years and above), sex and educational level............. 9

Table 2.6: Main source of drinking water........................................................................................... 10

Table 2.7: Type of toilet facility used by household members ........................................................ 11

Table 2.8: Main type of fuel used in the households for cooking .................................................... 11

Table 2.9: Number of rooms used for sleeping.......................................................................... 12

Table 2.10: Ownership of household commodities/land ............................................................ 13

Table 3.1: Current age and age at marriage .................................................................................... 16

Table 3.2a: Education level and literacy of MWRA ........................................................................ 17

Table 3.2b: Education and literacy of the husbands of MWRA ......................................................... 17

Table 3.3: Percentage distribution of married women by number of children ever born, mean number of children ever born, living children and age group, compared to the 1998 Population census................................................................................................ 18

Table 3.4: Percentage distribution of married women by length of preceding birth interval....... 19

Table 3.5: Frequency of watching television..................................................................................... 20

Table 3.6: $\quad$ Place where respondent usually watches television ......................................................... 20

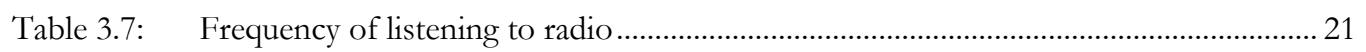

Table 3.8: Place where respondent listens to the radio................................................................... 22

Table 4.1: $\quad$ Source of information regarding danger signs during pregnancy .................................. 31

Table 4.2: Knowledge of existence and importance of transport, blood and finances by the community at the time of delivery .................................................................................. 32

Table 5.1: Importance of antenatal check-ups ................................................................................ 34

Table 5.2: Month of pregnancy when women should obtain antenatal care ................................ 34

Table 5.3: Number of antenatal visits considered necessary by respondents................................ 35

Table 5.4: Respondents who believe that women should receive delivery services from

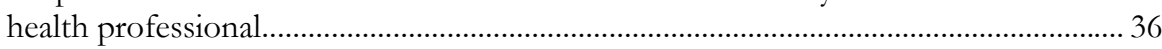


Table 5.5: Person who should make decisions regarding the health of a pregnant women ......... 37

Table 5.6: Belief in necessity of postnatal care ................................................................................ 38

Table 5.7: Presence of lady health worker in the community.......................................................... 39

Table 5.8: $\quad$ LHW ever visited home during last three months ........................................................... 39

Table 6.1: $\quad$ Ever use of family planning method by contraceptive.................................................... 42

Table 6.2: Current use of family planning method by contraceptive............................................. 43

Table 6.3: Distribution of contraceptive users by last source of supply ...................................... 44

Table 7.1: Pregnancy outcome by gestational age ......................................................................... 48

Table 7.2: Antenatal Check-ups by Place of Residence .................................................................... 49

Table 7.3: $\quad$ Type of complications experienced during the last delivery........................................... 56

Table 7.4: Person who made decision to seek health care/mode of transport used to reach

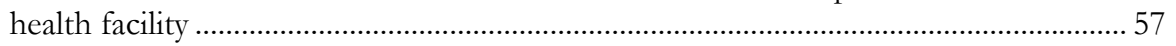

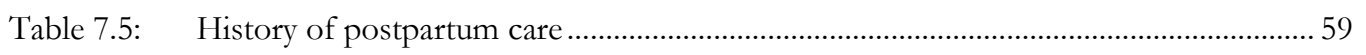

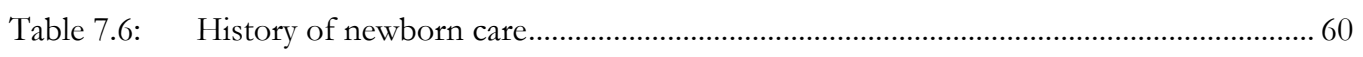

Table 7.7: $\quad$ Place where treatment was sought for newborn complications ................................... 63

\section{List of Figures}

Figure 2.1: Material used for construction of roof ........................................................................ 12

Figure 3.1: Age distribution ..................................................................................................... 16

Figure 3.2: Percentage of women who watch television or listen to the radio ............................... 20

Figure 3.3: Influence of television programs on the health behaviors of people ............................ 21

Figure 3.4: Influence of radio on health behaviors.......................................................................... 22

Figure 3.5: Frequency of reading newspaper........................................................................... 23

Figure 3.6: Exposure to mass media (radio, television or newspaper) ........................................... 23

Figure 3.7: Most trustworthy form of media................................................................................. 24

Figure 3.8: Percentage of married women who had heard/read maternal and newborn messages during the last 3 months by place of residence, PAIMAN Baseline

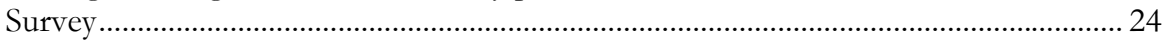

Figure 4.1: Knowledge of danger signs during pregnancy, which require medical attention ........ 26

Figure 4.2: Percentage distribution of women by knowledge of the number of danger signs

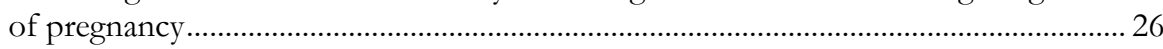

Figure 4.3: Percentage distribution of respondents who had knowledge about complications

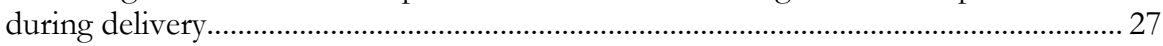

Figure 4.4: Percentage distribution of women by knowledge of number of danger signs of

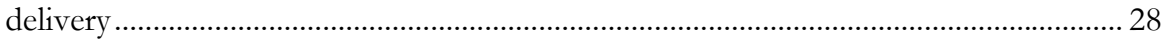

Figure 4.5: Percentage of married women who had knowledge about complication during postpartum period.

Figure 4.6: Percentage distribution of women by number of known danger signs of postpartum period

Figure 4.7: Percentage distribution of respondents who had knowledge about danger signs in newborns 
Figure 4.8: Percentage distribution of women by knowledge of the number of danger signs

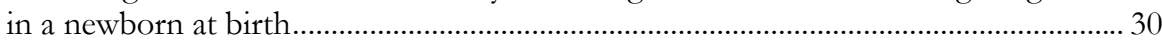

Figure 5.1: Percentage of married women who thought it necessary to receive TT shots and take iron/folate tablets during pregnancy ..................................................................... 35

Figure 5.2: $\quad$ Percentage of respondents who believe women in their community obtain delivery services from Health Professionals ..................................................................... 36

Figure 5.3: Perception of respondent regarding place of delivery .................................................. 37

Figure 5.4: Percentage of married women by mode of transport they would use to reach a health facility

Figure 5.5: Number of postnatal care visits women should have in the community by place of residence 38

Figure 6.1: Percentage of married women by knowledge of specific contraceptive method rural Dadu. 41

Figure 6.2: Percentage of married women by knowledge of specific contraceptive method -

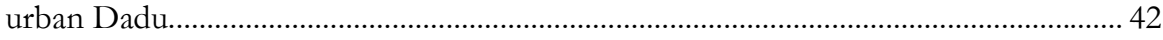

Figure 6.3: Percentage of married women by future intention to use contraceptives .................... 45

Figure 7.1: Number of antenatal check-ups obtained .................................................................... 48

Figure 7.2: $\quad$ Services performed/questions asked during antenatal check-up ............................... 50

Figure 7.3: Percentage of pregnant women by issues discussed during antenatal check-up.......... 51

Figure 7.4: Percentage of married women by status of TT injections during the last

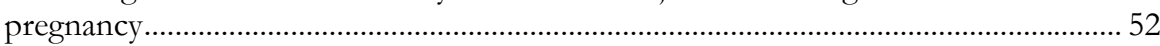

Figure 7.5: Percentage of married women who experienced complications during their last

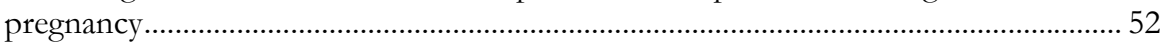

Figure 7.6: Percentage of married women who made arrangements for their last delivery ........... 53

Figure 7.7: Percentage of women by place of delivery and place of residence.............................. 54

Figure 7.8: Distribution of births by type of attendant (of those births that took place at

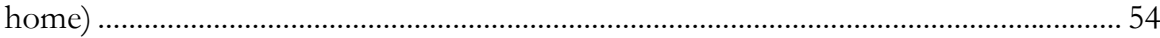

Figure 7.9: Main reason for using a TBA/dai to assist with the last delivery ................................. 55

Figure 7.10: Percentage of delivery attendants reporting clean delivery practices............................ 55

Figure 7.11: Mode of transport used to reach health facility to seek treatment for complication during delivery.....

Figure: 7.12: Time taken to reach the health facility for delivery complications .............................. 58

Figure 7.13: Average (median) time to get the transport, to reach the health facility and to obtain the treatment after reaching the facility ................................................................ 58

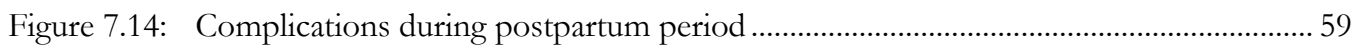

Figure 7.15: Percentage of live births by their size (small, normal and big) at birth ...................... 61

Figure 7.16: Percentage of babies by time of given bath after birth................................................ 61

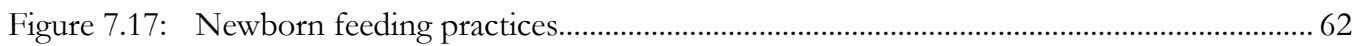

Figure 7.18: Percentage of newborns with danger signs/symptoms soon after delivery ................. 63

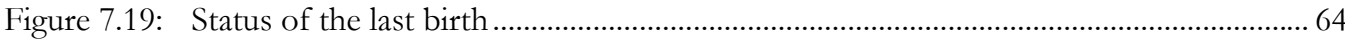




\section{Acknowledgements}

The PAIMAN Baseline Household Survey is a collaborative effort involving many partners, and will be the foundation of the PAIMAN project as a whole. Firstly, we would like to acknowledge our major partners. The United States Agency for International Development (USAID), in particular Mr. Chris McDermott, made funding available for this activity. Dr. Nabeela Ali, Chief of Party for PAIMAN, encouraged the study in general, and greatly facilitated the partnership between the Population Council and NIPS. The role of NIPS was supported under a separate agreement with PAIMAN. The comments, suggestions and feedback received from PAIMAN partners with regard to the design of this activity greatly contributed towards the success of the household survey.

The National Institute of Population Studies (NIPS) ably carried out the fieldwork for this study and was responsible for the completion of a clean dataset. We would like to appreciate the efforts of the Executive Director, Dr. Saeed Shafqat; and the Director Mr. Mahboob Sultan for the timely execution of the fieldwork; Computer Programmer, Mr. Fateh-ud-din, who managed the entry and cleaning of the data and the numerous NIPS staff members who carried out the study.

The Population Council was primarily responsible for designing the study, overseeing the data collection, analysis of data, and writing the reports. Dr. Arshad Mahmood, Director of Monitoring and Evaluation for PAIMAN, used his capable technical and managerial skills to oversee the entire study with enthusiasm and energy. Mr. Peter Miller, Deputy Country Director, contributed substantially in the design phase, and Dr. Sathar and Mr. Miller contributed towards the report preparation.

The essential work of the study was carried out by several Council staff members at all phases. During the design and pre-testing phases, we would particularly like to acknowledge Shagufta Naheed, Bushra Bano, Tayyaba Gul, and Saima Pervaiz for monitoring fieldwork and ensuring quality data collection in the field. Muhammad Ashraf and Saman Naz assisted in preparing graphs and tables as well as with the writing process. Dr. Arshad Mahmood and Reem Khan jointly prepared the first draft of the baseline survey report, which served as the template for all ten district reports. Shafique Arif, Azeema Faizunisa and Nadia Abid also contributed to the report writing and reviewing process. Reem Khan completed the initial editing of the baseline reports, Mehdi Ali Khan designed their layout, Ali Ammad was responsible for the formatting, and Ms. Mary DeSouza carried out the final proofreading of the district reports.

Finally, we must express our gratitude to the women of Dadu, who gave their time freely and cooperated with us in order to make this study possible. We hope to repay them by using the information obtained from them to improve maternal and neonatal health services in the district of Dadu. 



\section{Chapter}

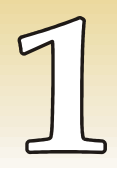

\section{Introduction}

\section{Background}

The Pakistan Initiative for Mothers and Newborns (PAIMAN) is a five-year project funded by the United States Agency for International Development (USAID). PAIMAN is committed to assisting the Government of Pakistan (GoP) in the implementation of the full spectrum of interventions necessary to address maternal and neonatal health $(\mathrm{MNH})$ issues.

The consortium is led by John Snow Incorporated (JSI), with partners from Pakistani and international organizations including Aga Khan University, Contech, Greenstar Social Marketing, Johns Hopkins University Center for Communication Program (JHU), PAVHNA, Population Council and Save the Children USA.

USAID has provided a grant to implement PAIMAN in 10 districts of Pakistan's four provinces. These districts are: Rawalpindi, Jhelum, Khanewal, and DG Khan in Punjab; Dadu and Sukkur in Sindh; Jaffarabad and Lasbela in Balochistan; and Upper Dir and Bunner in the North West Frontier Province. The goal of the project is to reduce maternal, newborn and child mortality in Pakistan. The project is based on the "Pathway to Care and Survival" framework. The five major strategic objectives are to:

1) Increase awareness and promote positive maternal and neonatal health behaviors

2) Increase access (including essential obstetric care) to and community involvement in maternal and child health services, while ensuring that services are successfully delivered through health and ancillary health services

3) Improve service quality in both the public and private sectors, particularly related to management of obstetrical complications

4) Increase capacity of Maternal and Newborn Health $(\mathrm{MNH})$ managers and care providers

5) Improve management and integration of services at all levels

The PAIMAN Project will promote skilled attendants as the long-term goal for all deliveries in Pakistan, while acknowledging that maternal and neonatal health outcomes are influenced by factors other than health care. The PAIMAN Project calls for a multi-pronged and integrated strategic approach, combining individual health care with public health and community-based interventions.

To ensure that the success of PAIMAN is properly attained and that the appropriate lessons are learned, PAIMAN has developed a Monitoring and Evaluation Plan. Included in this plan is the 
establishment of baseline measures for a set of indicators which will be used to evaluate the success of the project. This baseline report explores the level of knowledge of, as well as the attitudes and behaviors towards, maternal and newborn health in the DG Khan district. The specific objectives of the baseline survey were as follows.

\section{Objectives}

- To measure the Intermediate Result 7 indicators necessary as part of PAIMAN's obligation to USAID.

- To measure PAIMAN indicators for which household survey data are appropriate for measurement and for which sample sizes are feasible.

- To obtain information on maternal and neonatal health along with related issues, which may be of use to district Departments of Health for health management purposes.

- To obtain information needed for the detailed design of the PAIMAN project, in particular behavior change communication, public/private partnerships, and health systems strengthening.

\section{Methodology}

\section{Study Population}

PAIMAN is primarily a district-level project, intended to improve the health of all pregnant women, women with neonatal children, as well as all neonates of the district over the course of the project. To this end, the study covers community residents - notably mothers and prospective mothers - in order to understand and measure general knowledge and practice of issues in relation to pregnancy, delivery, obstetric and neonatal emergencies etc.

Hence, the study population for the baseline includes all currently married women of reproductive age (15-49 years) living in the selected districts. More specifically, it includes women who have experienced a pregnancy during the last three years.

\section{Sample Design}

The sampling design adopted for the survey is a stratified, systematic sample of households. The universe consists of all urban and rural areas of the district. The number of blocks selected in urban areas, along with the number of villages selected in rural areas, are presented in table 1.1. The selection procedure is described below:

Table 1.1: $\quad$ Number of blocks/villages and households selected for the sample population

\begin{tabular}{lrr} 
Area & $\begin{array}{r}\text { Number of Sample } \\
\text { Blocks/Villages }\end{array}$ & $\begin{array}{r}\text { Number of Households } \\
\text { Selected }\end{array}$ \\
\hline Urban & 8 & 196 \\
\hline Rural & 32 & 764 \\
Total & 40 & 960
\end{tabular}




\section{Urban Sample}

The required numbers of enumeration blocks were selected with probability proportional to size (number of circles). The "Enumeration Circle" was the smallest unit available in the 1998 Population District Census Reports as demarcated by the Population Census organizations. The maps of these circles were obtained from the Population Census Organization.

The areas were already divided into blocks of approximately 250-300 households depending upon the number of households in each circle. Later, blocks were randomly selected with probability proportional to size from the list of total blocks in that circle. The listing of each block was then updated by the enumeration teams before selecting the sampled households. A fixed number of 24 households were drawn from each sample enumeration block by using systematic random technique.

\section{Rural Sample}

The 1998 Population Census list of villages was used as the sampling frame for the selection of the rural sample. Villages in rural areas have been treated as primary sampling units (PSU). Sample PSUs have been selected with probability proportional to size (number of households). Households within the sample PSUs were considered secondary sampling units. The enumeration teams then updated the listing of each village before selecting the sampled households. A fixed number of 24 households were drawn from each sample enumeration village by the systematic random technique.

\section{Questionnaire Design}

The questionnaires have been developed by the Population Council, based on a combination of current general Demographic and Health Survey methodologies and the questionnaire developed by the Population Council for the Safe Motherhood Applied Research and Training (SMART) Project. The questionnaire contains data sufficient to estimate all PAIMAN indicators.

Information on the following is included in the questionnaires:

- Households information

- Socio-economic status of women

- Fertility, pregnancy history and reproductive intentions

- Attitude towards, as well as knowledge and practice of contraceptive methods

- Attitude towards pregnancy, delivery and the postpartum period

- Current birth preparedness/complications readiness (BP/CR) and knowledge of newborn care

- Current birth practices

- Health seeking behaviors

- Future BP/CR intentions

- Personal beliefs regarding pregnancy, delivery and the postpartum period

- Common perceptions pertaining to women who are pregnant, delivering or in their postpartum period

- Facilities regarding BP/CR available in the community

- Factors that facilitate or hinder behaviors related to BP/CR

- Media habits 


\section{Pre-testing of Questionnaires}

The questionnaire was reviewed by the PAIMAN's M\&E thematic group, along with other interested stakeholders, and was pre-tested in non-PAIMAN districts. The main objective of the pre-testing was to examine the suitability and effectiveness of questions in eliciting adequate responses, and to find out if there were any linguistic problems faced either by interviewers or by respondents. Finally, the pre-testing also helped determine the approximate time required to complete a questionnaire. The pre-tests were carried out by the Population Council's female staff members, who recorded their experiences with regard to each question. These records were then used to revise and finalize the questionnaire.

\section{Hiring of Interviewers and Supervisors}

Since the respondents in the baseline were to be MWRA and married men, it was decided that female interviewers would be used to interview women and male interviewers for men. Based on the constitution of each team, the required number of female interviewers were hired by NIPS according to its own internal procedures.

\section{Data Entry and Edit Procedures}

Data processing was started from the field level with the checking of the questionnaires. Each team leader completed on-the-spot checks and preliminary editing of questionnaires during the enumeration period. Editing instructions were provided to the team leaders, and emphasis was laid on the importance of completing each questionnaire, correctly identifying each eligible respondent, and the completeness of household composition.

\section{Training of Interviewers and Supervisors}

The quality of training received by interviewers is reflected in the quality of data they record. In order to ensure that interviews were of a high and uniform quality and that interviewers understood the definitions and concepts behind the language of the questions, training was conducted by the Population Council in collaboration with NIPS. The training took place in Islamabad over two weeks and interviewers were schooled in questionnaire and survey procedures. Interviewers visited 3-4 households to conduct practice interviews;

It was very important for the interviewers to thoroughly understand the methodology and statistical importance of the sampled households. Training regarding the importance of the criterion for the selection of primary sampling units, mapping and listing procedure, sample selection, field operation procedures, as well as the selection of the particular households and respondents was also provided by experts.

\section{Quality Assurance}

To ensure the quality of the data, Population Council staff monitored the fieldwork accompanying the field teams. While supervising the fieldwork, Population Council supervisory staff was also available to provide on-the-spot guidance to interviewers in the event that any part of the questionnaire was unclear to them. This ensured the completeness and accuracy of each questionnaire. 


\section{Chapter

\section{Socioeconomic and Demographic Characteristics}

\section{Introduction}

This chapter presents the demographic and socioeconomic characteristics of the population in the households surveyed in Dadu. Information was collected on some demographic and socioeconomic characteristics such as the condition of the households, including the source of drinking water, sanitation facilities, building materials, and possession of household durable goods. This information on the characteristics of the households is essential for the interpretation of survey findings. The definition of the household used for the baseline survey was "a person or a group of persons, related or unrelated, who live together in the same dwelling unit and share a common source of food".

\section{Urban/Rural Sample Population}

The results of the household interviews by their completion status are presented in table 2.1. The data shows that the overall rate of success was very high. Only 10 households out of 960 (1 percent) refused to take part in the survey, while only one household interview could not be completed.

Table 2.1: $\quad$ Interview completion status

\begin{tabular}{lr|r|r|rrr} 
& \multicolumn{2}{c}{ Rural } & \multicolumn{2}{c}{ Urban } & \multicolumn{2}{c}{ Total } \\
\cline { 2 - 8 } \multicolumn{1}{c}{ Result } & Percent & Number & Percent & Number & Percent & Number \\
\hline Completed & 98.7 & 758 & 99.5 & 191 & 98.9 & 949 \\
\hline Incomplete & 0.1 & 1 & & & 0.1 & 1 \\
\hline Refused & 1.2 & 9 & 0.5 & 1 & 1.0 & 10 \\
Total & 100.0 & 768 & 100.0 & 192 & 100.0 & 960
\end{tabular}

\section{Languages Spoken}

In order to design effective information and communication campaigns, and service delivery programs for an area, language and ethnic composition is one of the most critical variables to consider. Language spoken at home is the key to the ethnic identity of the household, and can also be a proxy for the socio-economic status of the household in a particular community. Table 2.2 shows the languages spoken in the surveyed households of Dadu. About half of the respondents in the district of Dadu speak Sindhi in their homes. The other two commonly spoken languages are Saraiki (32 percent) and Balochi (16 percent). The urban-rural differential in this regard is negligible. Households that speak Urdu, Punjabi or Barahvi make up less than 1 percent of the sample population, showing quite a homogenous ethnic picture for the area. 
Table 2.2:

Language spoken in the households

\begin{tabular}{lrrrrrr}
\multicolumn{1}{r}{ Language } & \multicolumn{2}{c}{ Rural } & \multicolumn{2}{c}{ Urban } & \multicolumn{2}{c}{ Total } \\
\cline { 2 - 7 } Urdu & Percent & Number & Percent & Number & Percent & Number \\
\hline Punjabi & 0.1 & 1 & 2.1 & 4 & 0.5 & 5 \\
\hline Sindhi & & & 1.6 & 3 & 0.3 & 3 \\
\hline Balochi & 48.9 & 371 & 59.2 & 113 & 51.0 & 484 \\
\hline Barahvi & 18.2 & 138 & 7.3 & 14 & 16.0 & 152 \\
\hline Saraiki & 0.4 & 3 & 0.5 & 1 & 0.4 & 4 \\
\hline Others & 32.2 & 244 & 29.3 & 56 & 31.6 & 300 \\
\hline Total & 0.1 & 1 & & & 0.1 & 1 \\
& 100 & 758 & 100.0 & 191 & 100.0 & 949
\end{tabular}

\section{Population Composition}

The age-sex distribution of all household members is presented in Table 2.3. The largest age group is the 5-9 year age group, which (erroneously) suggests a fertility decline in the youngest age group (less than 5 years). However, it should be noted that underreporting the youngest age group is a typical enumeration error in developing countries.

The population in this district could be considered "very young" as more than half (54 percent) are below the age of 20 . One fifth (20 percent) of the respondents fall into the 15 to 24 year age group. Moreover, the proportion of senior citizens ( 65 years or older) in the sampled households is 4 percent. The overall sex ratio in Dadu is 108 males per 100 females, which is almost the same as noted in the 1998 Population Census for Pakistan.

Table 2.3: $\quad$ Age-sex distribution of population

\begin{tabular}{lrrrrrr} 
& \multicolumn{2}{c}{ Males } & \multicolumn{2}{c}{ Females } & \multicolumn{2}{c}{ Both Sexes } \\
\multicolumn{1}{c}{ Age-group } & Number & Percent & Number & Percent & Number & Percent \\
\hline$<5$ & 579 & 13.7 & 504 & 12.8 & 1083 & 13.3 \\
\hline $5-9$ & 659 & 15.5 & 680 & 17.3 & 1339 & 16.4 \\
\hline $10-14$ & 583 & 13.8 & 486 & 12.4 & 1069 & 13.1 \\
\hline $15-19$ & 473 & 11.2 & 456 & 11.6 & 929 & 11.4 \\
\hline $20-24$ & 375 & 8.8 & 363 & 9.2 & 738 & 9.0 \\
\hline $25-29$ & 321 & 7.6 & 311 & 7.9 & 632 & 7.7 \\
\hline $30-34$ & 222 & 5.2 & 211 & 5.4 & 433 & 5.3 \\
\hline $35-39$ & 220 & 5.2 & 162 & 4.1 & 382 & 4.7 \\
\hline $40-44$ & 141 & 3.3 & 126 & 3.2 & 267 & 3.3 \\
\hline $45-49$ & 153 & 3.6 & 76 & 1.9 & 229 & 2.8 \\
\hline $50-54$ & 127 & 3.0 & 229 & 5.8 & 356 & 4.4 \\
\hline $55-59$ & 124 & 2.9 & 99 & 2.5 & 223 & 2.7 \\
\hline $60-64$ & 91 & 2.1 & 83 & 2.1 & 174 & 2.1 \\
\hline 65 and older & 170 & 4.0 & 141 & 3.6 & 311 & 3.8 \\
\hline Total & 4,238 & 100.0 & 3,927 & 100.0 & 8,165 & 100.0
\end{tabular}




\section{Marital Status}

The survey also collectd information on the marital status of all household members over 15 years of age. The marital status of all household members above the age of 14 in the district of Dadu is given in table 2.4. For comparison, the results are juxtaposed with the 1998 Population Census data for marriage. Overall, 40 percent of the male and 29 percent of the female population in our sample have never married. More than half of the males (57 percent) and around two thirds of the females (63 percent) were currently married at the time of the survey. Only a very small proportion (3 percent among males and 8 percent among females) reported that they were currently widowed, divorced or separated from their spouses. Looking at the age-related data, it is apparent that there has been a drop in early marriages for both the sexes since the 1998 Population Census. More than half of males marry before the age of 30 years, whereas by the age of 40, over 90 percent indicated the same. However, among the female household members, only 17 percent of the respondents in the 15-19 year age group are married, while over half (51 percent) of the females in the $20-24$ age group. By the age of 40, as with the males, more than 90 percent females were reportedly married. 
Table 2.4: $\quad$ Housebold population by age (15 years and above), sex and marital status

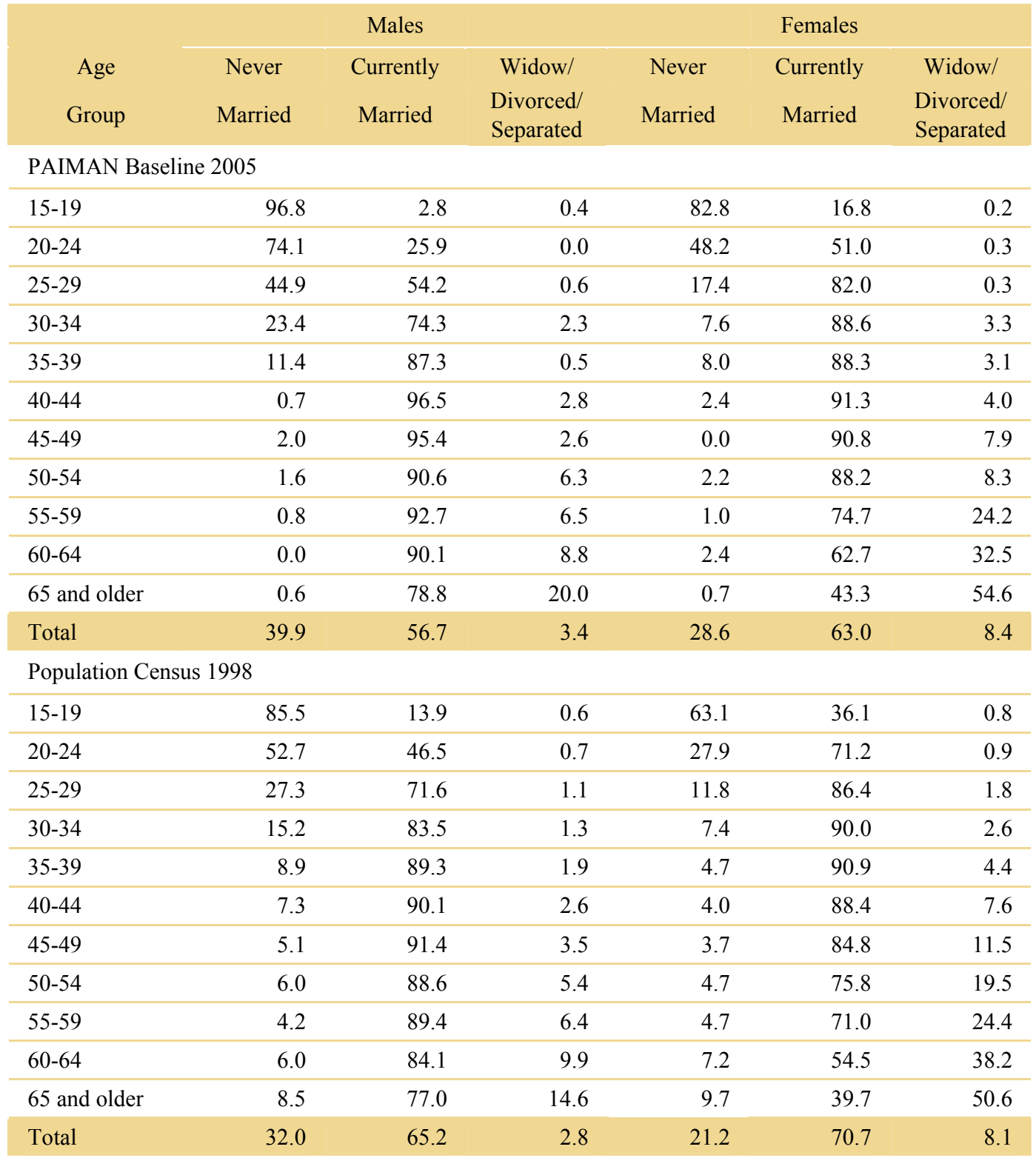

\section{Education Attainment}

Education is considered the most important indicator for social development. Unfortunately, Pakistan's educational scenario is not positive despite the government's commitment to universal free primary education. The education distribution of each surveyed household in Dadu by age and sex is provided in Table 2.5. Overall, almost 40 percent of males and 76 percent of females have never attended school, showing an abysmal education situation in the district.

More positively, the age distribution of schooling shows a positive trend, with the proportion of the school going population increasing with the younger age group. Over the years, the highest gain for males can be observed in secondary schooling (6-10 years), whereas females have made strides in 
completing primary level schooling. Despite wide levels of poor socio-economic indicators, around a quarter of males in this district (in age groups 20 to 39 years), have attained 11 or more years of education. The highest educational attainment among females is among the 20-24 year olds, of which a tenth has spent 11 or more years in school.

Table 2.5: $\quad$ Household population by age (10 years and above), sex and educational level

\begin{tabular}{|c|c|c|c|c|c|}
\hline Age & No & $1-5$ & $6-10$ & 11 and & Total \\
\hline Group & Schooling & Years & Years & More years & \\
\hline \multicolumn{6}{|l|}{ Males } \\
\hline $10-14$ & 38.1 & 47.5 & 14.4 & 0.0 & 583 \\
\hline $15-19$ & 33.6 & 18.2 & 38.3 & 9.9 & 473 \\
\hline $20-24$ & 25.9 & 18.7 & 33.3 & 22.1 & 375 \\
\hline $25-29$ & 34.3 & 14.3 & 25.5 & 25.9 & 321 \\
\hline $30-34$ & 38.3 & 14.9 & 20.3 & 26.6 & 222 \\
\hline $35-39$ & 39.5 & 20.5 & 15.9 & 24.1 & 220 \\
\hline $40-44$ & 54.6 & 19.9 & 12.8 & 12.8 & 141 \\
\hline $45-49$ & 38.6 & 37.9 & 14.4 & 9.2 & 153 \\
\hline $50-54$ & 45.7 & 29.9 & 14.2 & 10.2 & 127 \\
\hline $55-59$ & 46.8 & 35.5 & 8.1 & 9.7 & 124 \\
\hline $60-64$ & 58.2 & 23.1 & 13.2 & 5.5 & 91 \\
\hline 65 and older & 65.3 & 24.7 & 7.1 & 2.9 & 170 \\
\hline Total & 39.2 & 26.3 & 21.5 & 13.1 & 3000 \\
\hline \multicolumn{6}{|l|}{ Females } \\
\hline $10-14$ & 60.1 & 32.7 & 7.2 & 0.0 & 486 \\
\hline $15-19$ & 54.6 & 22.6 & 18.0 & 4.8 & 456 \\
\hline $20-24$ & 59.2 & 18.5 & 12.1 & 10.2 & 363 \\
\hline $25-29$ & 70.4 & 11.9 & 9.0 & 8.7 & 311 \\
\hline $30-34$ & 81.0 & 8.1 & 5.7 & 5.2 & 211 \\
\hline $35-39$ & 83.3 & 7.4 & 5.6 & 3.7 & 162 \\
\hline $40-44$ & 88.1 & 7.9 & 0.8 & 3.2 & 126 \\
\hline $45-49$ & 88.2 & 10.5 & 1.3 & 0.0 & 76 \\
\hline $50-54$ & 90.4 & 7.0 & 1.3 & 1.3 & 229 \\
\hline $55-59$ & 90.9 & 7.1 & 1.0 & 1.0 & 99 \\
\hline $60-64$ & 95.2 & 2.4 & 2.4 & 0.0 & 83 \\
\hline 65 and older & 95.0 & 4.3 & 0.7 & 0.0 & 141 \\
\hline Total & 75.7 & 17.1 & 8.4 & 4.3 & 2602 \\
\hline
\end{tabular}




\section{Housing Characteristics}

\section{Source of Drinking Water}

Access to safe drinking water is regarded as a fundamental marker of social development. In Dadu, almost 70 percent of the households reported having some kind of drinking water facility within the premises of their house (Table 2.6). Less than two-thirds (65 percent) of the households cited indoor motorized/hand pumps as their main source of drinking water, whereas a little more than a tenth (13 percent) reported having access to a motorized/hand pump outside the house. Governmental water supply seems to be very poor in the district of Dadu. Overall, only 7 percent of the households have access to government water supply facilities. Furthermore, half of the respondents who reported having access to a government supply of water, had access to this facility in the form of communal water taps. Ponds/canals/rivers/streams are the source of drinking water for about 1 percent of the sample population. One interesting aspect of the data is that there are no huge urban-rural differentials, as typically observed in other PAIMAN districts.

Table 2.6: $\quad$ Main source of drinking water

\begin{tabular}{lrrrrrr} 
& \multicolumn{2}{c}{ Rural } & \multicolumn{2}{c}{ Urban } & \multicolumn{2}{c}{ Total } \\
\cline { 2 - 7 } Source & Percent & Number & Percent & Number & Percent & Number \\
\hline Govt. supply (tap water inside) & 2.1 & 16 & 10.5 & 20 & 3.8 & 36 \\
\hline Govt. supply (communal) & 3.3 & 25 & 2.1 & 4 & 3.1 & 29 \\
\hline Motorized/hand pump (inside) & 60.4 & 458 & 83.8 & 160 & 65.1 & 618 \\
\hline Motorized/hand pump (outside) & 16.0 & 121 & 2.1 & 4 & 13.2 & 125 \\
\hline Well (inside) & 0.5 & 4 & 0.5 & 1 & 0.5 & 5 \\
\hline Well (outside) & 10.6 & 80 & 0.5 & 1 & 8.5 & 81 \\
\hline Tube-well & 0.3 & 2 & 0.0 & 0 & 0.2 & 2 \\
\hline River/canal/stream & 1.8 & 14 & 0.0 & 0 & 1.5 & 14 \\
\hline Pooled/pond water & 1.1 & 8 & 0.0 & 0 & 0.8 & 8 \\
\hline Others & 4.0 & 30 & 0.5 & 1 & 3.3 & 31 \\
\hline Total & 100.0 & 758 & 100.0 & 191 & 100.0 & 949
\end{tabular}

\section{Toilet Facilities}

The type of toilet facility used is another critical development indicator, and is strongly linked with infant deaths due to diseases like diarrhea. The data on toilet facilities for the district of Dadu is presented in table 2.7. The table demonstrates a grim picture for the whole district, as more than a quarter (28 percent) of the residents do not have any toilet facilities, and are forced to use fields. The picture is quite stark in rural areas as well, as one-third (33 percent) of the residents use fields as their main toilet facility. 
Table 2.7: $\quad$ Type of toilet facility used by household members

\begin{tabular}{lrrrrrrr}
\multirow{2}{*}{ Toilet facility } & \multicolumn{2}{c}{ Rural } & \multicolumn{2}{c}{ Urban } & \multicolumn{2}{c}{ Total } \\
\cline { 2 - 8 } & Percent & Number & Percent & Number & Percent & Number \\
Flush to sewerage & 0.5 & 4 & 13.1 & 25 & 3.1 & 29 \\
\hline Flush connected to septic tank & 9.2 & 70 & 3.7 & 7 & 8.1 & 77 \\
\hline Flush connected to open drain & 2.6 & 20 & 0.5 & 1 & 2.2 & 21 \\
\hline Raised latrine & 30.9 & 234 & 14.1 & 27 & 27.5 & 261 \\
\hline Pit latrine & 15.0 & 114 & 53.9 & 103 & 22.9 & 217 \\
\hline In fields & 33.0 & 250 & 9.4 & 18 & 28.2 & 268 \\
\hline Others & 8.7 & 66 & 5.2 & 10 & 8.0 & 76 \\
\hline Total & 100.0 & 758 & 100.0 & 191 & 100.0 & 949
\end{tabular}

\section{Fuel used for Cooking}

Due to its obvious connection with health and respiratory diseases, an important factor to ascertain development is the type of fuel used in households for the purpose of cooking. It is obvious from the statistics presented in table 2.8 that more than half (53 percent) of the respondents in this district use firewood as their main source of fuel for cooking needs. A closer look reveals that there are wide disparities between urban and rural areas. While almost three quarters (72 percent) of the households in urban areas enjoy the luxury of natural gas for cooking, in rural areas more than 90 percent of the population rely on either firewood or dry animal dung for this purpose.

Table 2.8: $\quad$ Main type of fuel used in the households for cooking

\begin{tabular}{lrrrrrrr}
\multirow{2}{*}{ Type of fuel } & \multicolumn{2}{c}{ Rural } & \multicolumn{2}{c}{ Urban } & \multicolumn{2}{c}{ Total } \\
\cline { 2 - 8 } Fire wood & Percent & Number & Percent & Number & Percent & Number \\
\hline Natural gas (Sui gas) & 62.4 & 473 & 17.8 & 34 & 53.4 & 507 \\
\hline Dry dung & 7.0 & 53 & 71.7 & 137 & 20.0 & 190 \\
\hline Charcoal/coal & 30.5 & 231 & 8.9 & 17 & 26.1 & 248 \\
\hline Others & 0.1 & 1 & 0.5 & 1 & 0.2 & 2 \\
Total & & & 1.0 & 2 & 0.2 & 2 \\
\hline
\end{tabular}

\section{Material Used for the Roof}

Material used for construction of the roof is another indication of the household economic status. Figure 2.1 presents findings on the materials used for roofs in the sample households. While a large majority of houses in urban areas (88 percent) have roofs made with girder and T-iron, only one tenth have wood/bamboo or mud roofs. In contrast, more than half (55 percent) roofs of the houses in rual areas are made with wood/bamboo or mud, and 44 percent are made with girder and T-iron. 
Figure 2.1: $\quad$ Material used for construction of roof

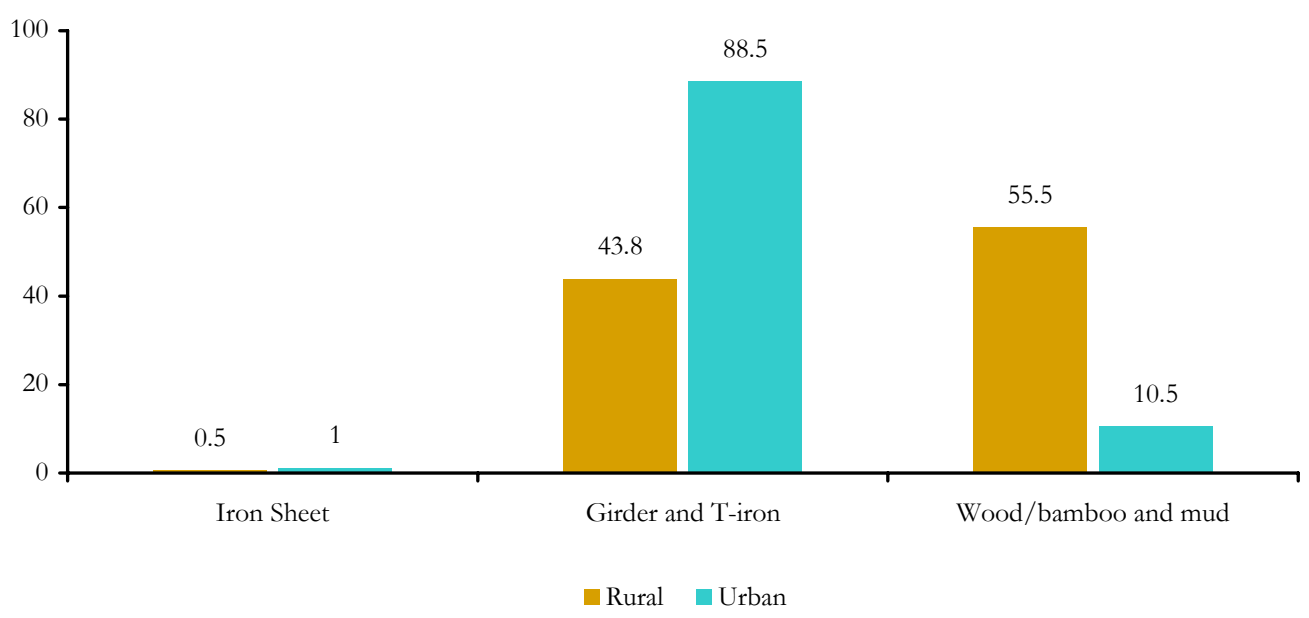

\section{Number of Rooms for Sleeping}

According to table 2.9, nearly half (47 percent) of the respondents live in one-bedroom households. A little more than a third (37 percent) live in two-bedroom houses. One-tenth of the households surveyed in Dadu have three rooms for the purpose of sleeping. Given the average household size of 8.4 members and 2.2 rooms, it can be concluded that there is a high level of crowding in the district (an average of 4.5 persons per room). The urban-rural differentials are minimal, which suggests that the district's overall economic status is quite low.

Table 2.9:

Number of rooms used for sleeping

\begin{tabular}{lrrrrrrr}
$\begin{array}{l}\text { Number of } \\
\text { rooms }\end{array}$ & \multicolumn{2}{c}{ Rural } & \multicolumn{2}{c}{ Urban } & \multicolumn{2}{c}{ Total } \\
\hline 1 & Percent & Number & Percent & Number & Percent & Number \\
\hline 2 & 53.9 & 406 & 18.3 & 35 & 46.7 & 441 \\
\hline 3 & 35.7 & 269 & 41.4 & 79 & 36.9 & 348 \\
\hline 4 & 6.1 & 46 & 25.1 & 48 & 10.0 & 94 \\
\hline $5+$ & 2.8 & 21 & 9.9 & 19 & 4.2 & 40 \\
\hline Total & 1.5 & 11 & 5.2 & 10 & 2.2 & 21 \\
\hline
\end{tabular}

\section{Household Possessions}

In Pakistan, as in other developing countries, where collection of income data is difficult, the ownership of property along with various household commodities measure household affluence. Often, it is easier to obtain information on household possessions than to ask for details about the household income, which respondents may be less willing to provide for various reasons. The PAIMAN Baseline household survey provides data on various commonly used household items such as irons, fans, telephones, televisions and property owned by the household etc. Findings are presented in Table 2.10. It is not surprising to see that there no major urban-rural differentials in the ownership of these items. Taking household possessions as a proxy indicator for progress can shed some light on household wealth levels. 
Two of the most commonly owned items in the households interviewed were electric irons and fans (53 percent and 78 percent respectively). Sewing machines were present in one third of the rural households and more than two thirds of urban households. About 40 percent of the rural households and 48 percent of the urban households confirmed radio ownership. Television was present in one third (37 percent) of the rural households and more than three-quarters ( 80 percent) of the urban households. In terms of means of transport, the most common possession was a bicycle (19 percent) followed by motorcycles (13 percent). One-third (37 percent) of the households owned some agricultural land, and of those, one-third (31 percent) indicated that they relied on income from these lands for their livelihood. A majority (96 percent) of the houses in which the respondents live are owned by the incumbents themselves.

Table 2.10: $\quad$ Ownership of household commodities/land

\begin{tabular}{lrrrr} 
& \multicolumn{1}{c}{ Household items } & Rural & Urban & Total \\
& & & Percentage & Number \\
\hline Electric iron & 44.2 & 87.4 & 52.9 & 502 \\
\hline Electric fan & 73.2 & 99.0 & 78.4 & 744 \\
\hline Sewing machine & 33.2 & 69.6 & 40.6 & 385 \\
\hline Radio or cassette player & 40.1 & 48.2 & 41.7 & 396 \\
\hline Chair/table & 14.5 & 52.4 & 22.1 & 210 \\
\hline Television & 36.5 & 80.1 & 45.3 & 430 \\
\hline Telephone/mobile phone & 13.3 & 46.6 & 20.0 & 190 \\
\hline Watch/clock & 57.3 & 89.0 & 63.6 & 604 \\
\hline VCR/VCP/VCD/CD player & 11.6 & 27.2 & 14.8 & 140 \\
\hline Refrigerator/deep freezer & 11.9 & 47.6 & 19.1 & 181 \\
\hline Air cooler & 1.7 & 15.7 & 4.5 & 43 \\
\hline Air conditioner & 1.3 & 16.2 & 4.3 & 41 \\
\hline Computer & 2.5 & 7.3 & 3.5 & 33 \\
\hline Bicycle & 18.2 & 20.4 & 18.7 & 177 \\
\hline Motorcycle & 10.9 & 20.9 & 13.0 & 123 \\
\hline Car/jeep & 2.9 & 7.9 & 3.9 & 37 \\
\hline Tractor/truck & 2.0 & 3.1 & 2.2 & 21 \\
\hline HH own any agriculture land & 39.7 & 25.1 & 36.8 & 349 \\
\hline Agriculture major source of livelihood & 33.9 & 16.8 & 30.5 & 289 \\
\hline Own household & 98.2 & 89.5 & 96.4 & 915 \\
\hline & & & & \\
\hline
\end{tabular}





\section{Chapter 3}

\section{Background Characteristics of Married Women of Reproductive Age}

\section{Introduction}

Information regarding the basic background characteristics of respondents is essential for the interpretation of survey findings. This chapter describes the basic background characteristics including age, education level, and place of residence of the respondents. It also describes detailed information on the educational status of respondents and their husbands, literacy levels, and exposure to mass media. Only currently married women aged 15-49 were interviewed for this portion of the survey.

\section{Women's Characteristics}

\section{Age Distribution of Married Women}

Table 3.1 gives an overview of the age distribution of the respondents, as well as the average age at which they got married. Of the eight hundred and ninety four women interviewed, a larger proportion belonged to the middle order age group, i.e. the 25-39 year age groups. The 15-19 and 45-49 year age groups made up only 7 percent of the total respondents, whereas the 25-29 year age group represents almost a quarter of the respondents.

The second part of the table shows respondents' age at marriage by their residence status. A majority of the women in this district (62 percent) got married between the ages of 15 to 19 years. Another 20 percent married between the ages of 20 to 24 . While only a small proportion ( 4 percent) of the women were married after the age of 25 , a sizeable number (13 percent) were married before the age of 15 years. The average age of marriage is 17 and 18 years, in rural and urban areas, respectively. 
Table 3.1: $\quad$ Current age and age at marriage

\begin{tabular}{lrrrrrr}
\hline \multicolumn{1}{c}{$\begin{array}{c}\text { Age of } \\
\text { respondent }\end{array}$} & \multicolumn{2}{c}{ Rural } & \multicolumn{2}{c}{ Urban } & \multicolumn{2}{c}{ Total } \\
\hline $15-19$ & Percent & Number & Percent & Number & Percent & Number \\
\hline $20-24$ & 17.1 & 53 & 5.7 & 11 & 7.2 & 64 \\
\hline $25-29$ & 21.9 & 153 & 28.4 & 55 & 23.3 & 208 \\
\hline $30-34$ & 19.1 & 134 & 15.5 & 30 & 18.3 & 164 \\
\hline $35-39$ & 15.3 & 107 & 16.0 & 31 & 15.4 & 138 \\
\hline $40-44$ & 12.4 & 87 & 11.3 & 22 & 12.2 & 109 \\
\hline $45-49$ & 6.6 & 46 & 6.7 & 13 & 6.6 & 59 \\
\hline Total & 100.0 & 700 & 100.0 & 194 & 100.0 & 894 \\
\hline Age at marriage & & & & & & 13.4 \\
\hline$<15$ & 14.0 & 98 & 11.3 & 22 & 13.4 & 120 \\
\hline $15-19$ & 63.1 & 442 & 59.3 & 115 & 62.3 & 557 \\
\hline $20-24$ & 18.6 & 130 & 24.7 & 48 & 19.9 & 178 \\
\hline $25+$ & 4.3 & 30 & 4.6 & 9 & 4.4 & 39 \\
\hline Total & 100.0 & 700 & 100.0 & 194 & & 894 \\
\hline $\begin{array}{l}\text { Mean age at } \\
\text { marriage }\end{array}$ & 17.5 & 700 & 18.1 & 194 & 17.6 & 894 \\
\hline
\end{tabular}

Figure 3.1: $\quad$ Age distribution

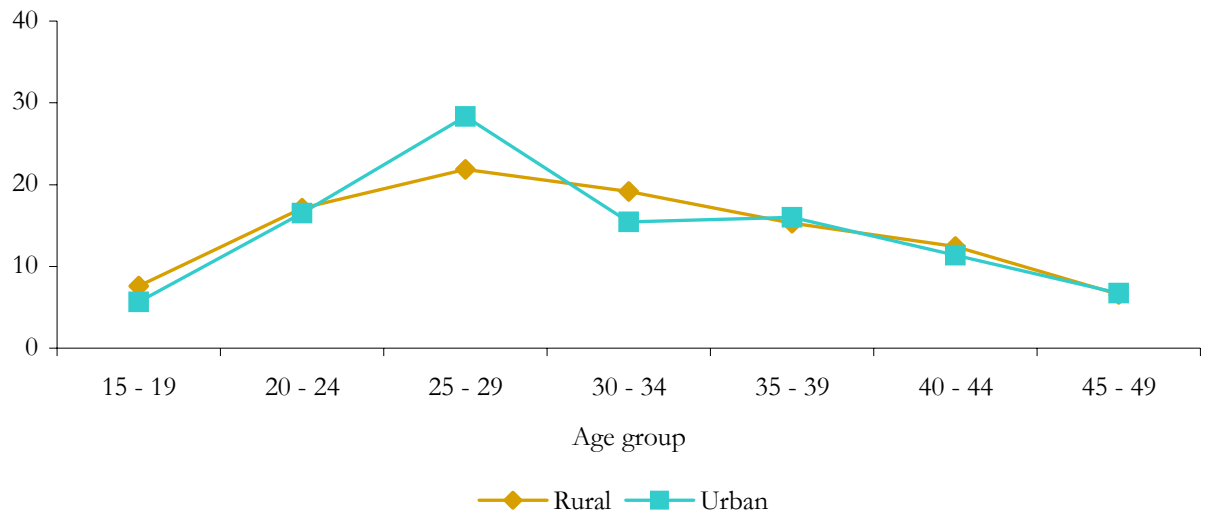

Figure 3.1 depicts the age distribution of eligible women in the sample. The data shows that there are no significant differences in the proportion of married women between the urban and rural areas, except in the 25 to 34 year age group. The highest proportions of women are found to be in the 2034 year age groups. 


\section{Education/Literacy Level}

The level of education obtained by a woman can be a good indicator of her status in society as well as the independent decision-making power available to her. It is presumed that the higher the level of education obtained by a woman, the more say she has in matters concerning her health and that of her children. With regards to maternal health, a higher literacy rate in women can result in an increased use of contraceptives, higher awareness of complications during and after pregnancy, a strong understanding of neonatal and newborn health, and finally, a more complete understanding of safe birth practices.

Table 3.2a and table 3.2b depict the educational and literacy levels of the respondents, along with the literacy levels of their husbands.

Table 3.2a: $\quad$ Education level and literacy of $M W R A$

\begin{tabular}{lrrrrrrr}
\multicolumn{1}{c}{$\begin{array}{c}\text { Respondent's } \\
\text { educational level }\end{array}$} & \multicolumn{2}{c}{ Rural } & \multicolumn{2}{c}{ Urban } & \multicolumn{2}{c}{ Total } \\
\cline { 2 - 8 } No education & Percent & Number & Percent & Number & Percent & Number \\
\hline Up to primary & 84.3 & 590 & 58.8 & 114 & 78.7 & 704 \\
\hline Up to middle & 9.9 & 69 & 16.0 & 31 & 11.2 & 100 \\
\hline Up to secondary & 1.9 & 13 & 4.1 & 8 & 2.3 & 21 \\
\hline Secondary + & 1.9 & 13 & 9.8 & 19 & 3.6 & 32 \\
\hline Total & 2.1 & 15 & 11.3 & 22 & 4.1 & 37 \\
Respondent is literate & 100.0 & 700 & 100.0 & 194 & 100.0 & 894 \\
\hline
\end{tabular}

It has also been shown that the mortality rates among children with mothers who have six or more years of education are considerably lower than the mortality rates among children with uneducated mothers (Martin, 1983). Educated women are more likely to recognize signs of illness in their children, actively seek assistance from a doctor, and administer the treatment in the manner required. Educated women are also more likely to return to a doctor in the event that the treatment administered failed to take effect. Therefore, the proactive nature of educated women with regard to the health of their children lowers the morbidity and mortality rates of infants and young children (Caldwell, 1986).

Table 3.2b:

Education and literacy of the husbands of $M W \mathrm{R} A$

\begin{tabular}{llllllll}
\hline \multirow{2}{*}{$\begin{array}{c}\text { Husbands' educational } \\
\text { level }\end{array}$} & \multicolumn{1}{c}{ Percent } & Number & Percent & Number & Percent & Number \\
\cline { 2 - 7 } No education & 48.0 & 335 & 20.6 & 40 & 41.9 & 375 \\
\hline Up to primary & 23.4 & 163 & 16.5 & 32 & 21.8 & 195 \\
\hline Up to middle & 3.7 & 26 & 5.2 & 10 & 4.0 & 36 \\
\hline Up to secondary & 11.3 & 79 & 20.6 & 40 & 13.3 & 119 \\
\hline Secondary + & 13.6 & 95 & 37.1 & 72 & 18.7 & 167 \\
\hline Total & 100.0 & 668 & 100.0 & 194 & 100.0 & 892 \\
\hline Husband is literate & 51.9 & 363 & 79.4 & 154 & 57.8 & 894
\end{tabular}


The level of education of fathers also affects the mortality rates amongst children. This is partly an indication of socio-economic level, as typically the more education the father of a child has, the higher his socio-economic status and standard of living are likely to be. However, the effect educated fathers have on the mortality rates of children is lower than the effect educated mothers have. (Mahmood, 1992).

In terms of the husband's level of education, almost half (48 percent) of the husbands interviewed in rural areas and one-fifth (21 percent) in urban areas received no schooling (Table 3.2b). Nearly 58 percent were reportedly literate. The majority ( 23 percent) of rural males received education only up to primary school level, while about one-third of urban males (37 percent) obtained secondary or higher levels of schooling.

\section{Children Ever Born and Living}

The number of children ever born and the age of the mother can gauge the trends in fertility levels. A drop in fertility among the younger age group suggests an increase in the age at marriage. Table 3.3 illustrates the number of children ever born to women in the district of Dadu. Overall, 13 percent of the women have never had any children, while a quarter ( 24 percent) had one to two children, and 21 percent had three to four children. The rest (43 percent) had five or more children.

In Dadu, almost two-thirds ( 64 percent) of the respondents in the youngest age group, and a quarter (25 percent) in the 20-24 year age group were found to be nulliparus. A very small proportion (2 percent) of respondents in the 40 to 49 year age group were still childless. A total of about 43 percent of the respondents reportedly had five or more children. Nearly 90 percent of the respondents in the 40 to 49 year age group had five or more children, while in the 15 to 19 year age group, the highest number of children ever born was still two. However, in the next age group, 5 percent of the respondents reportedly had five or more children, while 20 percent had three to four children.

Table 3.3: $\quad$ Percentage distribution of married women by number of children ever born, mean number of children ever born, living children and age group, compared to the 1998 Population census

\begin{tabular}{lrrrrrrrrr} 
& \multicolumn{4}{c}{ Number of Children Ever Born } & \multicolumn{3}{c}{ Mean No. of Children } & No. of \\
\hline Age group & 0 & $1-2$ & $3-4$ & 5 or more & Total & Ever born & Living & Women \\
\hline $15-19$ & 64.1 & 35.9 & 0.0 & 0.0 & 100.0 & 0.4 & 0.3 & 64 \\
\hline $20-24$ & 25.0 & 50.0 & 19.7 & 5.3 & 100.0 & 1.8 & 1.5 & 152 \\
\hline $25-29$ & 11.5 & 32.7 & 33.7 & 22.1 & 100.0 & 3.0 & 2.6 & 208 \\
\hline $30-34$ & 3.7 & 13.4 & 31.7 & 51.2 & 100.0 & 4.8 & 4.2 & 164 \\
\hline $35-39$ & 4.3 & 9.4 & 17.4 & 68.8 & 100.0 & 5.7 & 5.0 & 138 \\
\hline $40-44$ & 3.7 & 5.5 & 2.8 & 88.1 & 100.0 & 7.3 & 6.0 & 109 \\
\hline $45-49$ & 1.7 & 3.4 & 8.5 & 86.4 & 100.0 & 7.6 & 6.9 & 59 \\
\hline Total & 13.4 & 23.5 & 20.6 & 42.5 & 100.0 & 4.2 & 3.6 & 894
\end{tabular}


The mean number of children ever born as determined by the PAIMAN baseline survey is 4.2, while the mean number of surviving children is 3.6. In the highest age group (45-49 years), the mean number of children ever born is as high as 7.6, showing a history of high fertility levels. The overall figures of mean number of children are similar to the 1998 Population Census, which recorded 4.1 children ever born and 3.1 surviving children in the district of Dadu.

The length of birth intervals for the last birth is presented in Table 3.4. It is encouraging to see that only 3 percent of the births occurred after a birth interval of less than one year. A little less than a third of the respondents (30 percent) had an interval of 25-36 months, whereas almost the same proportion ( 33 percent) had a gap of three or more years between their last two births.

Table 3.4: $\quad$ Percentage distribution of married women by length of preceding birth interval

\begin{tabular}{lrr} 
Length of Preceding Birth Interval & Percent & Number \\
\hline Less than 12 Months & 2.9 & 12 \\
\hline 13-18 Months & 16.5 & 69 \\
\hline 19-24 Months & 17.2 & 72 \\
\hline $25-36$ Months & 29.8 & 125 \\
\hline More than 36 Months & 33.7 & 141 \\
\hline Total & 100 & 419
\end{tabular}

\section{Access To Information}

In the baseline survey, respondents were asked several questions regarding access and exposure to television, radio and newspapers. One of the main objectives of the baseline survey was to determine the knowledge of married women on different maternal and newborn health issues and the source of that knowledge. This information is useful in determining which media channels should be employed in the dissemination of maternal and newborn health information to target audiences. Moreover, it is important to measure the likelihood of reaching target audiences, as well as to determine which media channels are most effective when it comes to reaching that target audience.

\section{Television}

In the recent past, television has emerged as the most popular media, while radio use has declined. The purpose of the survey was to not only determine the proportion of respondents who watch TV, but also to establish the frequency of TV viewing, as well as the location at which television is most often watched.

In district Dadu, only about half of the women said that they watched television, and only 8 percent said that they listened to the radio (Figure 3.2). There were wide differences in TV viewing between the rural and urban areas. While 80 percent of the urban respondents watched television, only half (42 percent) of their rural counter parts reported doing the same. In terms of radio, the popularity was higher in rural areas ( 9 percent) compared to urban areas where only 3 percent did so. 
Figure 3.2: $\quad$ Percentage of women who watch television or listen to the radio

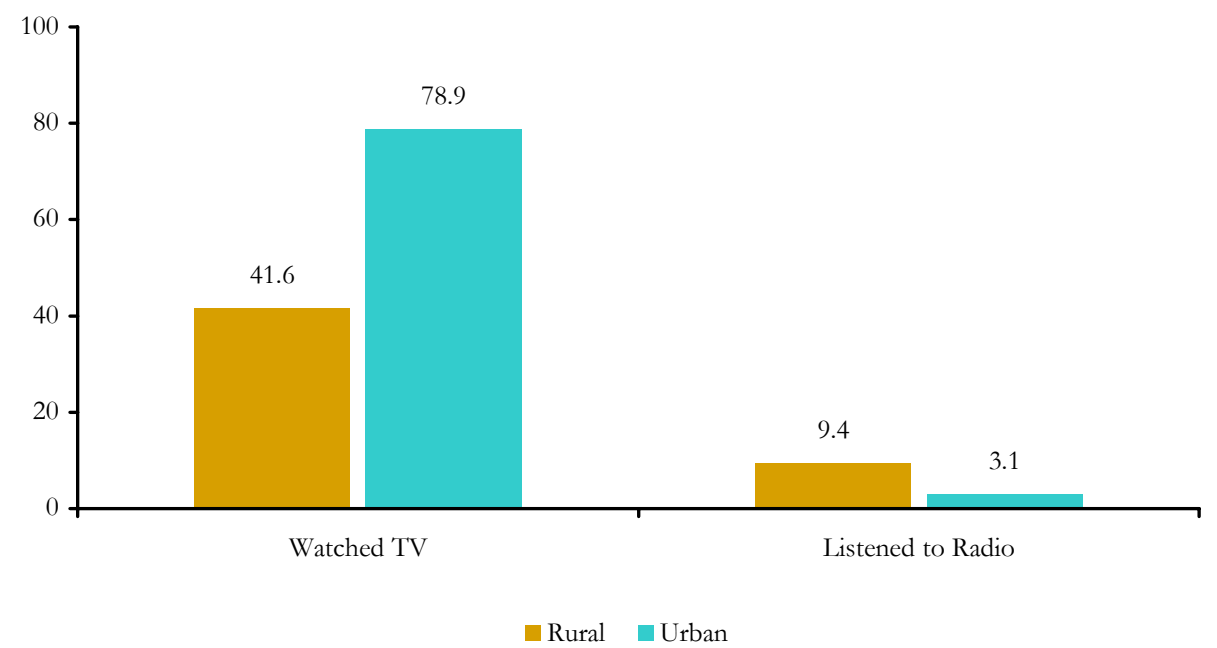

According to table 3.5, among the rural women who watched television, almost 80 percent watched on a daily basis, 3 percent did so once a week, and 18 percent reported that they rarely watched TV. Among the urban women, 91 percent watched television daily, less than a percent watched at least once a week and 8 percent do so rarely.

Table 3.5: $\quad$ Frequency of watching television

\begin{tabular}{lrrrrrr}
\multirow{2}{*}{ Frequency } & \multicolumn{2}{c}{ Rural } & \multicolumn{2}{c}{ Urban } & \multicolumn{2}{c}{ Total } \\
& Percent & Number & Percent & Number & Percent & Number \\
\hline Almost daily & 79.0 & 230 & 91.5 & 140 & 83.3 & 370 \\
\hline At least once a week & 3.1 & 9 & 0.7 & 1 & 2.3 & 10 \\
\hline Rarely & 17.9 & 52 & 7.8 & 12 & 14.4 & 64 \\
Total & 100.0 & 291 & 100.0 & 153 & 100.0 & 444
\end{tabular}

Table 3.6 shows the place where respondents watched television. The results are quite similar to the last table. In the rural areas, 87 percent women reported that they watched TV at home, followed by 10 percent who watched TV at a relative's house. Similarly, in urban localities a majority (96 percent) revealed that they watched TV at home. The rest mentioned relatives' and neighbors' houses as the location at which they watched TV.

Table 3.6: $\quad$ Place where respondent usually watches television

\begin{tabular}{lrrrrrrr}
\multirow{2}{*}{ Place } & \multicolumn{2}{c}{ Rural } & \multicolumn{2}{c}{ Urban } & \multicolumn{2}{c}{ Total } \\
\cline { 2 - 8 } At home & Percent & Number & Percent & Number & Percent & Number \\
\hline At relative's house & 87.3 & 254 & 96.1 & 147 & 90.3 & 401 \\
\hline At neighbor's house & 10.0 & 29 & 1.3 & 2 & 7.0 & 31 \\
\hline Others & 0.7 & 2 & 1.3 & 2 & 0.9 & 4 \\
\hline Total & 2.1 & 6 & 1.3 & 2 & 1.8 & 8 \\
\hline
\end{tabular}


Respondents were then asked to indicate the influence they believed TV programs had on the health behavior of people (Figure 3.3). More than a third of the women in both rural and urban areas (39 and 36 percent respectively) affirmed that television had a great deal of impact on health behaviors. Around a fifth said that it had a moderate or very small amount of influence. A negligible proportion said that it had no influence at all.

Figure 3.3: $\quad$ Influence of television programs on the health behaviors of people

Rural

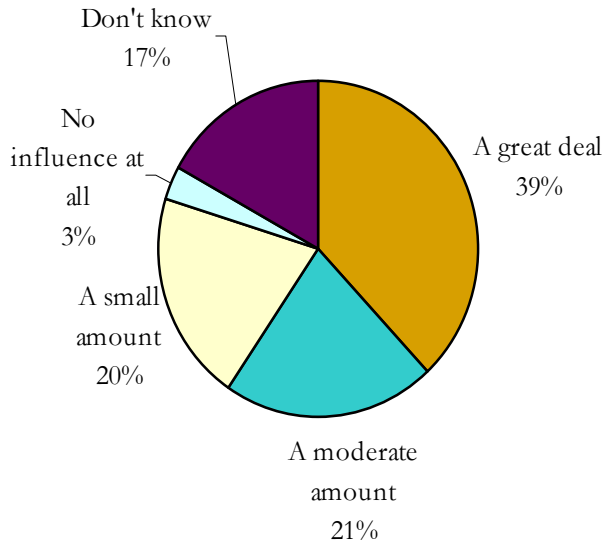

Urban

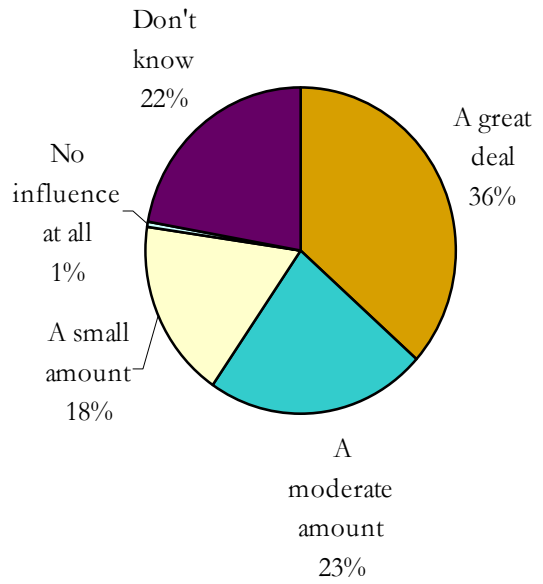

\section{Radio}

Though the percentage of respondents who said that they listened to the radio was very low in Dadu, it still remains the second most popular media source after television. Table $3.7^{1}$ depicts the frequency with which respondents listened to the radio in Dadu. From the respondents who listened to the radio, two-thirds (64 percent) listened to it on a daily basis, while another one-third (33 percent) listened only rarely, along with 3 percent who did so once a week $/$ month.

Table 3.7: $\quad$ Frequency of listening to radio

\begin{tabular}{|c|c|c|}
\hline \multirow{2}{*}{ Frequency } & \multicolumn{2}{|c|}{ Total } \\
\hline & Percent & Number \\
\hline Almost daily & 63.9 & 46 \\
\hline At least once a week/month & 3.0 & 2 \\
\hline Sometimes & 33.3 & 24 \\
\hline Total & 100.0 & 72 \\
\hline
\end{tabular}

Respondents who listened to the radio indicated that they did so mostly in their own house (Table 3.8). A very small proportion went to their relatives' houses to listen to the radio.

\footnotetext{
${ }^{1}$ Due to very small numbers in urban areas the table is presented in consolidated form only
} 
Table 3.8:

Place where respondent listens to the radio

\begin{tabular}{|c|c|c|}
\hline \multirow{2}{*}{ Place } & \multicolumn{2}{|c|}{ Total } \\
\hline & Percent & Number \\
\hline At home & 95.8 & 69 \\
\hline At relative's house & 4.2 & 3 \\
\hline Total & 100.0 & 72 \\
\hline
\end{tabular}

The women who reported listening to the radio were asked about the influence they believe radio had on health behaviors of people. According to figure 3.4, 41 percent believed radio had a moderate influence, followed by 26 percent who felt it had a great deal of influence. About one fifth (21 percent) of the women thought it had very small influence, while 12 percent thought it had no influence at all.

Figure 3.4: $\quad$ Influence of radio on health behaviors

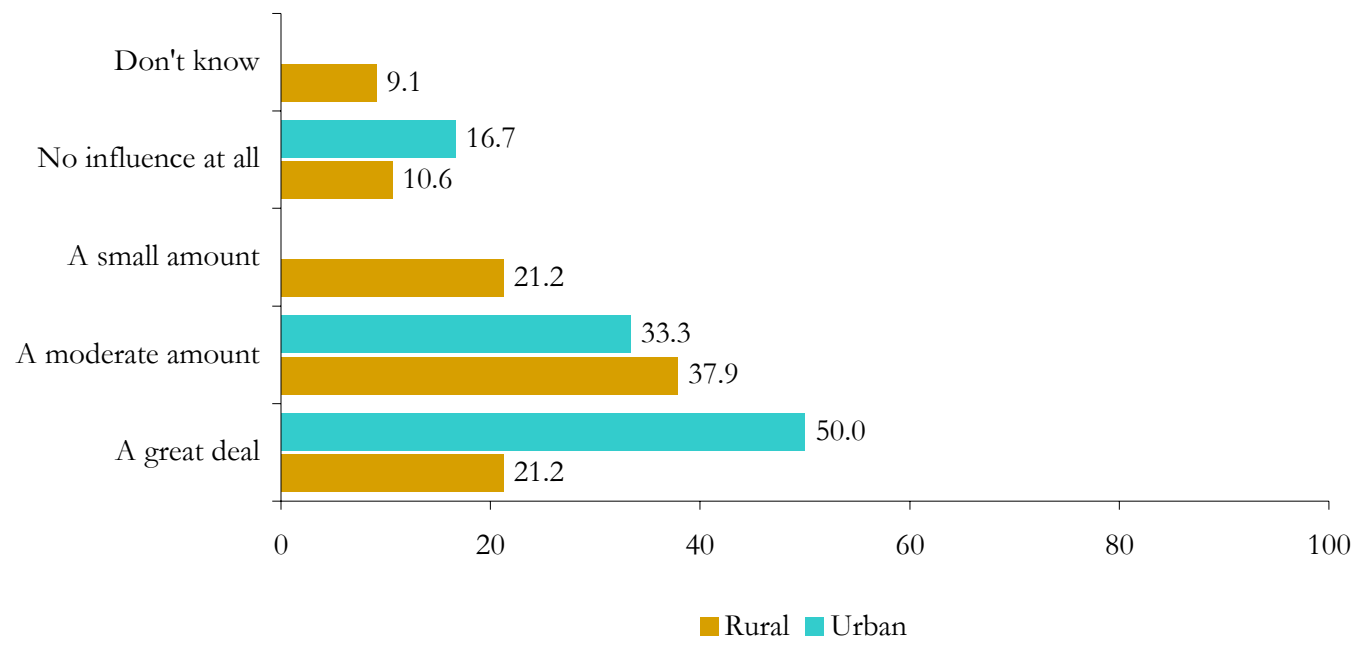




\section{Newspapers}

Given the fact that about 80 percent of the women in the sample population for the district of Dadu are illiterate, the popularity of print media cannot be expected. Figure 3.5 presents the frequency with which the respondents interviewed read the newspaper. A majority of the women interviewed (91 percent in rural areas and 68 percent in urban areas) mentioned that they were illiterate or never read any newspaper. Only 1 percent from the rural areas and 8 percent from the urban areas read newspapers on a daily basis. A comparatively significant proportion of women in both areas $(6 \%$ in rural and $16 \%$ in urban areas) reported that they read newspapers only rarely.

Figure 3.5: $\quad$ Frequency of reading newspaper

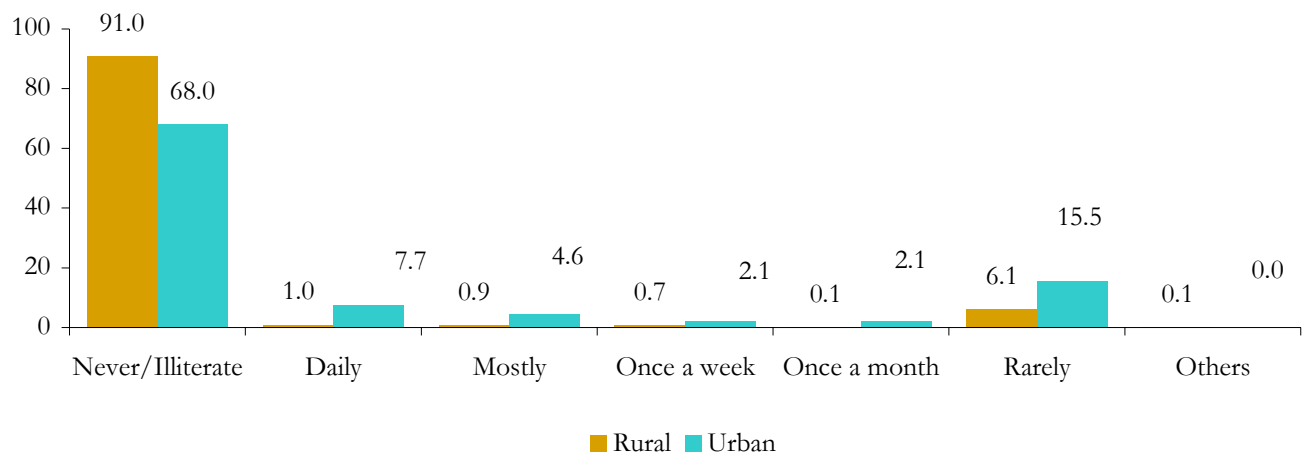

\section{Exposure to Mass Media}

The data obtained was further analyzed to measure the level of media penetration. Figure 3.6 indicates that almost 50 percent of the rural women and more than 80 percent of their urban counterparts had access to at least one form of media. This is indicative of the fact that relying on traditional mass media to relay health messages of PAIMAN to the population of Dadu would be ineffective, as a large portion of the population will remain out of reach.

Figure 3.6: $\quad$ Exposure to mass media (radio, television or newspaper)

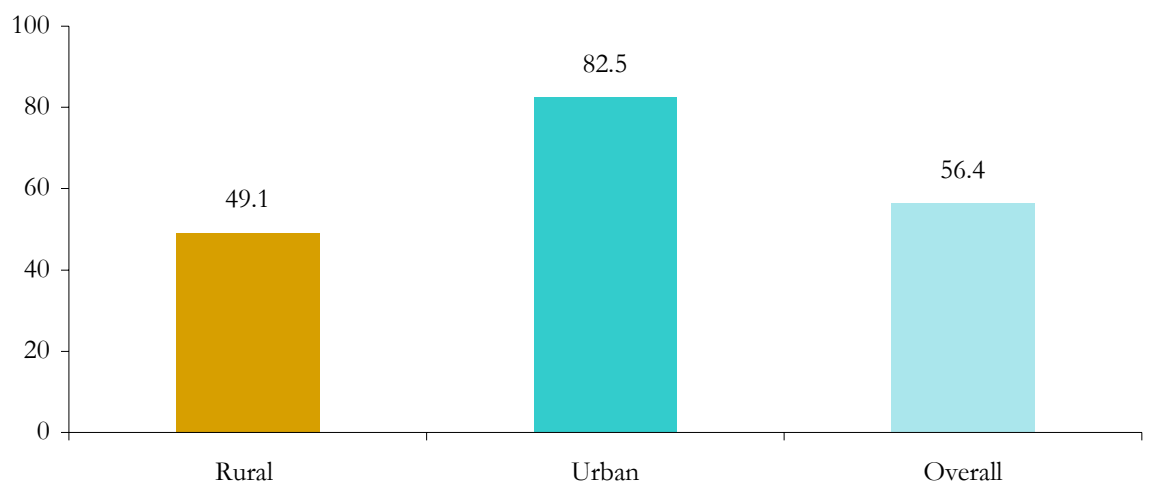


The respondents were asked to indicate what they believed to be the most effective form of media. Television emerged as the most trustworthy media form for more than 80 percent and 50 percent of the respondents in rural and urban areas respectively.

Figure 3.7: $\quad$ Most trustworthy form of media

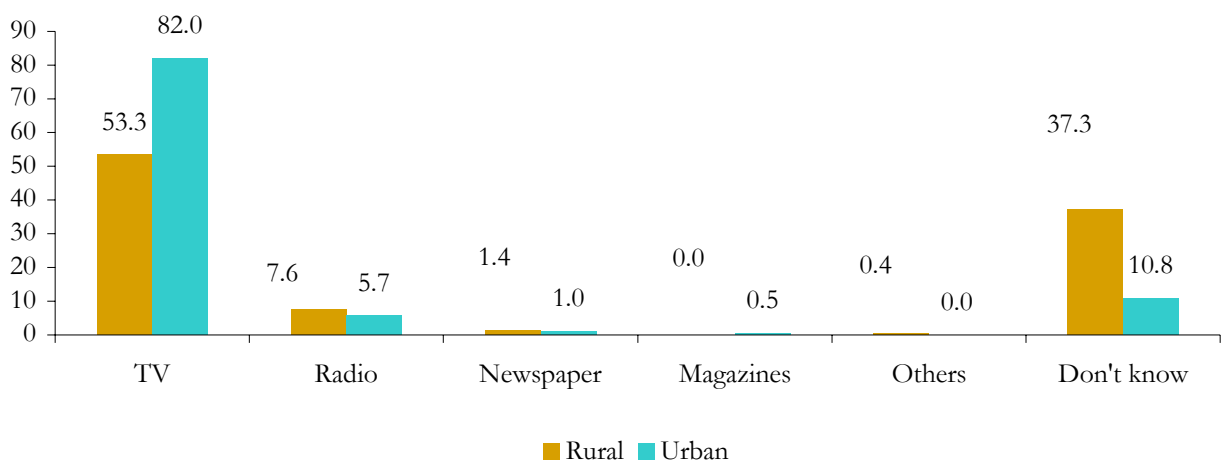

\section{Information/Education Through Media}

Respondents were asked to indicate if they had either heard/read any messages related to maternal and newborn health within the past three months. In rural areas, only about 13 percent of the respondents reported having heard/read anything regarding maternal health, while 11 percent had been exposed to messages pertaining to newborn health. In urban areas 24 percent and 23 percent of the respondents had heard/read anything regarding maternal and newborn health respectively.

Figure 3.8: $\quad$ Percentage of married women who had heard/ read maternal and newborn messages during the last 3 months by place of residence, PAIMAN Baseline Survey

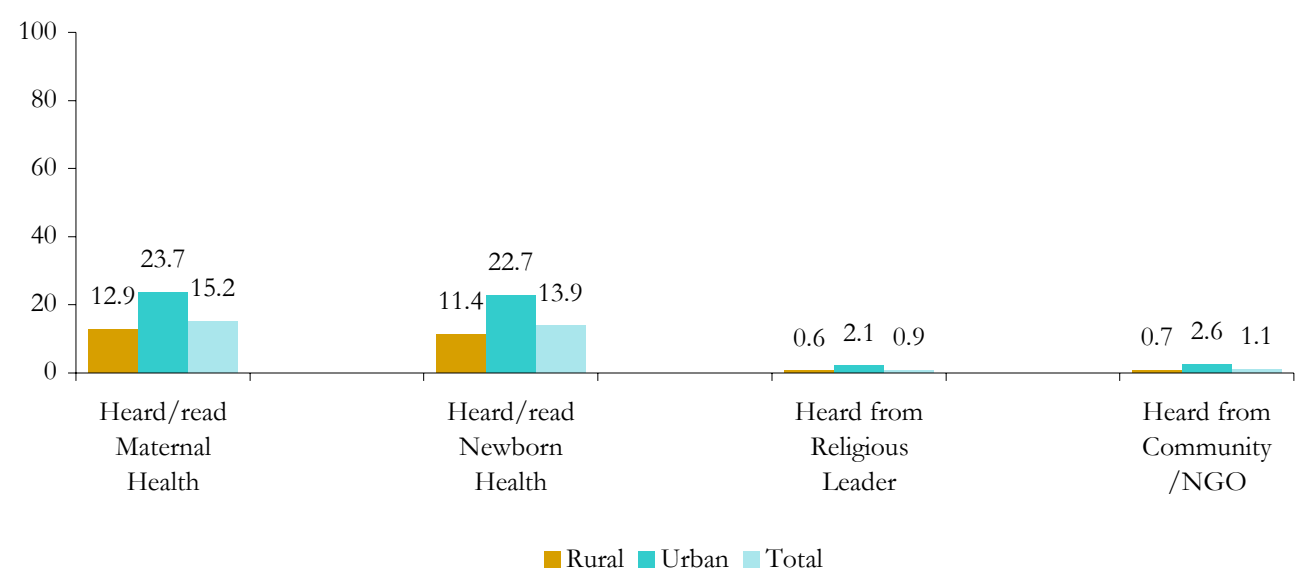

Respondents were then asked to indicate if they had heard any religious leader or community/NGO worker speak about these issues. Only around 2 percent of the respondents in urban areas claimed having heard a religious leader or community/NGO worker speak about these issues, whereas in rural areas less than 1 percent of the women reported the same. 


\section{Chapter 4}

\section{Knowledge of Safe Motherhood, Birth Preparedness and Community Resources}

This chapter explores the level of understanding women have knowledge of safe motherhood practices, birth preparedness and the use of community resources. It examines the level of health awareness women in the district possess, and thus provides an explanation for the maternal and newborn mortality rates. Respondents were asked questions regarding knowledge of complications during pregnancy, delivery, the postpartum period, and newborn health. They were also asked about the community resources available to them within the community. The findings of those responses are presented in this chapter.

\section{Knowledge of Danger Signs}

\section{Knowledge of Danger Signs During Pregnancy}

Figure 4.1 outlines the various complications that may occur during pregnancy. Respondents were asked to indicate which complications they believe are dangerous and require medical attention. Of all the signs, most respondents identified severe abdominal pain (64 percent urban and 59 percent rural), followed by jaundice ( 40 percent urban and 33 percent rural) and high fever ( 28 percent urban and 33 percent rural) as danger signs during pregnancy. Around a quarter of the respondents indicated other danger signs such as blurring of vision and swelling in the face. One-fifth of the women believed heavy vaginal bleeding, severe vomiting and fits/convulsions to be danger signs. Roughly one-sixth of the respondents also mentioned high blood pressure and spotting. Only 8 percent recognized unconsciousness as a danger sign. 
Figure 4.1: $\quad$ Knowledge of danger signs during pregnancy, which require medical attention

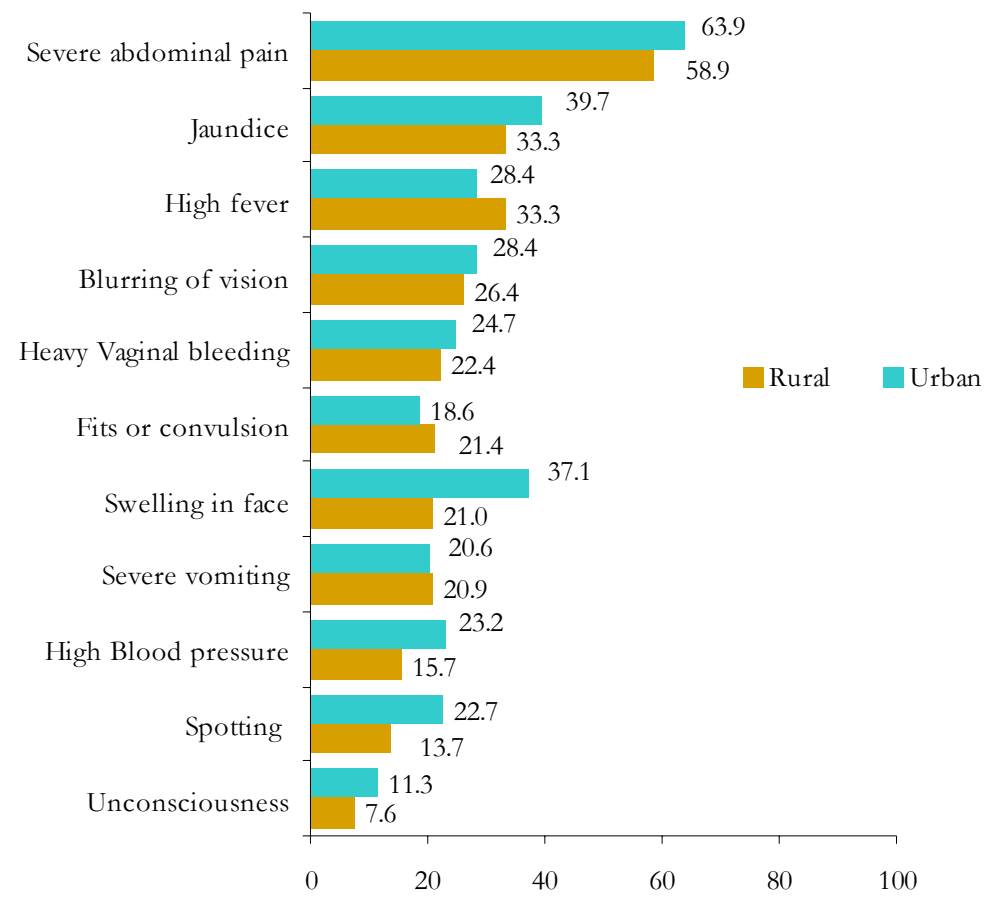

Overall, in rural areas of Dadu, 19 percent of the women did not know about any danger signs during pregnancy, 13 percent know at least one sign, 16 percent know two signs, and 52 percent knew of three or more danger signs during pregnancy. Among their urban counter parts, 58 percent knew three or more danger signs, while 12 percent and 16 percent of the respondents knew one and two signs respectively. A little more than 13 percent did not know any danger signs during pregnancy.

Figure 4.2: $\quad$ Percentage distribution of women by knowledge of the number of danger signs of pregnancy

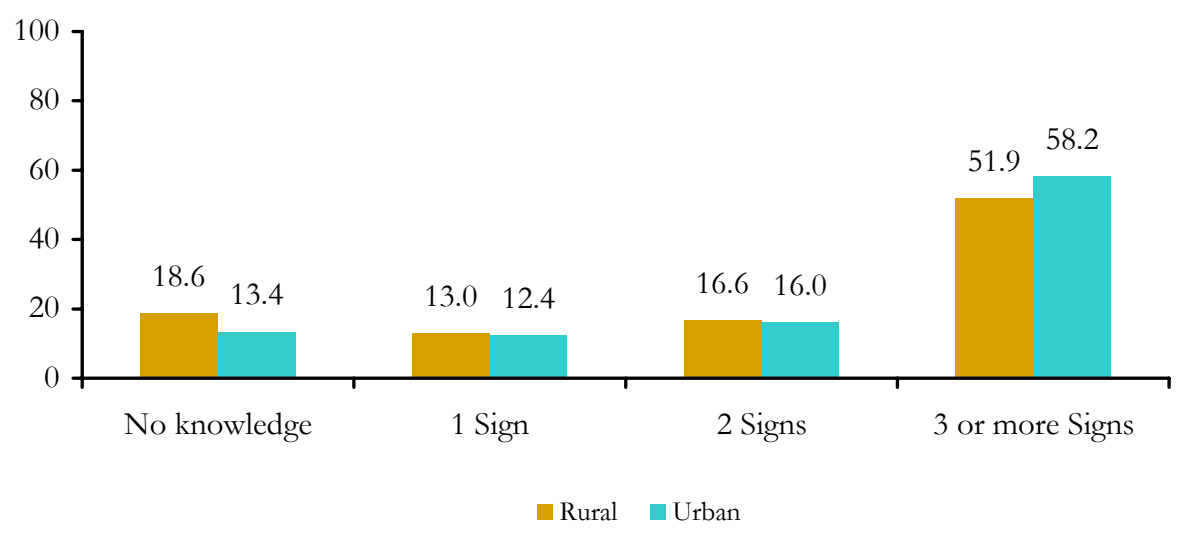




\section{Knowledge of Danger Signs during Childbirth/Delivery}

As in the case of pregnancy, many women are not aware of the complications that may arise during delivery. This lack of knowledge may eventually result in women not being taken to hospital if and when complications occur.

According to figure 4.3, almost half of the respondents (50 percent urban and 47 percent rural) in Dadu knew that prolonged labor was a complication during delivery and requires medical attention. A substantial proportion also knew that retained placenta (42 percent urban and 36 percent rural) and mal-positioning of the fetus (37 percent urban and 34 percent rural) required treatment. A little more than a quarter ( 32 percent urban and 27 percent rural) believed bleeding before labor was a danger sign, while 24 percent noted heavy bleeding during delivery to be a complication. Only about a tenth considered premature rupture of the membrane to be a danger sign.

Figure 4.3: $\quad$ Percentage distribution of respondents who had knowledge about complications during delivery

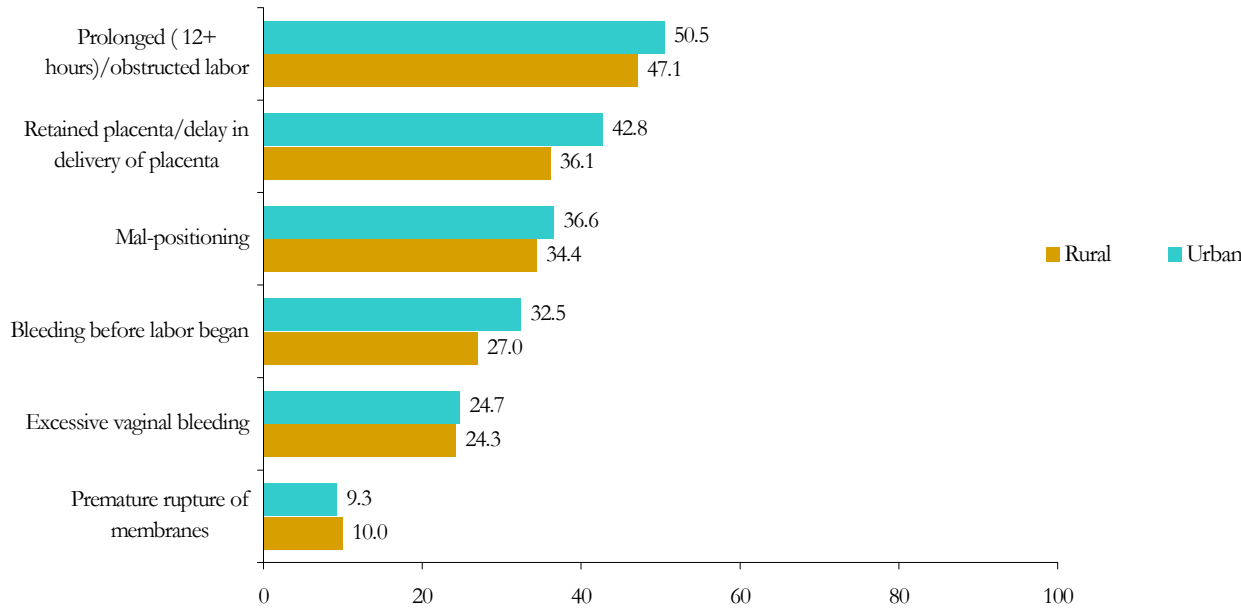

A large proportion of maternal mortalities occur during delivery in developing countries. Deliveries can only be made safe if married women are educated regarding danger signs that may appear during delivery so that they can decide when to seek treatment. Even under normal circumstances, approximately 15 percent of all pregnant women require emergency obstetric care to avoid maternal and newborn deaths.

According to figure 4.4, 19 percent of the respondents in rural areas and 14 percent in urban areas did not know of any danger signs during delivery. About a quarter of the women respondents knew at least one danger sign, while 33 percent in rural areas and 28 percent in urban areas knew two danger signs. Only 28 percent and 33 percent of the respondents in rural and urban Dadu knew of three or more danger signs during delivery. 
Figure 4.4: $\quad$ Percentage distribution of women by knowledge of number of danger signs of delivery

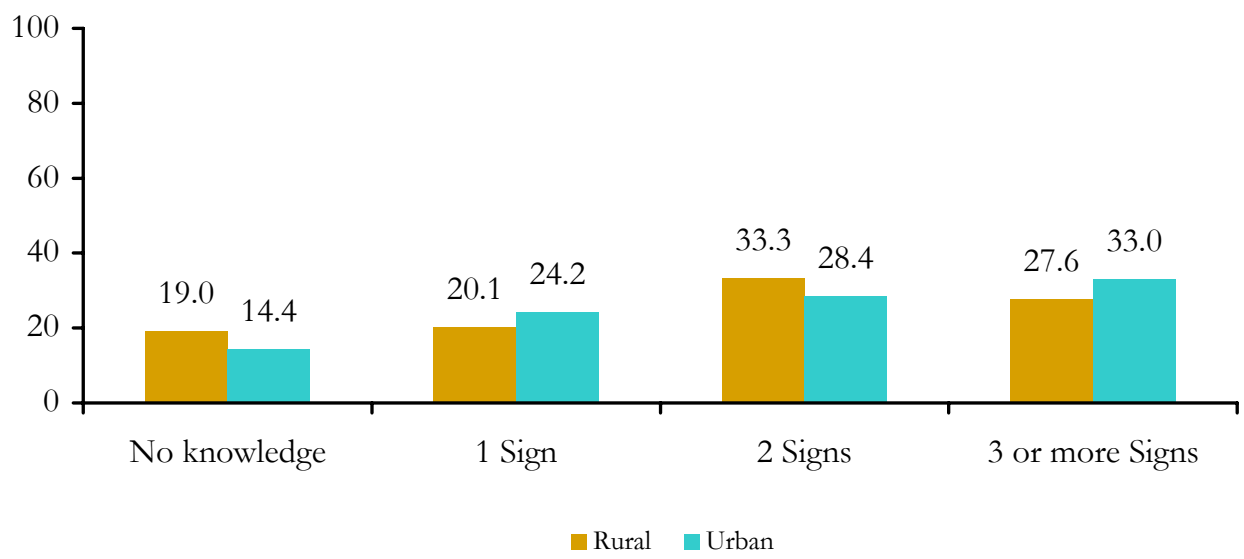

\section{Knowledge of Danger Signs During the Postpartum Period}

Postpartum period is defined as the first forty days following the delivery of a child. One of the most common causes of death during this period is heavy vaginal bleeding. Findings regarding the knowledge of various danger signs during this period are presented in Figure 4.5.

It is clear from the figure that level of knowledge with regard to excessive vaginal bleeding during the postpartum period is quite high among respondents in Dadu. Two out of three women believed this to be a danger sign during the postpartum period. Another sizeable proportion (46 percent urban and 43 percent rural) felt high fever with or without rigors was a complication. Around a third in both urban and rural areas pointed out fits or convulsions as being dangerous. The respondents also recognized prolapsed uterus, unconsciousness and offensive vaginal discharge as danger signs during the postpartum period.

Figure 4.5: $\quad$ Percentage of married women who had knowledge about complication during postpartum period

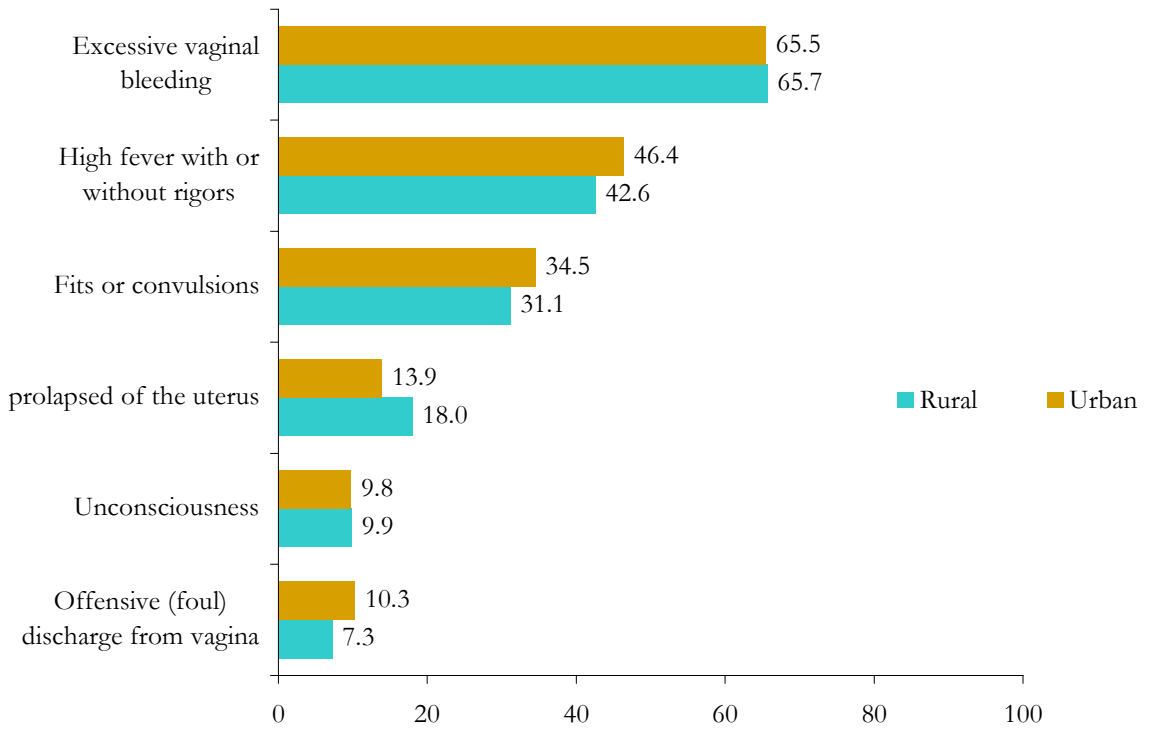


While the level of knowledge during the postpartum period seems conisdertably high, still a little more than a fifth of the women were found to have no knowledge about danger signs (Figure 4.6). About the same proportion knew just one danger sign. Around a third knew two or more danger signs.

Figure 4.6: $\quad$ Percentage distribution of women by number of known danger signs of postpartum period

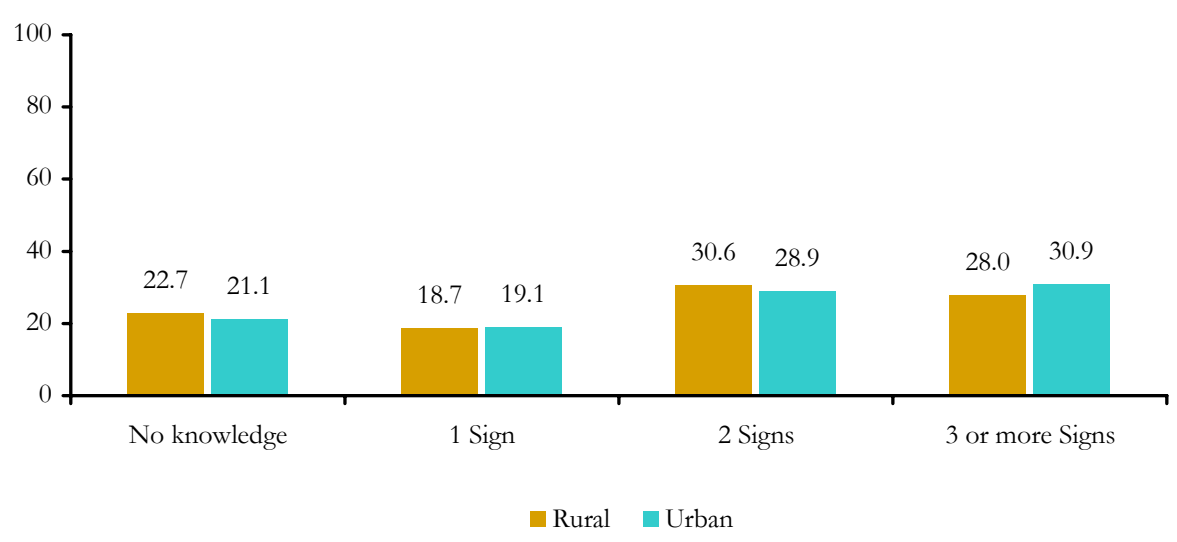




\section{Knowledge of Danger Signs in the Newborn}

Unfortunately, many women are also unaware of the danger signs that may appear in newborns, especially in the first seven days after the childbirth.

Overall, it is apparent that knowledge regarding the health of newborns is very poor in Dadu. The most widely recognized danger sign for newborns was jaundice (62 percent in urban and 45 percent in rural areas) closely followed by difficult breathing (58 percent urban and 42 percent rural) and high fever ( 32 percent urban and 38 percent rural). Almost a third ( 37 percent in urban and 30 percent in rural) of the women believed weak cry was a danger sign, while one-fifth of the women felt the same way about fits/jerky movements. About 18 percent identified blue skin, 16 percent noted inability to suckle, whereas around 10 percent listed red swollen eyes, skin lesions, fast breathing and hypothermia as being danger signs in newborn babies.

Figure 4.7: $\quad$ Percentage distribution of respondents who had knowledge about danger signs in newborns

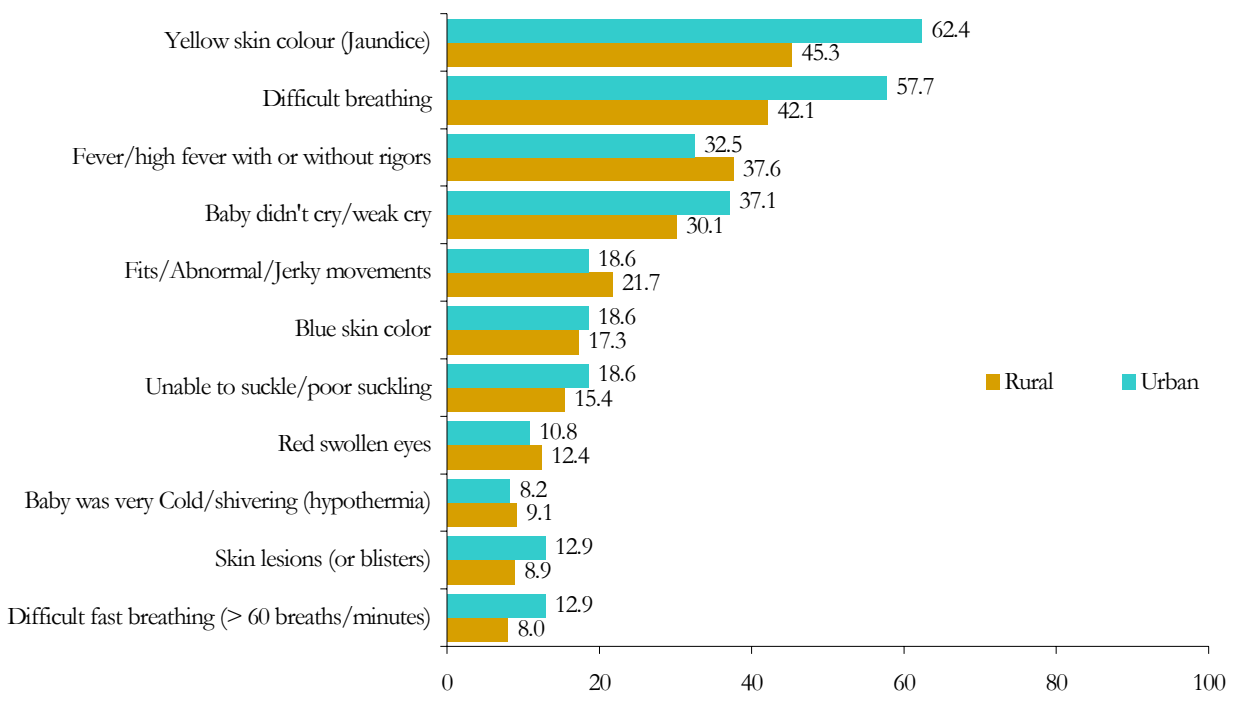

More than half of the respondents in Dadu knew three or more danger signs. One-fifth (21 percent) of the women from rural areas and 14 percent in urban areas did not know any of the danger signs.

Figure 4.8: $\quad$ Percentage distribution of women by knowledge of the number of danger signs in a newborn at birth

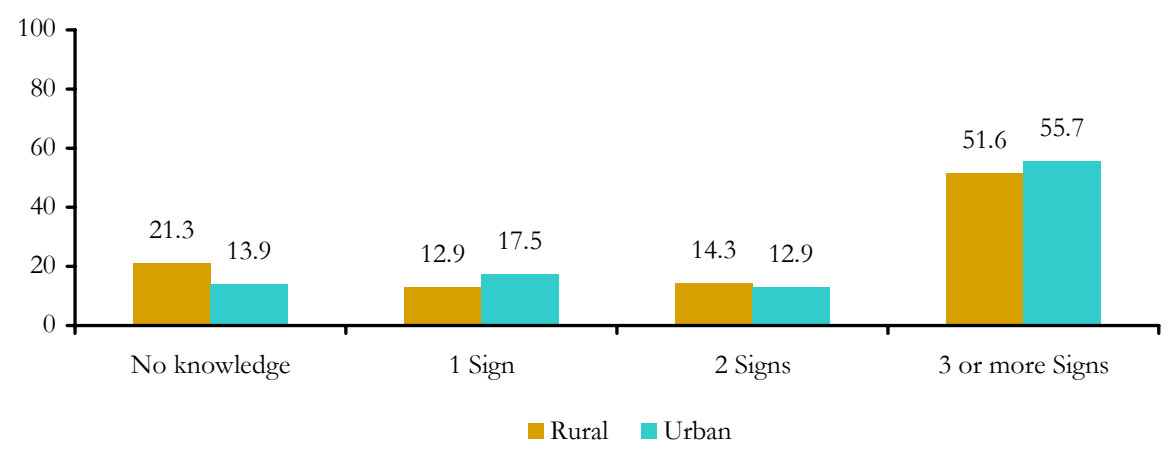




\section{Source of Information Regarding Danger Signs}

Finally, respondents were asked to state the source of their information regarding complications during pregnancy, delivery and the postpartum period. The most common sources were relatives/friends and in-laws. Among the health service providers, TBAs/Dais emerged as the most common source of knowledge for all types of information related to maternal and child health. TBAs/Dais were the main source of pregnancy and neonatal health for one-fifth of the women. LHWs and private hospital/clinic were cited by 12 to 20 percent of the women. Quite surprisingly, government hospitals/clinics and such as DHQs/THQ, BHU/RHC, FWC etc. were listed by a very small proportion. This is perhaps due to the absence of such facilities in the respondents' respective communities. Television was quoted by one-tenth of the women as a source of information for pregnancy, the postpartum period and newborn health.

Table 4.1: $\quad$ Source of information regarding danger signs during pregnancy

\begin{tabular}{lrrrr} 
& \multicolumn{3}{c}{ Source of information related to: } \\
\cline { 2 - 6 } Source & Pregnancy & Delivery & $\begin{array}{c}\text { Post partum } \\
\text { Period }\end{array}$ & $\begin{array}{c}\text { Newborn's } \\
\text { Health }\end{array}$ \\
Service Providers & & & & \\
\hline TBA/Dai & 21.8 & 32.0 & 35.0 & 20.4 \\
\hline LHW & 19.6 & 13.9 & 14.4 & 16.9 \\
\hline Private hospital/Clinic & 18.4 & 15.7 & 11.9 & 18.1 \\
\hline DHQ/THQ & 6.5 & 5.8 & 3.8 & 7.8 \\
\hline BHU/RHC/dispensary/MCH & 2.4 & 1.9 & 2.1 & 3.1 \\
\hline Nurse/LHV & 1.8 & 2.4 & 2.0 & 1.6 \\
\hline Midwife & 1.0 & 0.7 & 0.6 & 0.4 \\
\hline FWC/RHSC (A) & 0.6 & 0.7 & 0.3 & 0.1 \\
\hline Dispenser/hakim/homeopath & 0.4 & 0.4 & 1.0 & 1.1 \\
\hline Non-medical persons & & & & \\
\hline In-laws & 43.9 & 31.2 & 32.2 & 30.9 \\
\hline Friends/neighbors/relatives & 35.0 & 33.4 & 34.9 & 33.8 \\
\hline Mother/father/sister & 14.1 & 23.2 & 22.3 & 19.9 \\
\hline Husband & 3.1 & 1.7 & 1.8 & 3.5 \\
\hline Media & & & & \\
\hline Television & 11.0 & 5.5 & 7.9 & 9.8 \\
\hline Radio & 1.9 & 1.5 & 1.2 & 2.0 \\
Newspaper & 1.1 & 0.9 & 0.9 & 1.1 \\
\hline Number & 891 & 892 & 889 & 890 \\
\hline
\end{tabular}




\section{Knowledge of Community Schemes for the Welfare of Women and Newborns}

In addition to being asked questions regarding the knowledge of danger signs, married women were asked whether they were aware of any existing schemes in their respective communities designed to help women have a safe childbirth, while also providing basic education regarding newborn care. The baseline focused on schemes pertaining to transportation, blood arrangements and funding; all of which help ensure that there are no delays at the time of delivery. Lack of arrangement of transport to a health facility is a major cause of delay which can lead to maternal and newborn mortality, and therefore the arrangement of transport ahead of time is necessary to eliminate that delay. Unfortunately, many households lack transport facilities in their communities.

Table 4.2:

Knowledge of existence and importance of transport, blood and finances by the community at the time of delivery

\begin{tabular}{lcc}
\multicolumn{1}{c}{ Community services } & Total \\
& Percent & Number \\
\hline Existence of transport by the community at time of delivery & 0.9 & 8 \\
\hline $\begin{array}{l}\text { Importance of community provided transport facility as } \\
\text { perceived by respondents }\end{array}$ & 99.3 & 888 \\
\hline Existence of blood by the community at time of delivery & 1.3 & 12 \\
\hline $\begin{array}{l}\text { Importance of community provided blood facility as perceived } \\
\text { by respondents }\end{array}$ & 98.8 & 883 \\
\hline $\begin{array}{l}\text { Existence of money by community at the time of delivery } \\
\text { Importance of community provided money facility as } \\
\text { perceived by respondents }\end{array}$ & 0.0 & 88.7 \\
\hline
\end{tabular}

It is obvious from the table that the district of Dadu does not have any community level facilities to be utilized in the event of an emergency at the time of delivery. Only around 1 percent of the women said that they had transport and blood donation facilities in their locality. The practice of having a combined savings system or any other monetary arrangement at community level was lacking in all areas. Although actual services are next to zero, almost all the women in these areas recognized their importance and suggested having such resources. It is obvious from these statistics that the PAIMAN project would face obstacles in initiating such norms and services in the community. 


\section{Chapter}

\section{Attitude Towards Pregnancy, Delivery and the Postpartum period}

\section{Introduction}

This chapter explores the attitudes of married women towards pregnancy, delivery and the postpartum period. Determining these attitudes and beliefs is important for designing strategies that bring about a change in traditional thinking. While knowledge is the foundation for behavior change, attitude towards an issue will determine whether the person will actually adopt the messages promoted through the behavior change communication campaigns.

This chapter presents findings related to the respondents' perceptions about the importance of antenatal and postnatal checkups, the place of delivery and transportation needs at the time of delivery. Since the questions were related only to perceptions, and community practices, the findings in this chapter include all women in the sample, regardless of their birth history.

\section{Attitudes Towards Age at Marriage}

In response to the question of whether or not women should get married soon after puberty, both urban and rural populations yielded similar results. In rural Dadu, 42 percent believe a woman should be married just after puberty, whereas in urban areas 29 percent believe that women should be married soon after puberty. A deeper look into this issue shows that many families do not value girls' education, and place greater emphasis on marriage. As a result, women are married at an early age, and often do not have the opportunity to obtain any education whatsoever. There is also a link between the years of education obtained by women and the fertility rate of a country (Sathar et al, 1988). The younger the age at marriage, the greater the exposure to childbearing.

\section{Attitudes Towards Antenatal Care}

Women in both urban and rural areas of Dadu were then asked to indicate if they believed pregnant women needed to have antenatal check-ups. Overall, prenatal care provides an opportunity to offer preventive care that will benefit the newborn as well as the mother. Prenatal care also allows women to learn about hygiene, the benefits of breastfeeding, nutrition and general health (Mahmood, 2002). As expected, approximately 77 percent of the women felt that antenatal check-ups were important. This proportion is higher in urban areas. 
Table 5.1:

Importance of antenatal check-ups

\begin{tabular}{|c|c|c|c|c|c|c|}
\hline \multirow{2}{*}{$\begin{array}{l}\text { Have antenatal } \\
\text { check-up }\end{array}$} & \multicolumn{2}{|l|}{ Rural } & \multicolumn{2}{|c|}{ Urban } & \multicolumn{2}{|c|}{ Total } \\
\hline & Percent & Number & Percent & Number & Percent & Number \\
\hline Yes & 73.9 & 517 & 88.1 & 171 & 77.0 & 688 \\
\hline No & 22.1 & 155 & 11.3 & 22 & 19.8 & 177 \\
\hline Don't know & 4.0 & 28 & 0.5 & 1 & 3.2 & 29 \\
\hline Total & 100.0 & 700 & 100.0 & 194 & 100.0 & 894 \\
\hline
\end{tabular}

Table 5.2 and 5.3 present the attitudes of respondents towards the timing and frequency of antenatal care. A majority of the women gave non-numeric responses to these questions. Upon being asked to indicate the month of pregnancy in which antenatal care should be obtained, more than half of the respondents stated that antenatal care should be sought only when needed. One-fifth (20 percent) of the women believed antenatal care should be obtained in the first trimester, and one-sixth (14 percent) suggested the second trimester. However, 5 percent of the respondent said that such visits should be made as soon as possible after pregnancy.

Table 5.2:

Month of pregnancy when women should obtain antenatal care

\begin{tabular}{lrrrrrr} 
& \multicolumn{2}{c}{ Rural } & \multicolumn{2}{c}{ Urban } & \multicolumn{2}{c}{ Total } \\
\cline { 2 - 7 } & Percent & Number & Percent & Number & Percent & Number \\
\hline 1st trimester & 17.8 & 92 & 24.6 & 42 & 19.5 & 134 \\
\hline 2nd trimester & 14.0 & 72 & 14.6 & 25 & 14.1 & 97 \\
\hline 3rd trimester & 9.4 & 49 & 4.1 & 7 & 8.2 & 56 \\
\hline $\begin{array}{l}\text { As soon as possible after } \\
\text { pregnancy }\end{array}$ & 4.3 & 22 & 9.4 & 16 & 5.5 & 38 \\
\hline $\begin{array}{l}\text { When check-up is needed } \\
\text { Don't know }\end{array}$ & 52.7 & 272 & 46.8 & 80 & 51.2 & 352 \\
\hline Total & 1.7 & 9 & 0.6 & 1 & 1.5 & 10 \\
\hline
\end{tabular}

When asked how many antenatal care visits they believed necessary, a majority of respondents (65 percent) once again suggested obtaining care only when needed. About 15 percent felt two to three visits were necessary, 7 percent thought four to five visits were required, and about 10 percent felt six to thirteen antenatal visits should be sought. It is interesting to note that the mean number of suggested antenatal visits is 4.1 in rural areas and 5.3 in urban areas. 
Table 5.3: $\quad$ Number of antenatal visits considered necessary by respondents

\begin{tabular}{lrrrrrr}
\multirow{2}{*}{ Number of visits } & \multicolumn{2}{c}{ Rural } & \multicolumn{2}{c}{ Urban } & \multicolumn{2}{c}{ Total } \\
\cline { 2 - 7 } At least one & Percent & Number & Percent & Number & Percent & Number \\
\hline $2-3$ & 2.1 & 11 & 0.0 & 0 & 1.6 & 11 \\
\hline $4-5$ & 15.0 & 77 & 12.9 & 22 & 14.5 & 99 \\
\hline $6-13$ & 6.0 & 31 & 9.3 & 16 & 6.9 & 47 \\
\hline When check-up is needed & 8.6 & 44 & 15.2 & 26 & 10.2 & 70 \\
\hline Don't know & 66.3 & 341 & 62.0 & 106 & 65.3 & 447 \\
Total & 1.9 & 10 & 0.6 & 1 & 1.6 & 11 \\
Mean* & 100 & 514 & 100 & 171 & 100 & 685 \\
\hline Median* & 4.1 & 163 & 5.3 & 64 & 4.5 & 227 \\
\hline
\end{tabular}

*Of numeric responses only.

A very high proportion of women indicated the use of iron/folate supplements and tetanus toxoid (TT) injections (Figure 5.1). About 64 percent of the rural women and 84 percent of the urban respondents recognized the importance of iron/folate supplements during pregnancy. A slightly higher proportion of women from both locations reported the same for TT shots.

Figure 5.1: $\quad$ Percentage of married women who thought it necessary to receive TT shots and take iron/folate tablets during pregnancy

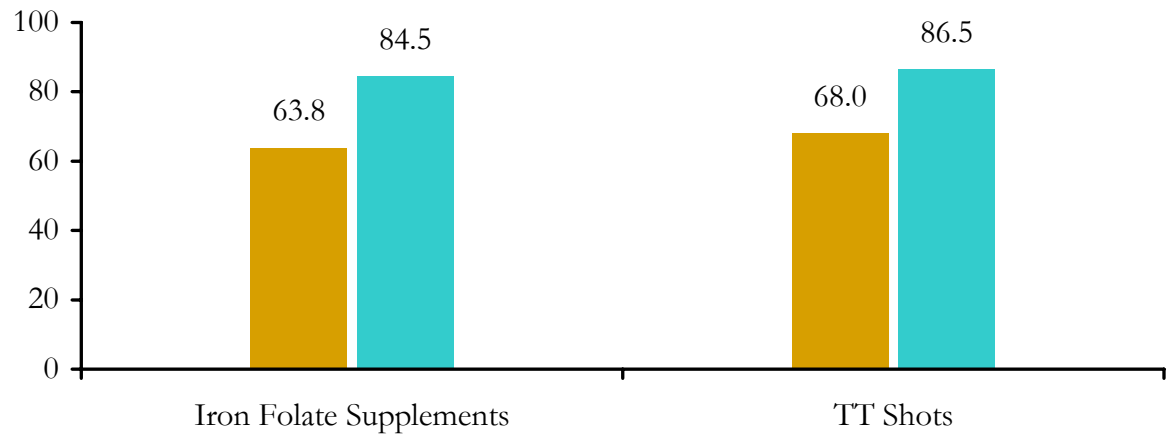




\section{Attitudes Towards Delivery}

Many families prefer the traditional practice of employing Traditional Birth Attendants (TBAs) or Dais to assist with deliveries. These TBAs/Dais have vast experience but no formal training and therefore do not qualify as skilled birth attendants. However, many families do not realize the impact a lack of training can have on childbirth, and chose to opt for TBAs over health professionals. As seen in table 5.4, a large majority ( 78 percent) of the respondents believed that women should receive delivery services from a health professional. Only 18 percent of the respondents in rural areas and 14 percent in urban areas believed women did not require such services.

Table 5.4: Respondents who believe that women should receive delivery services from health professional

\begin{tabular}{lrrrrrr}
\multirow{2}{*}{ Number } & \multicolumn{2}{c}{ Rural } & \multicolumn{2}{c}{ Urban } & \multicolumn{2}{c}{ Total } \\
\cline { 2 - 7 } Yes & Percent & Number & Percent & Number & Percent & Number \\
\hline No & 76.7 & 536 & 84.5 & 164 & 78.4 & 700 \\
\hline Don't know & 18.3 & 128 & 14.4 & 28 & 17.5 & 156 \\
\hline Total & 5.0 & 35 & 1.0 & 2 & 4.1 & 37 \\
\hline
\end{tabular}

The majority of the women ( 74 percent in rural areas and 71 percent in urban areas) felt that only "some" women obtained delivery services from a health professional (Figure 5.2). A quarter (28 percent) of the urban residents and a little more than a tenth (12 percent) of the rural respondents believed that "most" women in their areas sought delivery services from health professionals. About 13 percent of the rural residents said that "none" of the women went to a health professional.

Figure 5.2: $\quad$ Percentage of respondents who believe women in their community obtain delivery services from Health Professionals

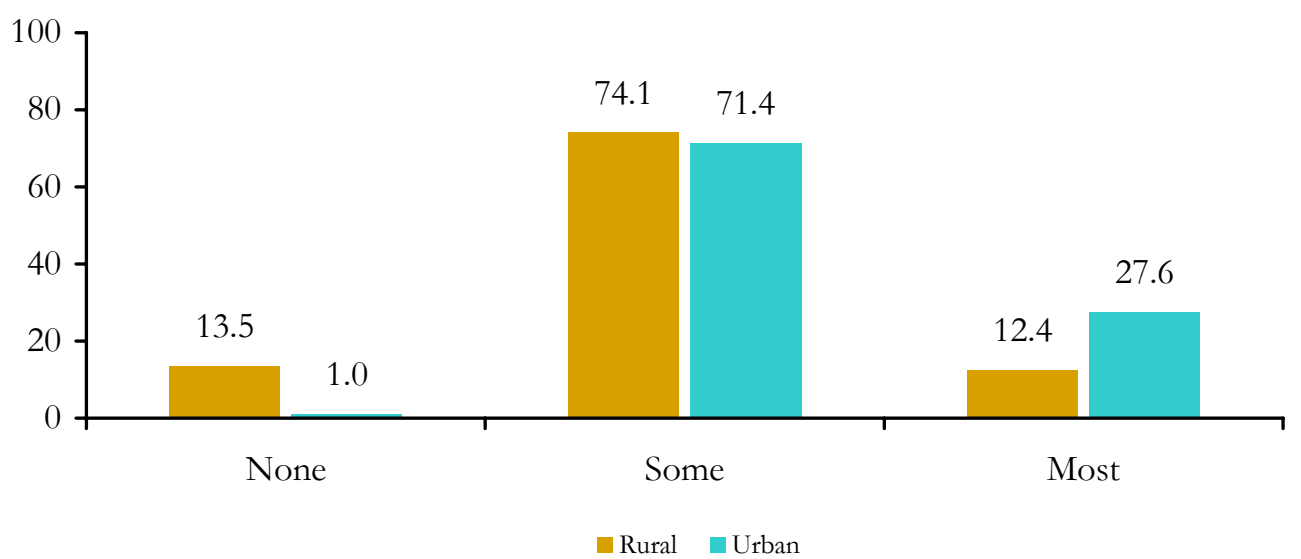

About a third ( 30 percent) of the women in the rural areas and around two thirds ( 63 percent) of their counterparts from urban areas suggested that delivery should take place in a hospital. However, a sizeable number (70 percent) of the rural women felt that a delivery should take place at home. 
Figure 5.3: $\quad$ Perception of respondent regarding place of delivery

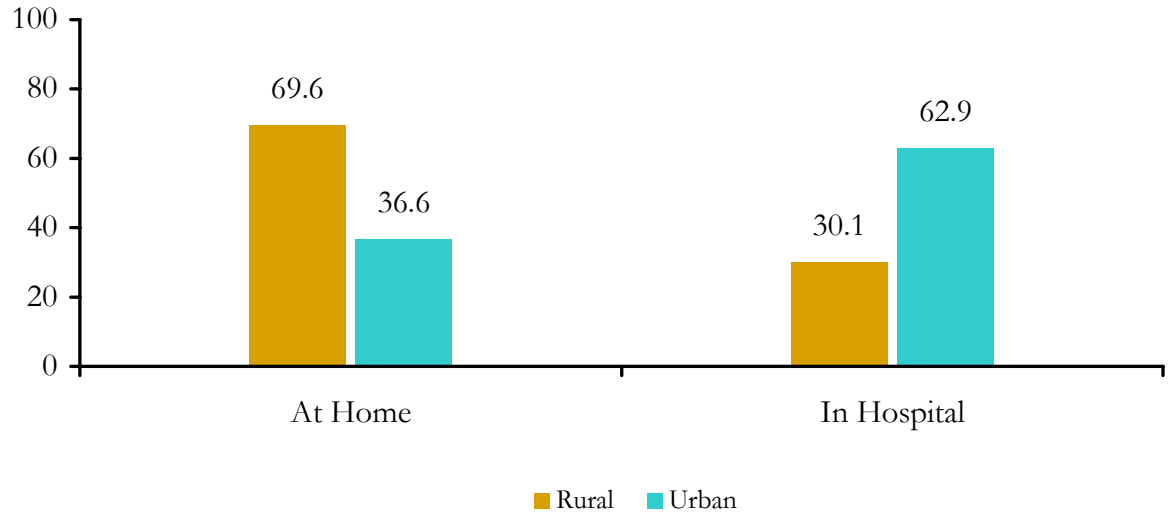

Respondents were asked to indicate the person in their communities who should take charge of a pregnant woman and should be responsible for making the important decisions regarding her health. Table 5.5 reveals the views of the women in our sample regarding the person who should make decisions about the health of a pregnant woman. It is apparent from the results that the power hierarchy is firmly accepted and believed by the respondents in both urban and rural localities. Three out of every four women thought that a husband should be the decision-maker when it came to seeking treatment for complications at the time of delivery. About 14 percent of the respondents in Dadu said family members should make decisions regarding the health of a pregnant woman. A small proportion of women also believes that TBAs/Dais should be the main decision maker. Only 6 percent of the respondents thought the pregnant women herself should decide when to seek medical attention.

Table 5.5:

Person who should make decisions regarding the bealth of a pregnant women

\begin{tabular}{lrrrrrr}
\multirow{2}{*}{ Person } & \multicolumn{2}{c}{ Rural } & \multicolumn{2}{c}{ Urban } & \multicolumn{2}{c}{ Total } \\
\cline { 2 - 7 } & Percent & Number & Percent & Number & Percent & Number \\
Pregnant woman & 5.3 & 37 & 10.8 & 21 & 6.5 & 58 \\
\hline Husband & 74.3 & 520 & 80.4 & 156 & 75.6 & 676 \\
\hline Other family members & 15.1 & 106 & 8.2 & 16 & 13.6 & 122 \\
\hline TBA/Dai & 2.7 & 19 & & & 2.1 & 19 \\
\hline Others & 2.1 & 15 & 0.5 & 1 & 1.8 & 16 \\
\hline Don't know & 0.4 & 3 & & & 0.3 & 3 \\
Total & 100.0 & 700 & 100.0 & 194 & 100.0 & 894
\end{tabular}

Finally, respondents were asked to indicate the mode of transportation they planned to use in order to reach a health facility at the time of delivery. The majority of the women ( 80 percent) planned to hire private transport, while 14 percent had their own transport, followed by 5 percent who planned to use community transport at the time of delivery. 
Figure 5.4: $\quad$ Percentage of married women by mode of transport they would use to reach a bealth facility

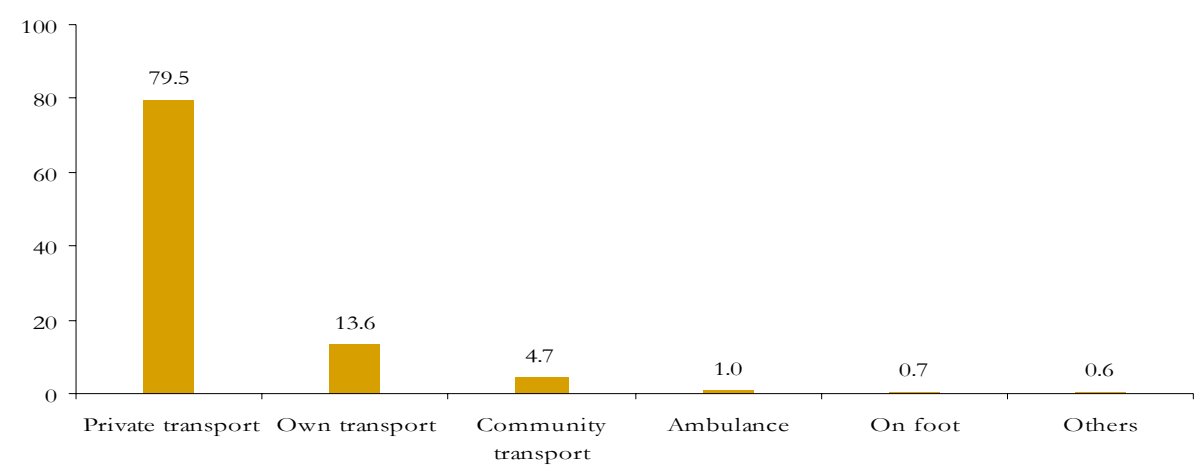

\section{Attitude Towards Postpartum and Neonatal Care}

The importance of postnatal care is often undervalued. Postnatal care ensures that both mother and newborn are in good health, and monitors the recovery process of new mothers. Respondents were asked to indicate if they believed postnatal check-ups were important in the postpartum period.

Findings are presented in table 5.6. Though the majority of women recognized the special needs of a woman in her postpartum period, still a significantly large number (70 percent) stated that women did not need any medical check-ups during this time.

Table 5.6: $\quad$ Belief in necessity of postnatal care

\begin{tabular}{lrrrrrr}
\multirow{2}{*}{ Need postnatal } & \multicolumn{2}{c}{ Rural } & \multicolumn{2}{c}{ Urban } & \multicolumn{2}{c}{ Total } \\
\cline { 2 - 7 } & Percent & Number & Percent & Number & Percent & Number \\
\hline Yes & 20.4 & 143 & 42.3 & 82 & 25.2 & 225 \\
\hline No & 75.0 & 525 & 53.6 & 104 & 70.4 & 629 \\
\hline Don't know & 4.6 & 32 & 4.1 & 8 & 4.5 & 40 \\
Total & 100.0 & 700 & 100.0 & 194 & 100.0 & 894
\end{tabular}

According to findings, 60 percent of the respondents did not go for any check-up, while the same was true for a little more than a quarter (28 percent) of urban women (Figure 5.5). A little more than a third ( 36 percent) of rural women and around two thirds ( 60 percent) of urban respondents said that some women in their areas went for postnatal check-ups. A very small proportion of women in both locations said that all the women in their areas went for check-ups.

Figure 5.5: $\quad$ Number of postnatal care visits women should have in the community by place of residence

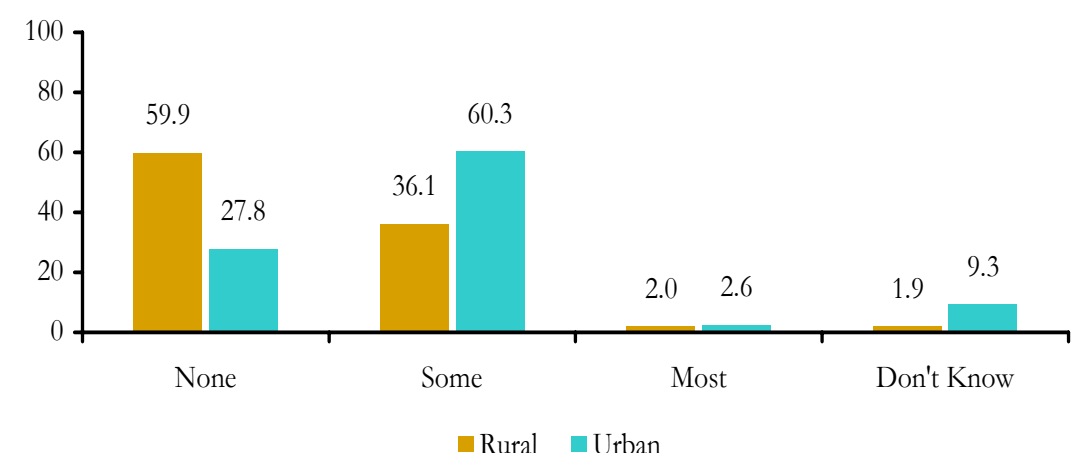




\section{Coverage of Lady Health Workers}

Lady Health Workers (LHWs) are the frontline grassroots workers of the National Programme of Family Planning and Primary Health Care of the Ministry of Health, Government of Pakistan. They are assigned to all the districts of Pakistan to provide free consultations, and family planning methods and primary health care medicines at the doorstep. They are the most critical conduit of information and services for basic health care for the majority of the population in this country. Hence, for the PAIMAN project, it is imperative to establish whether there are worker in these districts and whether they are visiting households.

Table 5.7: $\quad$ Presence of lady bealth worker in the community

\begin{tabular}{lrrrrrr} 
& \multicolumn{2}{c}{ Rural } & \multicolumn{2}{c}{ Urban } & \multicolumn{2}{c}{ Total } \\
Has LHW in the area & Percent & Number & Percent & Number & Percent & Number \\
Yes & 50.7 & 355 & 96.9 & 188 & 60.7 & 543 \\
\hline No & 47.3 & 331 & 2.1 & 4 & 37.5 & 335 \\
\hline $\begin{array}{l}\text { Respondent herself } \\
\text { is LHW }\end{array}$ & 0.6 & 4 & 1.0 & 2 & 0.7 & 6 \\
\hline $\begin{array}{l}\text { Don't know } \\
\text { Total }\end{array}$ & 1.4 & 10 & & & 1.1 & 10 \\
\hline
\end{tabular}

Table 5.7 and 5.8 shows the statistics for LHWs for the districy of Dadu. Among all women interviewed in the district, a little less than two-thirds (61 percent) reported that there was an LHW working in their area. While 97 percent of the urban respondents reported the presence of a worker in their area, only 51 percent of rural women noted the same. About 83 percent of the women who reported the presence of a worker in their area, mentioned that they had been visited by an LHW in the last three months. This figure is slightly higher in urban areas (88 percent) then in rural communities (80 percent).

Table 5.8: $\quad$ LHW ever visited home during last three months

\begin{tabular}{lrrrrrr}
\multirow{2}{*}{ Ever visited } & \multicolumn{2}{c}{ Rural } & \multicolumn{2}{c}{ Urban } & \multicolumn{2}{c}{ Total } \\
\cline { 2 - 7 } & Percent & \multicolumn{1}{c}{ Number } & Percent & Number & Percent & \multicolumn{1}{c}{ Number } \\
\hline Yes & 80.3 & 285 & 87.8 & 165 & 82.9 & 450 \\
\hline No & 19.7 & 70 & 12.2 & 23 & 17.1 & 93 \\
Total & 100.0 & 355 & 100.0 & 188 & 100.0 & 543
\end{tabular}





\section{Chapter}

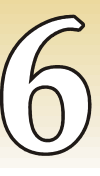

\section{Contraceptive Knowledge and Use}

\section{Introduction}

Respondents were asked to name the ways in which a couple could delay or avoid a pregnancy. If the respondent did not spontaneously mention a particular method, the interviewer described different methods and asked the respondent to indicate if she recognized them. In the questionnaire, descriptions were included for six modern contraceptive methods and two traditional methods.

\section{Knowledge of Contraceptive Methods}

Knowledge of specific contraceptive methods by residential status of women are provided in figures 6.1 and 6.2. To get a better understanding of knowledge levels, the data is divided into spontaneous and prompted knowledge. The rest of the women are categorized as having no knowledge.

Many women are unaware of the different types of contraceptives that may be used to either delay or prevent pregnancy. Knowledge of contraception is an important step towards reproductive choice.

In rural areas, nearly 90 percent of the respondents knew about pills and injections. In urban locations, spontaneous knowledge of these two methods was shown by more than 90 percent of the respondents. The next most widely known methods were IUDs and female sterilization. Among modern methods for males, condoms seemed to be the most popular, as indicated by 19 percent of the rural respondents and 44 percent of the urban respondents. A large number of women however, were unaware of these methods. The methods least recognized were male sterilization, rhythm and withdrawal. In rural areas, three quarters (73 percent) of the women did not know anything about male sterilization, whereas the same was true for almost two thirds ( 60 percent) of urban women.

Figure 6.1: $\quad$ Percentage of married women by knowledge of specific contraceptive method - rural Dadu

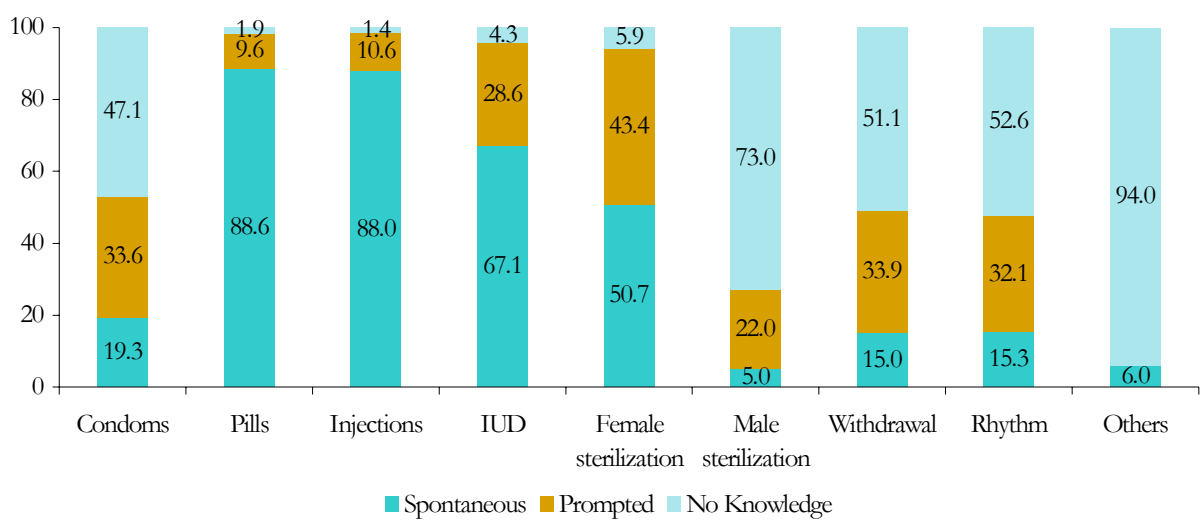


Figure 6.2: $\quad$ Percentage of married women by knowledge of specific contraceptive method - urban Dadu

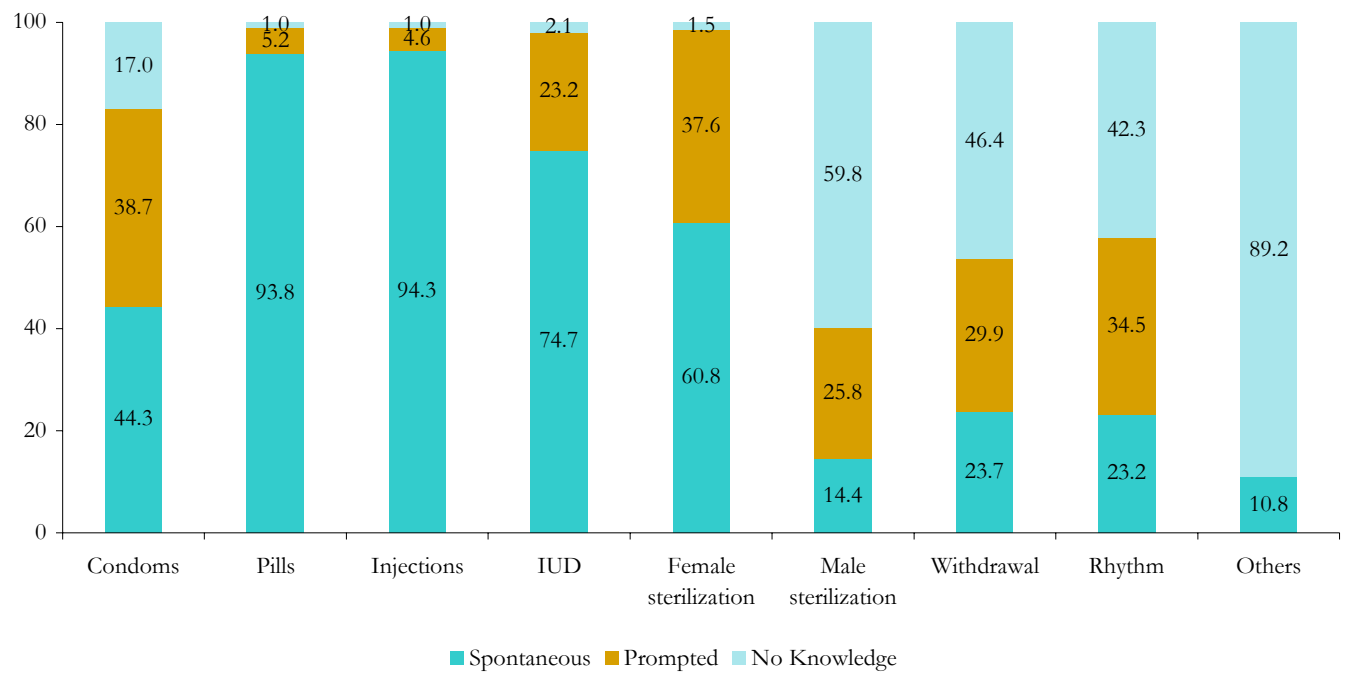

\section{Ever Use of Contraceptive Methods}

Women who have ever used any contraceptive method, regardless of their current use status are considered ever users of contraceptive methods. Table 6.1 presents data from Dadu on ever use status of the sampled women. The total ever use of contraceptives is 29 percent in Dadu. Injections were the most popular method (12 percent) followed by pills ( 8 percent); female sterilization and IUD (both 6 percent). Withdrawal and rhythm methods were only used by 2 percent of the respondents. There were no reported cases of male sterilization.

Table 6.1: $\quad$ Ever use of family planning method by contraceptive

\begin{tabular}{lrrrr}
\multicolumn{1}{c}{ Contraceptive method } & \multicolumn{2}{c}{ Place of residence } & \multicolumn{2}{c}{ Total } \\
\cline { 2 - 5 } Condoms & Rural & Urban & Percentage & Number \\
\hline Pills & 2.4 & 8.8 & 3.8 & 34 \\
\hline Injections & 6.7 & 14.4 & 8.4 & 75 \\
\hline IUD & 10.3 & 16.0 & 11.5 & 103 \\
\hline Female sterilization & 4.9 & 8.2 & 5.6 & 50 \\
\hline Male sterilization & 4.3 & 11.3 & 5.8 & 52 \\
\hline Withdrawal & 0.0 & 0.0 & 0.0 & 0 \\
\hline Rhythm & 1.6 & 3.6 & 2.0 & 18 \\
\hline Ever use & 2.1 & 4.1 & 2.6 & 23 \\
\hline
\end{tabular}




\section{Current Use of Contraceptive Methods}

Contraceptive prevalence is defined as the proportion of currently married women aged 15-49 years who were using some method of family planning at the time of the survey. Table 6.2 shows the percentage distribution of married women currently using specific family planning methods. The overall CPR of the district is 17 percent. This shows that one out of every six women is currently using any family planning method. The urban rural differentials are obvious in this area. While only 14 percent of the rural respondents currently use any method, 26 percent of their urban counterparts currently use contraceptives. In both areas, modern methods of contraception seem to be more popular than traditional ones (15 percent versus 2 percent). Among the modern methods, sterilization takes the lead in terms of popularity ( 6 percent) followed by injectables ( 4 percent), and pills ( 2 percent).

Table 6.2: $\quad$ Current use of family planning method by contraceptive

\begin{tabular}{lrrr}
\multicolumn{1}{c}{ Contraceptive Method } & Rural & Urban & All \\
Any method & 14.3 & 25.8 & 16.8 \\
\hline Any modern method & 12.9 & 23.7 & 15.2 \\
\hline Condom & 1.1 & 3.6 & 1.7 \\
\hline Pill & 2.0 & 2.6 & 2.1 \\
\hline Injectables & 3.9 & 4.6 & 4.0 \\
\hline IUD & 1.6 & 2.1 & 1.7 \\
\hline Female sterilization & 4.3 & 10.8 & 5.7 \\
\hline Any traditional method & 1.3 & 2.1 & 1.5 \\
\hline Withdrawal & 0.7 & 0.5 & 0.7 \\
\hline Rhythm & 0.6 & 1.5 & 0.8 \\
\hline Other & 0.1 & 0.0 & 0.1 \\
\hline Number & 700 & 194 & 894 \\
\hline
\end{tabular}




\section{Source of Contraceptive Supplies}

The women who are ever users of contraceptive methods were asked to indicate their last source of supply. Table 6.3 depicts the sources mentioned. The most common source for all women was DHQs/THQs (34 percent), followed by private clinics (27 percent). LHWs and medical stores were the next most important sources of supply, jointly providing methods to about one fifth of the women. Other sources like BHUs, Nurse/LHVs, RHCs, FWCs etc. were reported by a very small proportion of women.

Table 6.3: $\quad$ Distribution of contraceptive users by last source of supply

\begin{tabular}{lrrrrrr} 
& \multicolumn{2}{c}{ Rural } & \multicolumn{2}{c}{ Urban } & \multicolumn{2}{c}{ Total } \\
\cline { 2 - 7 } Source/Place & Percent & Number & Percent & Number & Percent & Number \\
\hline BHU/RHC/MCH center & 13.3 & 12 & 2.2 & 1 & 9.6 & 13 \\
\hline DHQ/THQ & 7.8 & 7 & 0.0 & 0 & 5.1 & 7 \\
\hline Private clinic/hospital & 27.8 & 25 & 45.7 & 21 & 33.8 & 46 \\
\hline Midwife & 25.6 & 23 & 28.3 & 13 & 26.5 & 36 \\
\hline Nurse/LHV & 1.1 & 1 & 0.0 & 0 & 0.7 & 1 \\
\hline FWC/RHSA & 3.3 & 3 & 0.0 & 0 & 2.2 & 3 \\
\hline Mobile Team & 2.2 & 2 & 2.2 & 1 & 2.2 & 3 \\
\hline Medical Store & 1.1 & 1 & 0.0 & 0 & 0.7 & 1 \\
\hline General Store/shop & 10.0 & 9 & 13.0 & 6 & 11.0 & 15 \\
\hline Others & 2.2 & 2 & 4.3 & 2 & 2.9 & 4 \\
\hline Don't know & 4.4 & 4 & 4.3 & 2 & 4.4 & 6 \\
\hline Total & 1.1 & 1 & 0.0 & 0 & 0.7 & 1 \\
\hline
\end{tabular}

While only 28 percent of rural respondents obtain their contraceptives from a DHQ/THQ almost half (46 percent) do so in urban areas. About a quarter of the population in both locations mentioned private hospital/clinic as their source.

LHWs are also an important source of contraception in rural Dadu, as 13 percent of the population get their methods from her. Howver, they are not so popular in urban areas. 


\section{Intentions of Future Use}

When the non-users of family planning methods were asked if they would like to use family planning methods in the future, the answers obtained were interesting. About half of the women (56 percent in rural areas and 35 percent in urban areas) said that they did not intend to use any method in future. More than a quarter of the women (26 percent in rural areas and 39 percent in urban areas) were unsure whether they would like to use any contraception. In other words, the PAIMAN project has a window of opportunity in motivating women to take up contraceptive method for their better future.

Figure 6.3: $\quad$ Percentage of married women by future intention to use contraceptives

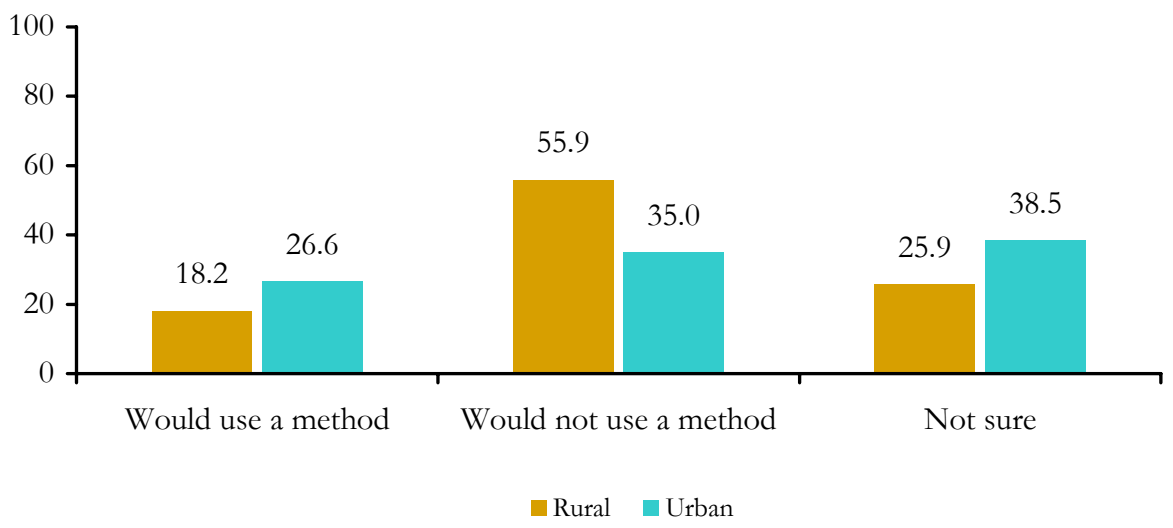





\section{Chapter

\section{Behavior Regarding Maternal and Newborn Health}

\section{Introduction}

Many of the women who were interviewed were currently pregnant. However, some women, especially those in the early stages of pregnancy, had not yet experienced the full range of events that take place over the nine-month gestational period. Women who had recently given birth were able to provide a full range of information on these events and thus constitute an important part of the sample population in terms of understanding attitudes and behaviors concerning maternal and newborn health. This chapter pertains to the respondents' last pregnancy, given that it was within the past three years. Respondents were asked several questions regarding their experience during their last pregnancy including antenatal and delivery care, complications during pregnancy and delivery, postnatal care, and problems in accessing health care. About fifteen percent of the respondents in our sample for Dadu were currently pregnant and a quarter of them had not experienced any pregnancy, and thus are not part of this chapter.

Information on antenatal care, delivery services and postnatal care is of great value in identifying segments of married women who do not utilize such services, and it is useful in planning for future improvements in these services. Delivery services are described according to the person assisting and the rate of caesarean section. Information on postnatal care was collected for women who did not give birth in a health facility, and it describes the time since delivery when it was received, as well as the caregiver.

In this chapter, the sections on antenatal and post partum care and birth preparedness include all women who have ever been pregnant in the last three years. However, the sections related to delivery and its complications pertain to women whose pregnancies resulted in childbirth (461 cases). The section on infant and childcare includes 451 women, who had live births within the past three years.

\section{Gestational Age}

The respondents were asked to indicate gestational age at the time at which the pregnancy ended. Table 7.1 shows that of those pregnancies that ended in live births, almost 83 percent of them were completed after a nine month gestational period, whereas 9 percent of the pregnancies ended before the nine month gestational period. It also shows that about half of the spontaneous abortions and two-thirds of the induced abortions ended within the first trimester, while around one-third of the abortions occurred during the 4 to 6 months gestational period. About 70 percent of the pregnancies that resulted in stillbirths occurred in 8-9 month period. 
Table 7.1: $\quad$ Pregnancy outcome by gestational age

\begin{tabular}{|c|c|c|c|c|}
\hline Gestational age when & Live Birth & Still birth & Spontaneous & Induced \\
\hline Pregnancy ended & & & Abortions & Abortions \\
\hline Less than 3 months & 0.0 & 0.0 & 54.3 & 66.7 \\
\hline 4 to 6 months & 0.0 & 10.0 & 37.1 & 33.3 \\
\hline 7 months & 1.3 & 20.0 & 5.7 & \\
\hline 8 months & 7.5 & 20.0 & 2.9 & \\
\hline 9 months & 83.4 & 50.0 & & \\
\hline 10 months & 7.8 & 0.0 & & \\
\hline Total & 100.0 & 100.0 & 100.0 & 100.0 \\
\hline Number of Pregnancies & 451 & 10 & 35 & 3 \\
\hline
\end{tabular}

\section{Antenatal Care}

In this survey, antenatal care (ANC) is defined according to the type of provider, the number of visits made, and the stage of pregnancy at the time of the first visit, including whether or not tetanus toxoid injections and iron/folate tablets were received. The survey also included questions regarding the antenatal care received by the respondent during the last pregnancy. Interestingly, the responses obtained were overall very positive.

According to the data presented in figure $7.1,54$ percent of the rural and 23 percent of the urban women received no antenatal care during pregnancy.

Figure 7.1: $\quad$ Number of antenatal check-ups obtained

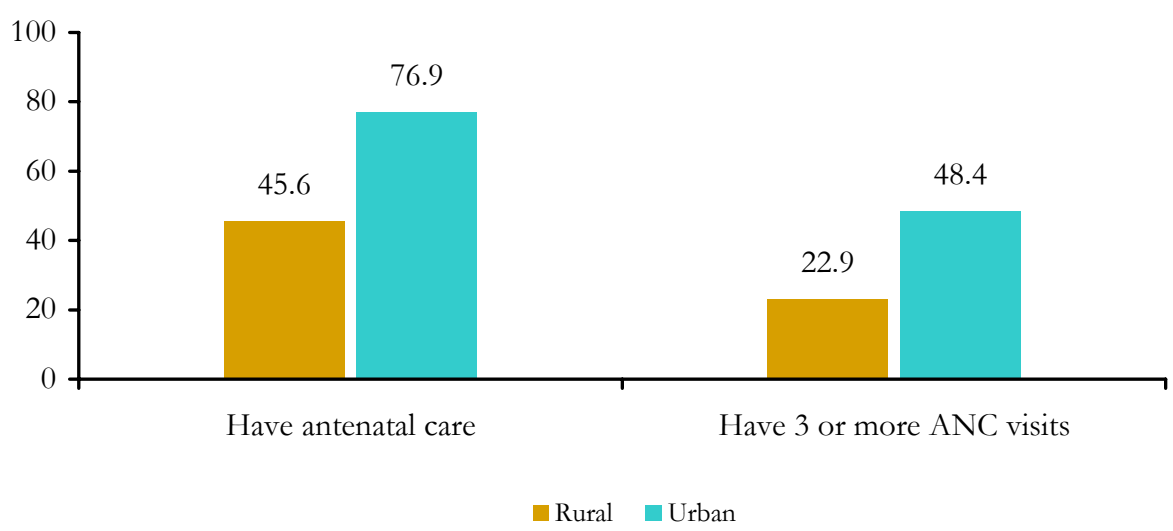

The respondents were asked to indicate the stage of pregnancy at which they obtained their first antenatal check-up. Of those who went for ANC, more than one third (37 percent) initiated an ANC during the first three months of the pregnancy. About 28 percent did so in their second trimester, and the rest went during the last three months of their pregnancy. 
Table 7.2: $\quad$ Antenatal Check-ups by Place of Residence

\begin{tabular}{|c|c|c|c|c|c|c|c|}
\hline \multirow{2}{*}{\multicolumn{2}{|c|}{ Check-ups }} & \multicolumn{2}{|c|}{ Rural } & \multicolumn{2}{|c|}{ Urban } & \multicolumn{2}{|c|}{ Total } \\
\hline & & Percent & Number & Percent & Number & Percent & Number \\
\hline \multirow{10}{*}{$\begin{array}{l}\text { Gestational } \\
\text { age of } \\
\text { pregnancy } \\
\text { at first antenatal } \\
\text { care }\end{array}$} & 1 & 9.1 & 17 & 24.3 & 17 & 13.3 & 34 \\
\hline & 2 & 8.1 & 15 & 15.7 & 11 & 10.2 & 26 \\
\hline & 3 & 14.0 & 26 & 11.4 & 8 & 13.3 & 34 \\
\hline & 4 & 5.9 & 11 & 12.9 & 9 & 7.8 & 20 \\
\hline & 5 & 11.8 & 22 & 10.0 & 7 & 11.3 & 29 \\
\hline & 6 & 9.7 & 18 & 5.7 & 4 & 8.6 & 22 \\
\hline & 7 & 18.8 & 35 & 11.4 & 8 & 16.8 & 43 \\
\hline & 8 & 9.7 & 18 & 4.3 & 3 & 8.2 & 21 \\
\hline & 9 & 10.8 & 20 & 4.3 & 3 & 9.0 & 23 \\
\hline & $\begin{array}{l}\text { Don't } \\
\text { know }\end{array}$ & 2.2 & 4 & & & 1.6 & 4 \\
\hline \multirow{11}{*}{$\begin{array}{l}\text { No. of times } \\
\text { have antenatal } \\
\text { check-ups during } \\
\text { pregnancy }\end{array}$} & 1 & 23.7 & 44 & 18.6 & 13 & 22.3 & 57 \\
\hline & 2 & 25.3 & 47 & 18.6 & 13 & 23.4 & 60 \\
\hline & 3 & 17.7 & 33 & 14.3 & 10 & 16.8 & 43 \\
\hline & 4 & 11.3 & 21 & 10.0 & 7 & 10.9 & 28 \\
\hline & 5 & 3.8 & 7 & 7.1 & 5 & 4.7 & 12 \\
\hline & 6 & 4.8 & 9 & 8.6 & 6 & 5.9 & 15 \\
\hline & 7 & 3.2 & 6 & 5.7 & 4 & 3.9 & 10 \\
\hline & 8 & 2.7 & 5 & 2.9 & 2 & 2.7 & 7 \\
\hline & $9+$ & 6.4 & 12 & 14.3 & 10 & 8.7 & 22 \\
\hline & $\begin{array}{l}\text { Don't } \\
\text { know }\end{array}$ & 1.1 & 2 & & & 0.8 & 2 \\
\hline & & 100.0 & 186 & 100.0 & 70 & 100.0 & 256 \\
\hline
\end{tabular}

Of those who made antenatal visits, one fifth (22 percent) went for only one antenatal check-up. An almost equal number of women made two visits. More than half of these women said that they had three or more antenatal visits.

The majority of women in Dadu reported having visited private facilities for antenatal care services. From the women who reported at least one ANC visit, three-quarters (74 percent) went to a private hospital/clinic, while one-quarter (26 percent) visited a public facility (such as a DHQ/THQ).

Most of the women who went for ANC were accompanied by their husbands (45 percent), followed by mothers in law (22 percent). Only 4 percent reported that they went for ANC services by themselved without any escort. 


\section{Components of Antenatal Care}

In Pakistan, it is recommended that every pregnant woman receive the following services: height and weight measurements, blood pressure measurement, tetanus toxoid immunization, and an abdominal examination. In any antenatal care visit, a woman should be informed of the danger signs of pregnancy, and provide blood and urine samples for testing. Antenatal care can improve certain outcomes through timely detection and management of possible complications. Antenatal care may improve birth weight and can also identify, treat and prevent iron deficiency and anemia in pregnant mothers.

Respondents were asked to state the number of antenatal check-ups they received as well as the questions that health providers asked them during those visits. This was to determine the level of care being provided by health care facilities in both urban and rural Dadu. Figure 7.2 outlines the questions asked of, and the tests performed on pregnant women during their antenatal check-ups in both urban and rural areas of Dadu.

Overall, the quality of care seems to be very inadequate; only 3 percent of the women who went for a ANC check up reported comprehensive coverage. About two-thirds had their blood pressure measured, around one half received an ultrasound, and the same figure were asked questions about their last menses. Around 40 percent were asked about their obstetric history, and the same percentage were checked for anemia. About one-third (36 percent) had a urine test performed.

Figure 7.2: $\quad$ Services performed/questions asked during antenatal check-up

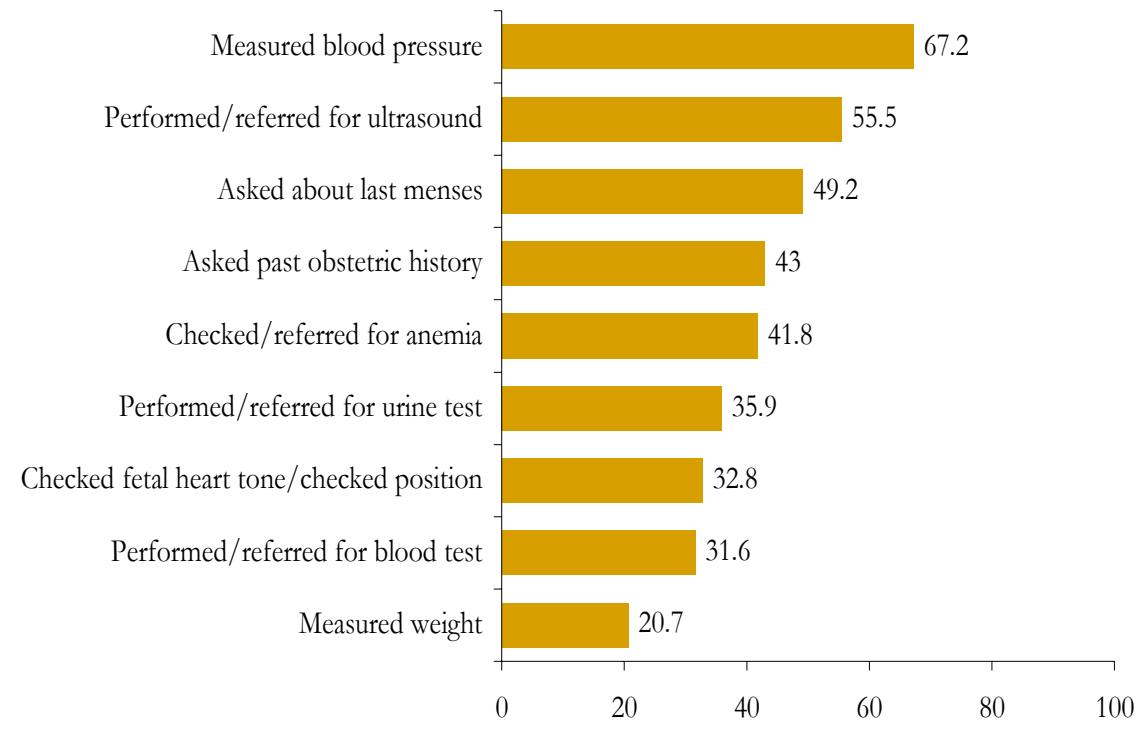

The topics that should be discussed with a pregnant women as part of comprehensive ANC care are depicted in Figure 7.3. Two-thirds (64 percent) of the respondents were educated about nutrition during pregnancy, 40 percent were educated about TT injections, and 16 percent were told about the importance/benefits of breastfeeding a newborn. Only 13 percent women were informed about danger signs during pregnancy. As well, only one out of every twenty women said that birth preparedness was discussed with them. 
Figure 7.3: $\quad$ Percentage of pregnant women by issues discussed during antenatal check-up

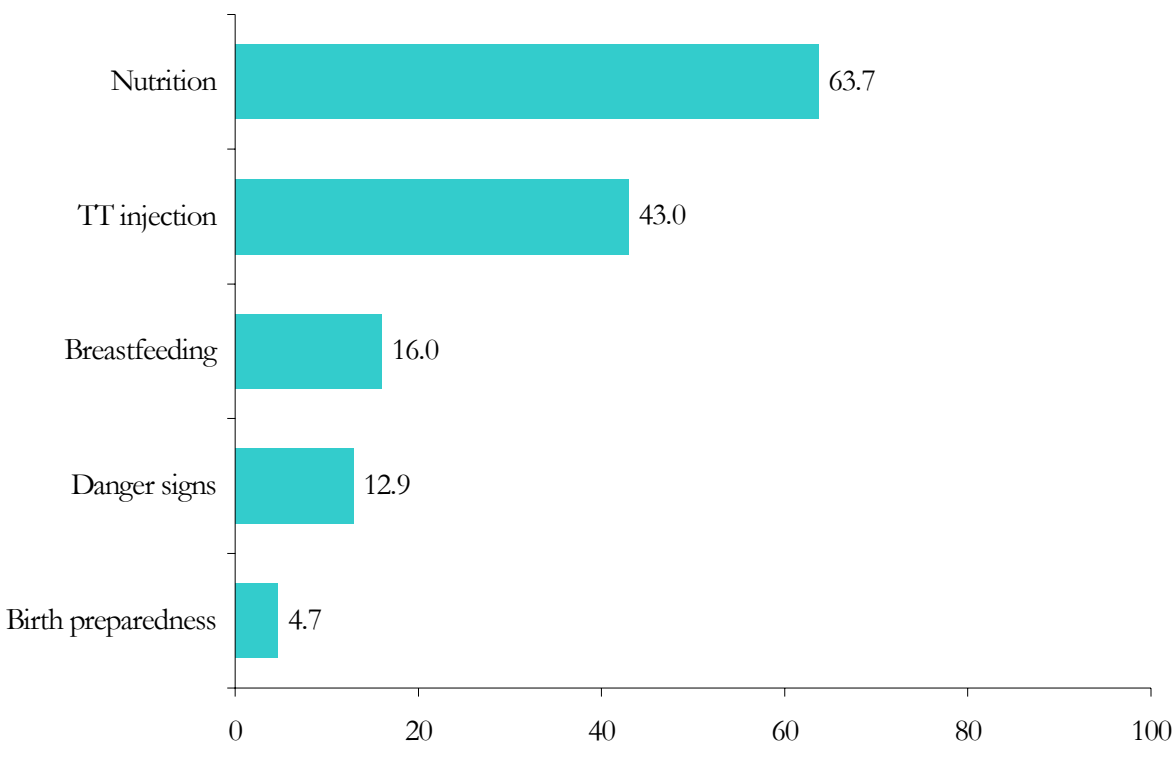

\section{Tetanus Toxoid Injections and Iron/Folate Supplements}

Respondents were also asked to state whether they took iron/folate supplements, and received TT shots during their last pregnancy. In Pakistan, the immunization of pregnant women is enforced by a program coordinated by the Expanded Program on Immunization (EPI) and the Maternal and Child Health Care $(\mathrm{MCH})$ departments at the district level. The program recommends that women receive two tetanus toxoid (T'T) injections during their first pregnancy. Booster injections are given once during each subsequent pregnancy to maintain full protection. In recent years, TT immunization has also been given to women before marriage, so that any pregnancy occurring within three years of their marriage would be protected against tetanus.

Figure 7.4 demonstrates the level of TT vaccination. Wide variations exist between rural and urban areas in the prevalence of these practices. Around 65 percent of the women in rural areas and 35 percent women in urban areas did not received TT shots during their last pregnancy. One third of the rural and two-thirds of the urban respondents received at least one shot. About 30 percent of the pregnant women in rural and 57 percent in urban areas had two or more TT shots.

Two-thirds of the respondents in urban areas, along with 35 percent of the respondents in rural areas reported using iron/folate supplements during their last pregnancy. 
Figure 7.4: $\quad$ Percentage of married women by status of TT injections during the last pregnancy

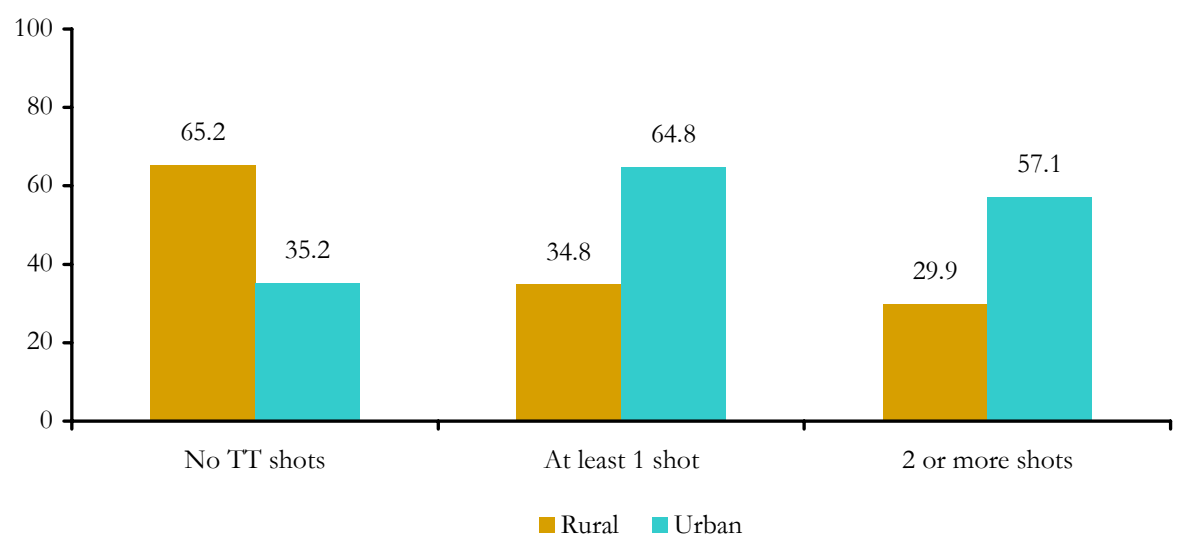

\section{Experience of Complications and Birth Preparedness}

\section{Complications During Pregnancy}

Of all the mothers, about a third (36 percent) did not experience any kind of complication during their last pregnancy (Figure 7.5). One-third (32 percent) of the women mentioned that they experienced severe lower abdominal pain, a little more than a quarter ( 30 percent) noted shortness of breath, and one fifth said that they experienced severe headache. The other complications that were considered danger signs were high fever with or without rigors (15 percent), severe/prolonged vomiting (14 percent), hypertension (10 percent), swelling of face (10 percent) and blurring of vision (6 percent).

Figure 7.5: $\quad$ Percentage of married women who experienced complications during their last pregnancy

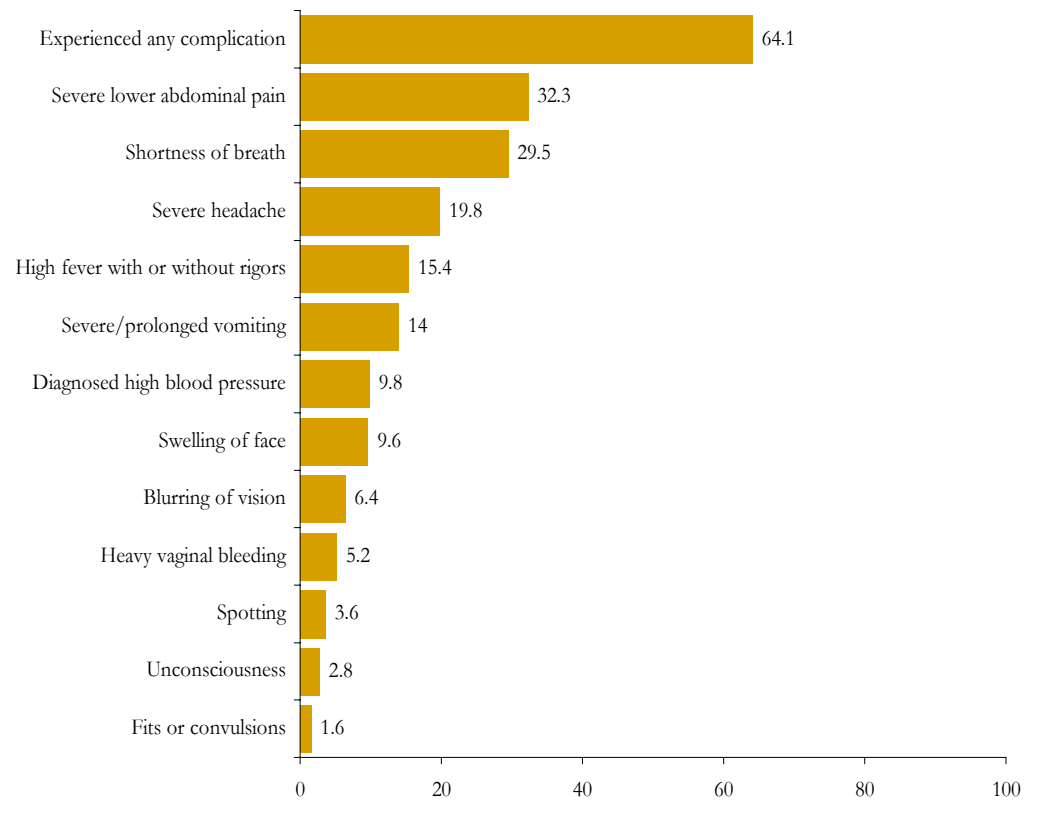


From those who experienced complications, one fifth did not seek any treatment. However, of those who sought treatment, the majority went to a private practitioner, about a fifth visited a DHQ/THQ, and a little less than one-tenth consulted a Nurse/LHV.

\section{Preparedness for Childbirth}

To ensure the safety of the mother and newborn at the time of delivery, certain preparations need to be made. These include deciding who is going to assist in the delivery, where the delivery is going to take place, how the woman is going to get to the place of delivery, and how much the delivery is going to cost. Delivery services, especially emergency obstetric care, are critical for pregnant women. Emergency care is important in the event that a pregnant mother experiences obstructed labor, pregnancy-induced hypertension, eclampsia or severe untreated anemia. Obstructed or prolonged labor is one of the most serious complications that can cause maternal death. Obstetric care can also prevent or treat complications that affect the neonate, such as birth asphyxia.

As depicted in Figure 7.6, the women in Dadu seem to be unaware of the necessary preparations for childbirth. The majority of them (75 percent) had arranged clothes for the baby and money for a normal delivery (56 percent). A little less than a third (29 percent) said that they had arranged for money in case of an emergency or that they knew about a nearby hospital. About a quarter (23 percent) knew about the doctor's delivery fee in that hospital or had talked beforehand to the selected delivery attendant. Only one out of six women had arranged for any kind of transportation.

Figure 7.6: $\quad$ Percentage of married women who made arrangements for their last delivery

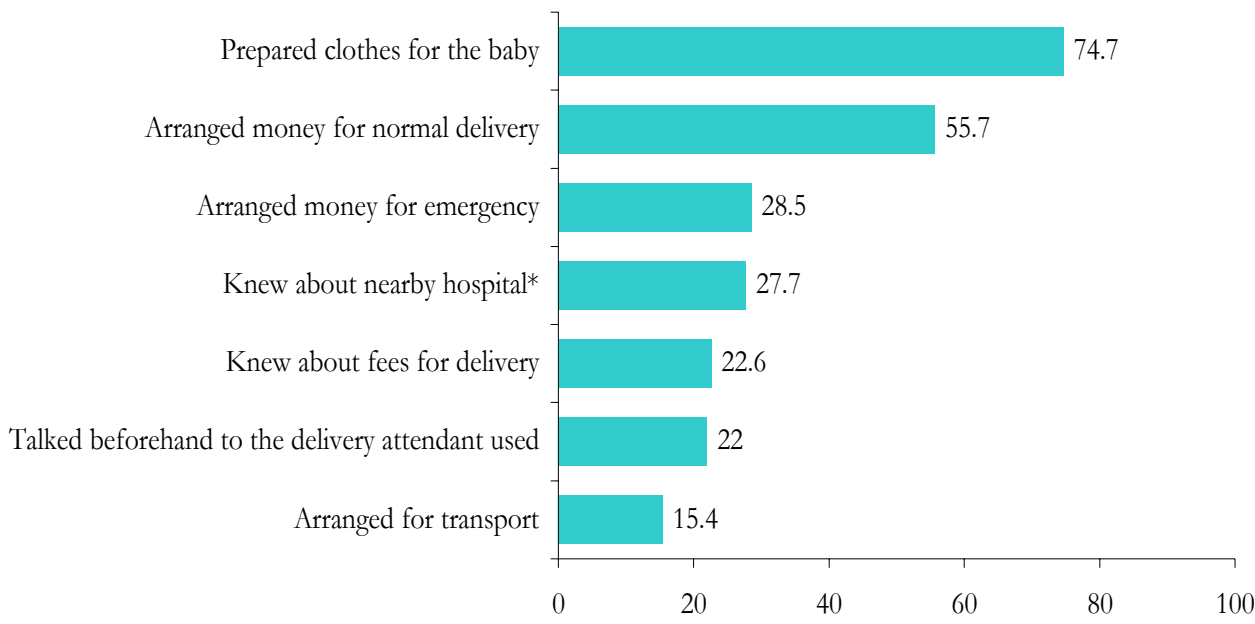

* A bospital that remains open 24 hours a day and could provide treatment for complications.

\section{Delivery Characteristics}

Around half of the respondents in this district had experienced a pregnancy that ended in the three years preceding the PAIMAN survey. Of these pregnancies, more than 90 percent resulted in a live birth, 2 percent in stillbirths, 7 percent in spontaneous abortions and 1 percent ended with induced abortions. Of all the births, 87 percent were normal vaginal deliveries, 3 percent were caesarean sections, and 2 percent of the women required assisted vaginal deliveries. 


\section{Place of Delivery}

In Dadu, 63 percent of the women reported that they delivered their last child at home (66 percent rural and 47 percent urban). Another, 21 percent of all rural and 38 percent of urban deliveries took place in a private hospital/clinic and only 9 percent rural and 15 percent urban women went to a DHQ/THQ. Utilization of other public facilities were almost negligible in both locations.(Figure 7.7).

Figure 7.7: $\quad$ Percentage of women by place of delivery and place of residence

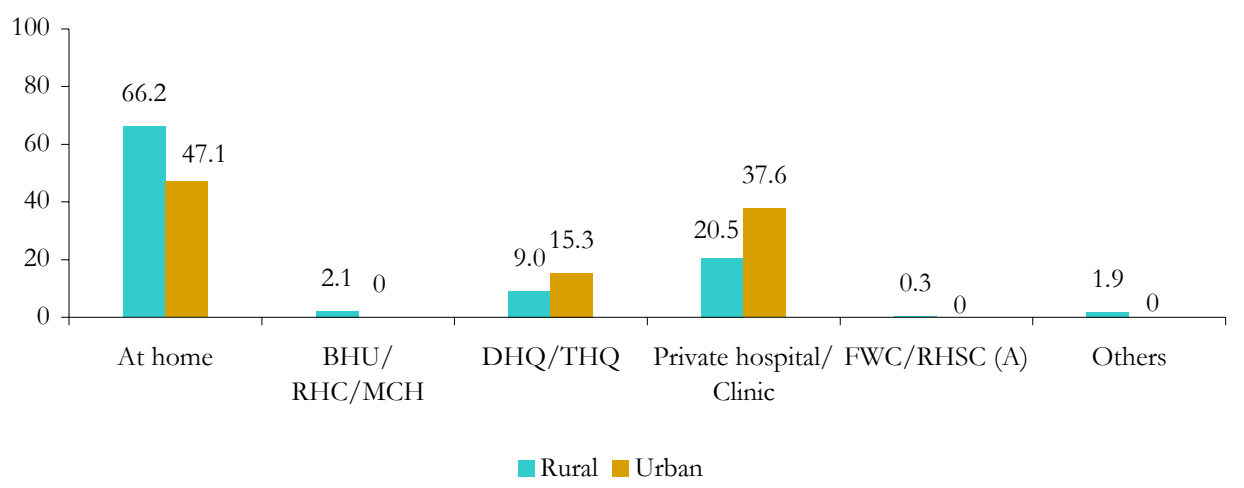

A TBA/Dai conducted the majority $(88 \%)$ of the deliveries that took place at home, while female relatives/family members were present for 6 percent of the deliveries. At home, only 3 percent of deliveries were conducted by a skilled birth attendant, i.e., doctor, nurse, LHV and midwife (figure 7.8).

Figure 7.8: $\quad$ Distribution of births by type of attendant (of those births that took place at home)

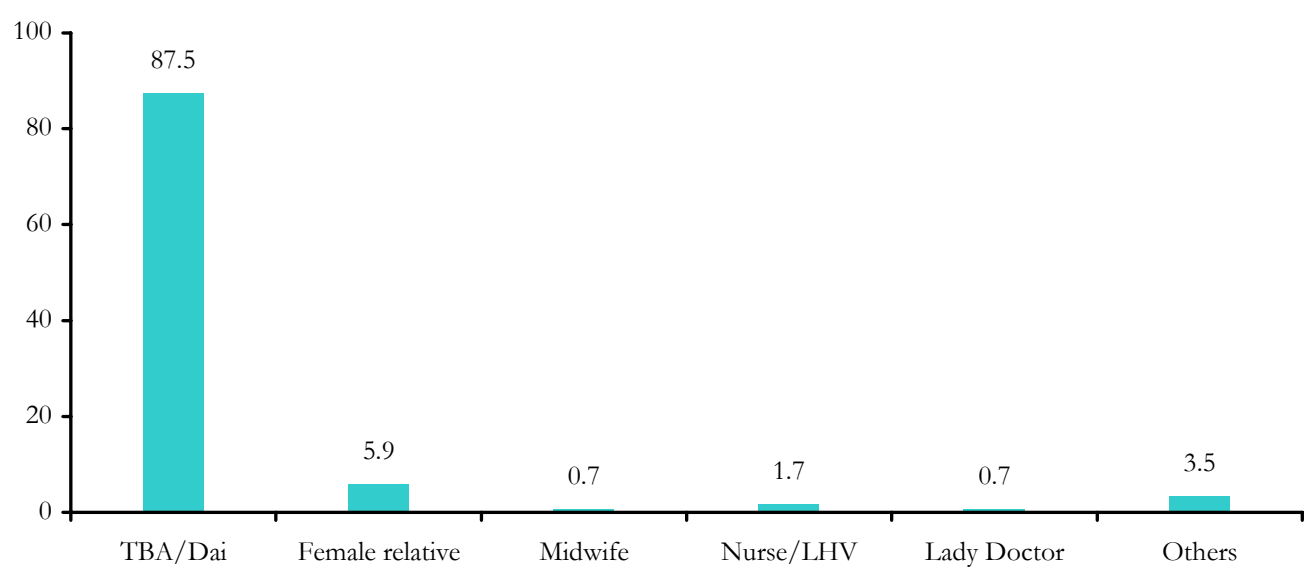




\section{Assistance During Delivery}

The most popular reasons provided by respondents for preferring the assistance of TBAs over health professionals during delivery were previous use (32 percent) and family choice ( 26 percent). Cost and geographical proximity were also important reasons (Figure 7.9).

Figure 7.9: $\quad$ Main reason for using a TBA/dai to assist with the last delivery

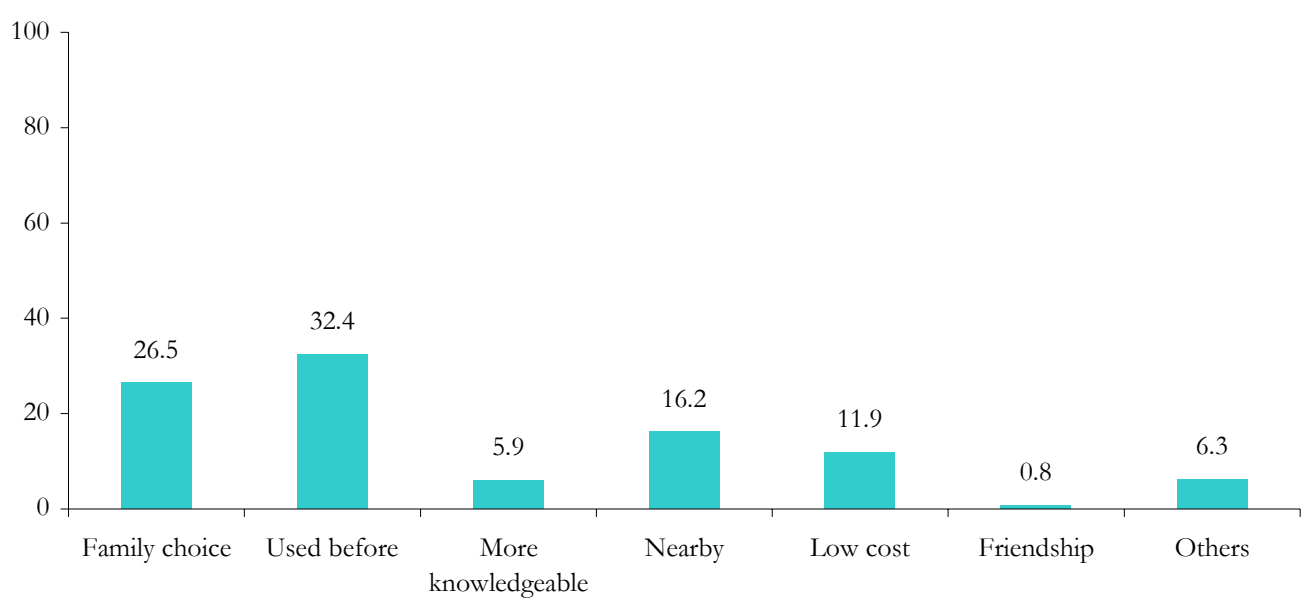

\section{Clean Delivery Practices}

The women who had delivered their babies at home were asked a number of questions related to safe birth practices. Around 95 percent of the women said that their birth attendant used a new blade to cut the cord and a new thread to tie it. Around 90 percent reported that their TBA washed her hands prior to the delivery. A new delivery kit was used in only 10 percent of the deliveries (figure 7.10).

Figure 7.10: $\quad$ Percentage of delivery attendants reporting clean delivery practices

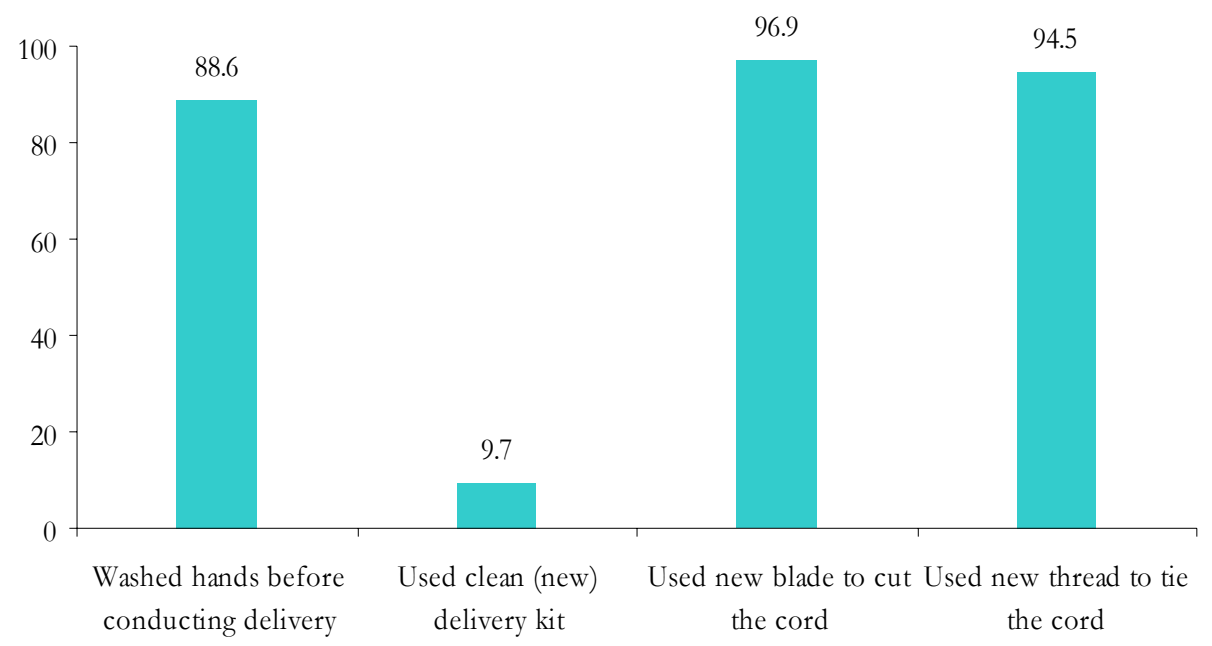




\section{Complications During Childbirth}

About a quarter of the women in Dadu, who were interviewed regarding their last pregnancy, reported that they experienced some kind of complications during delivery of their last baby (Table 7.2). The most commonly experienced complications were prolonged/obstructed labor (11 percent), followed by excruciating abnormal pain (10 percent), fever ( 5 percent), bleeding before labor ( 4 percent) and premature rupture of membranes (4 percent). About 3 percent experienced excessive bleeding on the day of delivery/abortion. Another two percent mentioned that they experienced a prolapsed uterus or fetal malpositioning. One percent stated that they suffered from tears in the vagina/cervix or uterus.

Table 7.3: $\quad$ Type of complications experienced during the last delivery

\begin{tabular}{lrr} 
& \multicolumn{1}{c}{ Complications } & Total \\
& & Number \\
Prolonged/obstructed labor & Percentage & 55 \\
\hline Bleeding before labor began & 11.0 & 21 \\
\hline Excruciating abnormal pain & 4.2 & 52 \\
\hline Premature rupture of membranes & 10.4 & 18 \\
\hline Delay in delivery of placenta/retained placenta & 3.6 & 7 \\
\hline Excessively postpartum bleeding on day of delivery/abortion & 1.4 & 15 \\
\hline Tear in vagina, cervix or uterus & 3.0 & 5 \\
\hline Prolapsed uterus & 1.0 & 11 \\
\hline Fever & 2.2 & 24 \\
\hline Abnormal position of fetus & 4.8 & 11 \\
\hline Any complication & 2.2 & 121 \\
Total Number & 26.2 & 461
\end{tabular}

Of the quarter (26 percent) of women who experienced any complication during pregnancy, around a third did not seek any treatment to address the problem. Of those who did so, around half went to a private hospital/clinic and a quarter visited a DHQ/THQ. One-tenth of the women sought help from a nurse or LHV (data not shown).

\section{Decision-making Within Family}

Deciding about seeking treatment is considered a major barrier in reaching a health facility on time, and the delay at that stage could prove fatal for many women. Low levels of autonomy and decisionmaking power mean pregnant women are not expected to decide about treatment for complications during pregnancy. In order to understand the power dynamics of decision-making related to delivery complications, women were asked about who decided to seek treatment. In Dadu, it was determined that in more than half (51 percent) of the cases, the husband was the main decision maker. Only 17 percent of the respondents were able to make decisions themselves, whereas in 12 percent of cases the mother-in-law had the final say (Table 7.4). 
Table 7.4:

Person who made decision to seek health care/mode of transport used to reach health facility

\begin{tabular}{lrr}
\multicolumn{1}{r}{ Person who made decision to seek health care } & \multicolumn{2}{c}{ Total } \\
\cline { 2 - 3 } Self & Percent & Number \\
\hline Husband & 16.7 & 13 \\
\hline Mother in law & 51.3 & 40 \\
\hline Other family member & 11.5 & 9 \\
\hline TBA/Dai & 9.0 & 7 \\
\hline Others & 10.3 & 8 \\
\hline Total & 1.3 & 1 \\
\hline
\end{tabular}

\section{Availability of Transport}

The modes of transport used to reach the health facility are depicted in Figure 7.11. About one half (47 percent) of the women said that they used a private transport (commercial), one-fifth either had their own transport or the service provider came to their house. About 1 percent said that they went to the facility on foot.

Figure 7.11: $\quad$ Mode of transport used to reach health facility to seek treatment for complication during delivery

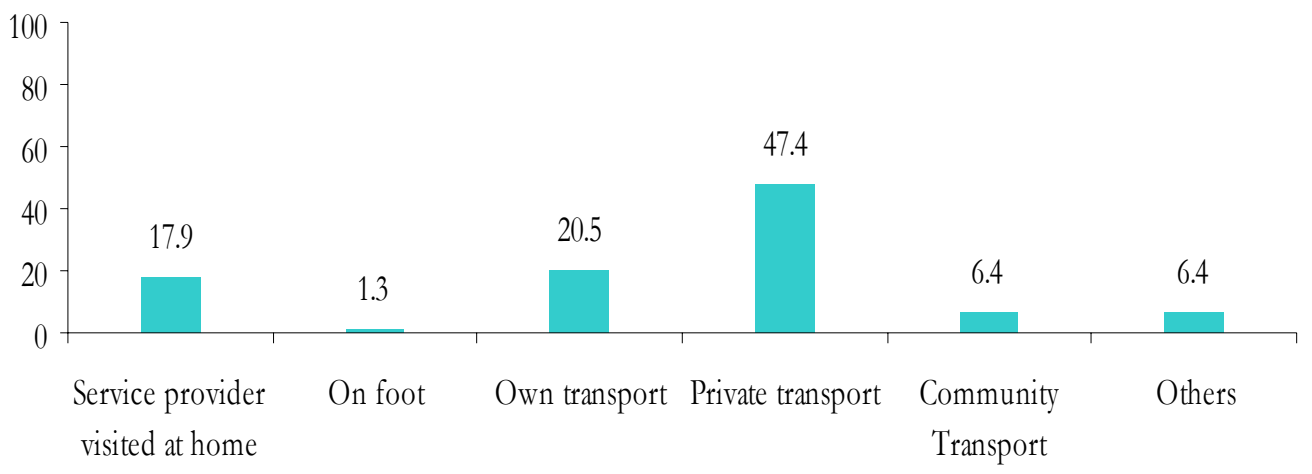

Figure 7.12 shows the distribution of respondents by the time they took to reach a health facility in the case of complication during delivery. About half of these women reached a facility within half an hour. One-third took 30 to 60 minutes. Only 2 percent said that they reached a facility after two hours. 
Figure: 7.12: $\quad$ Time taken to reach the health facility for delivery complications

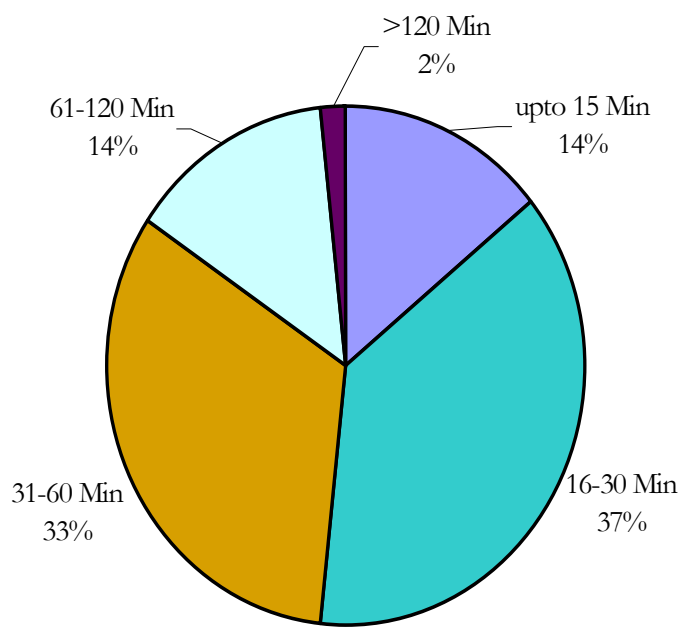

Figure 7.13 shows the median time to get transport, to reach a health facility and to obtain treatment after reaching the facility, for those women who experienced any complication during delivery and sought medical treatment. The data shows that in Dadu, it takes 20 minutes to get transport, 55 mintues to reach the health facility and 10 minutes to get treatment upon reaching the health facility. Overall, the average time taken to get a pregnant woman experiencing complications during delivery medical attention is around one and a half hours; from the time the decision to seek treatment is made, to the time treatment is actually obtained.

Figure 7.13: $\quad$ Average (median) time to get the transport, to reach the health facility and to obtain the treatment after reaching the facility

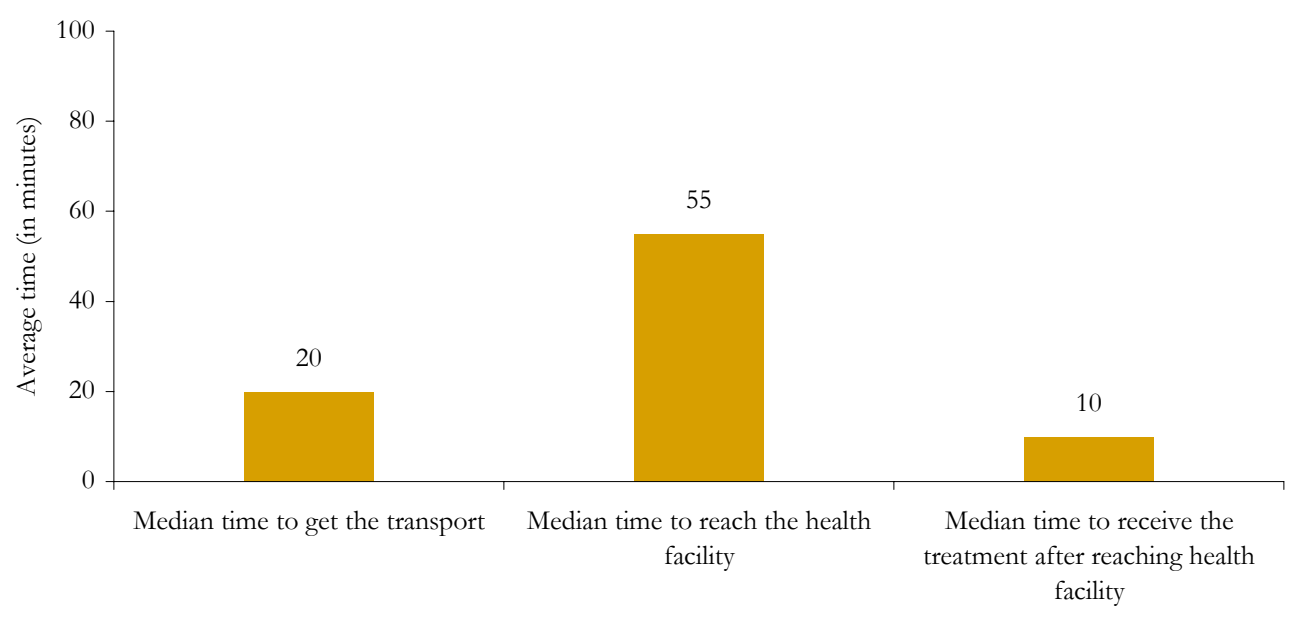

\section{Postpartum Care}

The postpartum period is a critical time for both the mother and the newborn. Respondents were asked about the quality and level of postpartum care they received after their last delivery. In district Dadu, postpartum care-seeking behavior seems to be extremely poor. More than 80 percent of the women who had had a live birth in the last three years said that they did not go for any postnatal 
check ups (Table 7.5). And, of those who did receive any check-up, only 17 percent received it on the day of delivery. A little more than a quarter (29 percent rural and 22 percent urban) of the women experienced any complication during the postpartum period.

Table 7.5:

History of postpartum care

\begin{tabular}{|c|c|c|c|c|c|c|c|}
\hline \multirow{2}{*}{\multicolumn{2}{|c|}{ History }} & \multicolumn{2}{|c|}{ Rural } & \multicolumn{2}{|c|}{ Urban } & \multicolumn{2}{|c|}{ Total } \\
\hline & & Percent & Number & Percent & Number & Percent & Number \\
\hline \multirow{3}{*}{ Have a postnatal check-ups } & Yes & 11.2 & 42 & 6.0 & 5 & 10.2 & 47 \\
\hline & No & 83.2 & 313 & 77.4 & 65 & 82.2 & 378 \\
\hline & $\begin{array}{l}\text { Delivered in } \\
\text { Hospital }\end{array}$ & 5.6 & 21 & 16.7 & 14 & 7.6 & 35 \\
\hline $\begin{array}{l}\text { No. of days after delivery, } \\
\text { have first check-up }\end{array}$ & Same day & 19.0 & 8 & & & 17.0 & 8 \\
\hline \multirow{2}{*}{$\begin{array}{l}\text { Experience complications } \\
\text { during postpartum period }\end{array}$} & Yes & 29.2 & 119 & 22.0 & 20 & 27.9 & 139 \\
\hline & No & 70.8 & 289 & 78.0 & 71 & 72.1 & 360 \\
\hline Total & & 100.0 & 408 & 100.0 & 91 & 100.0 & 499 \\
\hline
\end{tabular}

\section{Complications During Postpartum Period}

More than a quarter of the women in Dadu reportedly experienced some type of complication during their post partum period. Of those who answered in affirmative to this question were further asked about the details of their PPP complications. The results are listed in Figure 7.14. Most commonly noted problems during this period were high fever (58 percent) and lower abdominal pain (42 percent). One quarter of the women also experienced excessive vaginal bleeding.

Figure 7.14: $\quad$ Complications during postpartum period

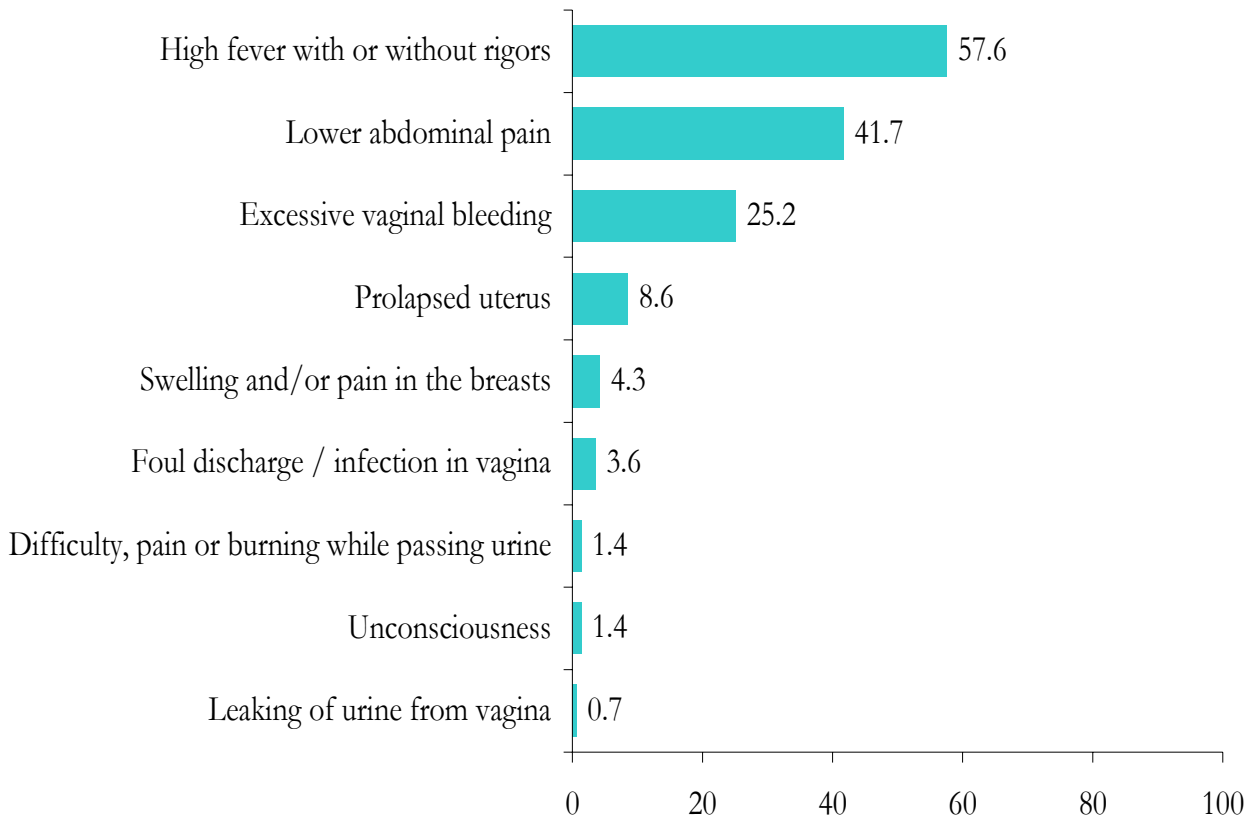


Upon asking the recourse for their problem, about a third of these women said that they did not get any treatment.

\section{Newborn/Infant Care}

The care provided to a newborn upon birth is crucial to the baby's health. Survey questions regarding initial infant and childcare help determined the cause of newborn morbidity and mortality.

\section{Child Care During Birth}

Since most births take place at home, it is important to ascertain the practices related to handling the baby soon after delivery. Table 7.6 portrays the results from Dadu for these practices. Immediately after birth, more than a third (38 percent) of the babies were reportedly placed with the mother, about a quarter (24 percent) were placed on a piece of cloth, one-tenth (12 percent) were placed on mattress, and one out of every 20 babies were put on the floor. In terms of care of the baby, 96 percent were dried before being given a bath. Almost all babies in both locations are dried up and cleaned before giving bath.

\section{Table 7.6: $\quad$ History of newborn care}

\begin{tabular}{|c|c|c|c|c|c|c|c|}
\hline & \multirow{2}{*}{ History } & \multicolumn{2}{|c|}{ Rural } & \multicolumn{2}{|c|}{ Urban } & \multicolumn{2}{|c|}{ Total } \\
\hline & & Percent & Number & Percent & Number & Percent & Number \\
\hline \multirow{6}{*}{$\begin{array}{l}\text { Placed child } \\
\text { immediately } \\
\text { after delivery }\end{array}$} & On floor & 5.2 & 19 & 2.4 & 2 & 4.7 & 21 \\
\hline & On mattress & 12.2 & 45 & 13.3 & 11 & 12.4 & 56 \\
\hline & On a piece of cloth & 25.8 & 95 & 13.3 & 11 & 23.5 & 106 \\
\hline & Put with the mother & 34.0 & 125 & 54.2 & 45 & 37.7 & 170 \\
\hline & Others & 22.3 & 82 & 15.7 & 13 & 21.1 & 95 \\
\hline & Don't know & 0.5 & 2 & 1.2 & 1 & 0.7 & 3 \\
\hline \multirow{3}{*}{$\begin{array}{l}\text { Child dried } \\
\text { up/cleaned } \\
\text { before giving } \\
\text { bath }\end{array}$} & Yes & 95.4 & 351 & 98.8 & 82 & 96.0 & 433 \\
\hline & No & 1.1 & 4 & 0.0 & 0 & 0.9 & 4 \\
\hline & Don't know & 3.5 & 13 & 1.2 & 1 & 3.1 & 14 \\
\hline
\end{tabular}

It is not very common to weigh a newborn baby if the birth took place at home. For those women who did not weigh their babies, a question was asked about the size of the baby at the time of birth. Figure 7.15 depicts the percentage distribution of babies by their size at birth. It appears that twothids of the babies were of 'normal' size at the time of their birth. One-fifth of the women do not remember the size of their babies, 13 percent reported that their babies were born smaller than average, while only 1 percent noted that their babies were born larger than average. 
Figure 7.15:

Percentage of live births by their size (small, normal and big) at birth

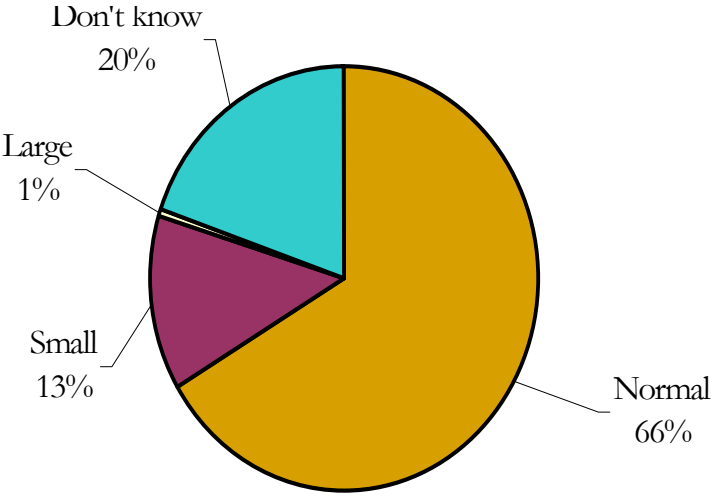

A question on the practice of bathing after birth was also asked. According to figure 7.16, half of the babies were given a bath within one hour of their birth. Another 18 percent were given a bath within one to three hours of birth. Only about a quarter ( 23 percent) of the babies were bathed after the recommended periof of 6 hours following birth.

Figure 7.16: $\quad$ Percentage of babies by time of given bath after birth

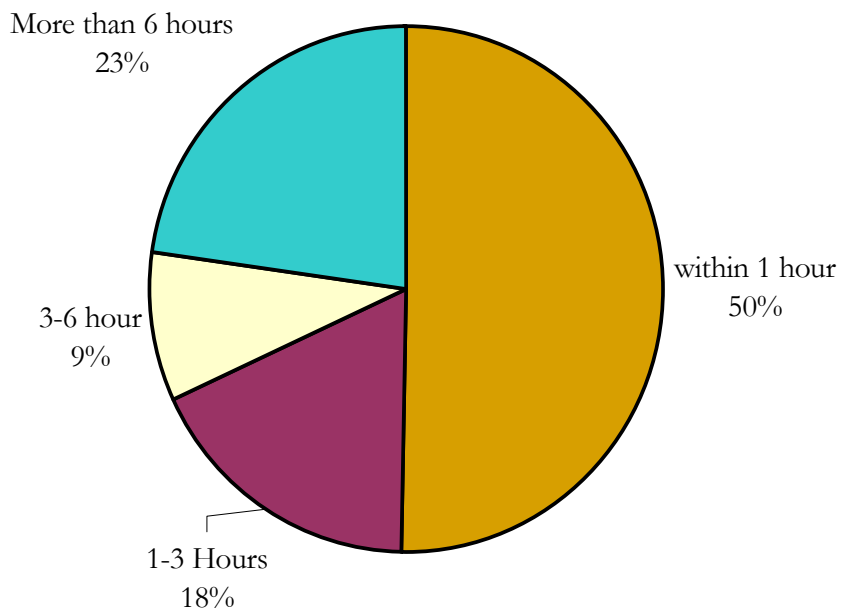




\section{Colostrum and Breastfeeding}

Though more than 90 percent of the women reported that they breastfed their last child, only 40 percent of the women said that they give colostrum to the baby. Around 60 percent of the eligible women had given something other than breast milk to their newborn babies.

Figure 7.17: $\quad$ Newborn feeding practices

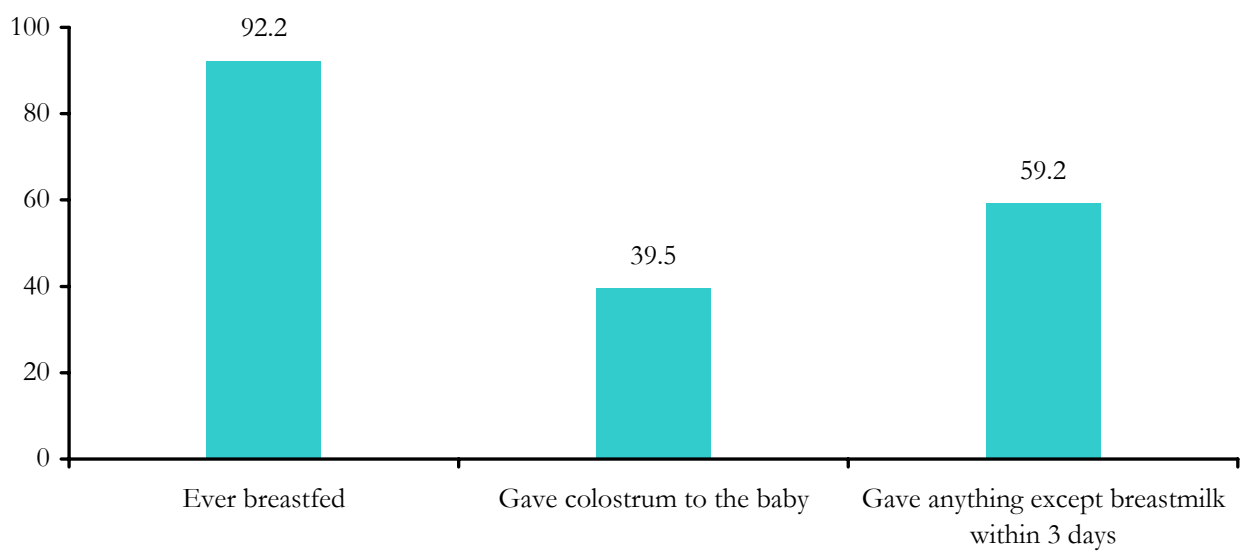

\section{Newborn Medical Check-ups}

Only abut a fifth (19 percent) of the babies were examined after birth, by a medical practitioner. All women who had a live birth were asked whether they observed any danger signs and symptoms that appeared within one hour of the birth. Around a fifth of the women remarked that their child suffered from danger signs and symptoms. Figure 7.18 illustrates all those options in detail. It is reassuring to see that for all the problems, the greatest proportion of recorded complications was fever $(9$ percent) and difficultly breathing ( 6 percent). Whereas other danger signs such as the baby not crying, yellow skin/jaundice, unable to suckle etc. were reported by less than 5 percent of the respondents. 
Figure 7.18: $\quad$ Percentage of newborns with danger signs/symptoms soon after delivery

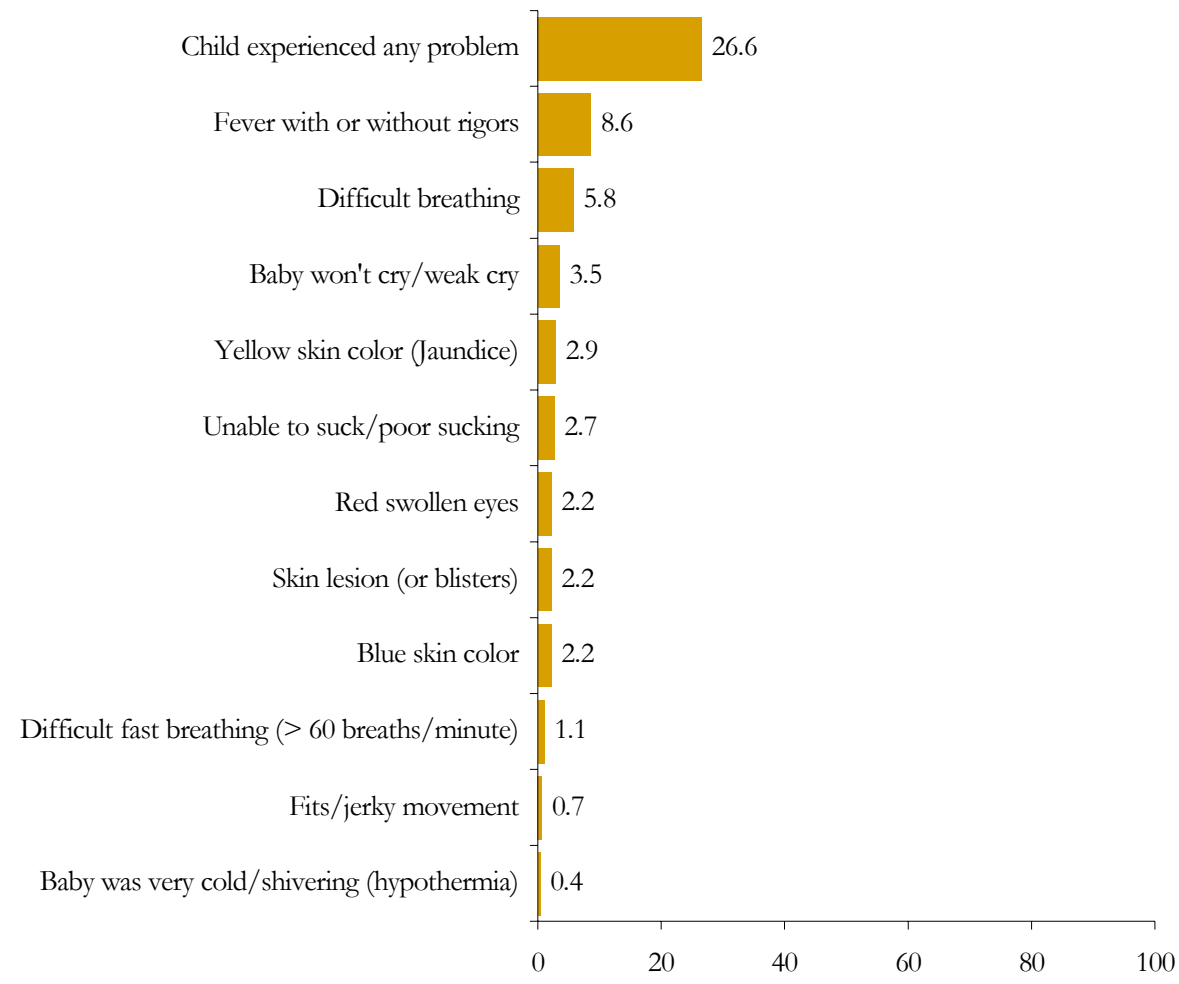

The data shows that for more than 85 percent of the cases in which complications were noted in the newborn, treatment was sought. Of those children/infants that suffered any complications or problems, more than half ( 57 percent) of the respondents went to a private health service provider, and one-sixth (15 percent) went to a DHQ/THQ.

Table 7.7: $\quad$ Place where treatment was sought for newborn complications

\begin{tabular}{|c|c|c|}
\hline Measures & Total & Number \\
\hline Didn't get treatment & 13.9 & 16 \\
\hline LHW & 0.9 & 1 \\
\hline TBA/Dai & 2.6 & 3 \\
\hline BHU/RHC/Dispensary/MCH Center & 4.3 & 5 \\
\hline DHQ/THQ & 14.8 & 17 \\
\hline Private hospital/clinic & 56.5 & 65 \\
\hline Hakim/homeopath & 1.7 & 2 \\
\hline Others & 5.2 & 6 \\
\hline Total & 100.0 & 115 \\
\hline
\end{tabular}


Figure 7.19: $\quad$ Status of the last birth

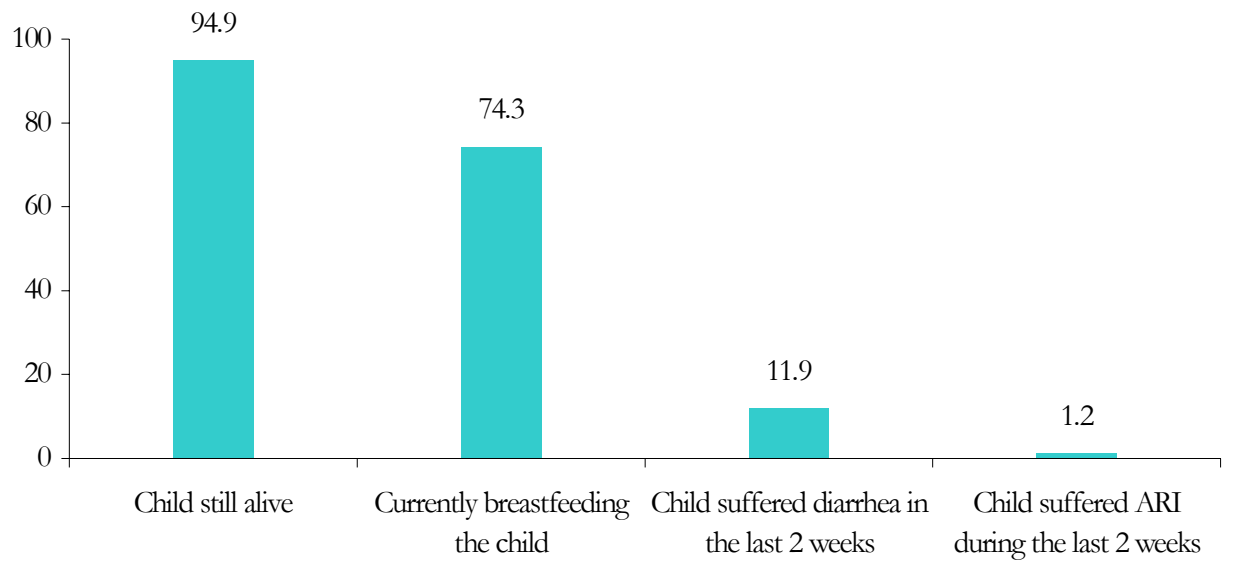

Figure 7.18 indicates the results of some of the key variables related to the status of the last birth. About 95 percent of the children born within the past three years were still alive at the time of the survey. Three-quarters ( 74 percent) were still being breastfed. About a tenth (12 percent) of the women interviewed said their child/infant had suffered from diarrhea in the two weeks preceding the survey. Only about 1 percent of the women's babies suffered from Acute Respiratory Infection (ARI) during the same reference period. 


\section{Chapter

\section{Conclusions}

The baseline household survey conducted in Dadu is an integral part of the process of understanding the prevailing knowledge, attitudes and practices regarding pregnancy and neonatal care for the PAIMAN project. Since the project is intended to improve the health of all pregnant women as well as their newborn children, it is important to understand the underlying nuances of the factors that hinder access to better health care. Therefore, keeping in mind the target recipient of the program interventions, the survey was designed to collect opinions and experiences of currently married women of reproductive age (15-19 year old). These baseline findings will not only help design the interventions according to the needs of each location but will also serve as the benchmark to evaluate the success of the PAIMAN project.

In district Dadu, the overall age-sex distribution of the households sample shows a sex ratio of 108, which is exactly the same as the national sex ratio obtained in the 1998 Population Census. The marital status clearly demonstrates a delay in female marriages which is an improvement on figures in the 1998 Population Census. However, women still tend to get married earlier than men. Surprisingly, it appears that there hasn't been any change in the number of average number of children ever born since the census. However, in the age-wise data there is certainly a huge reduction in children ever born: the mean number of children born to the $15-19$ year age group is 0.4 , compared to 2.2 as established in the census.

However, in the older age groups, the PAIMAN survey reported a higher average number of children. The household and community level socio-economic data shows that most people in this district are deprived of basic facilities. A majority of the households lack basic facilities such as access to water, hygienic cooking fuel and sanitation. Moreover, 40 percent of the males and 76 percent of the females in this district have never been to school.

Findings also show that almost half of the respondents (44 percent) of Dadu have no exposure to any of the three media channels; television, radio or newspapers. Therefore, it is obvious that in order to educate and inform this segment of the population regarding safe motherhood a multi-pronged communication strategy needs to be adopted including community level activities such as community gatherings, speeches and health education sessions. It should also be kept in mind that the majority (60 percent) of women consider television to be the most trustworthy media.

Regarding antenatal care, an overwhelming majority believe it is important for women to receive antenatal check-ups, while 22 percent and 11 percent of the married women in rural and urban areas respectively felt it was not necessary. However, in actual practice, only one-half of all pregnant women went for antenatal check-ups during their last pregnancy. Of those who made any antenatal visits, only 28 percent made three or more such visits, which is the recommended practice. It is quite 
clear that while many women do want to receive antenatal check-ups, a majority cannot access the services.

Respondents were asked to indicate which complications they believed were dangerous and required medical attention during the pregnancy period. About 60 percent of the women noted severe abdominal pain as a danger sign during pregnancy. About a third also mentioned jaundice and high fever. A large majority of women failed to recognize other danger signs like bleeding, high blood pressure, fits etc. More than half of the married women in both urban and rural areas knew three or more danger signs during pregnancy. However, there is still a significant proportion of women in both locations who could not name any danger sign during pregnancy (19 percent in rural areas and 13 percent in urban areas).

The findings also show that about 35 percent of the married women in rural areas and about 65 percent in urban areas indicated that they did in fact receive TT shots during their last pregnancy. A very large portion of the rural women ( 65 percent) and urban women (44 percent) indicated that they took no iron/folate supplements during their pregnancy.

Certain preparations before the delivery, for example, arranging medical help for delivery, organizing transport and finances etc. can save the life of the mother and the child. In Dadu, it is obvious that most households do not have access to their own or community provided means of transport to take a pregnant women to a health facility. Most women use private (rented) transportation.

In Pakistan most deliveries take place at home in both urban and rural locations. In Dadu, the trend is quite similar and 63 percent of the respondents reportedly had home deliveries. Surprisingly, while 12 percent of the women interviewed delivered their babies in government facilities, twice as many reported utilizing private facilities for their deliveries. The Dai or TBA seems to be the most widely used birth attendant in Dadu, conducting 55 percent of the home deliveries.

In general, the recommended hygienic practices for delivery, such as washing hands before delivery, using a new blade for cutting the cord and using a new thread for tying the cord were followed. However, usage of a new delivery kit was almost nonexistent (10 percent). Assessing the cost of deliveries, it appears that on average women pay around 1,500 rupees for a delivery. However, half of the women pay rupees 500 or less for each delivery.

In terms of danger signs during delivery, more than a third of the women were able to recognize prolonged labor, retained placenta and fetal malpositioning as danger signs. Around the same proportion (33 percent in urban areas and 27 percent in rural areas) were able to identify three or more signs. However, 14 percent and 19 percent of the urban and rural respondents could not list any danger signs during delivery. One-tenth of the women said that they experienced excruciatingly abnormal pain and the same proportion mentioned prolonged/obstructed labor during their last delivery. Abnormal position of the fetus, premature ruptures of membranes and excessive bleeding were other reported complications.

Though a large majority of the women recognized the special needs of the postnatal period, 70 percent of the women interviewed do not consider medical check ups during this period necessary.

The findings show that only 33 percent of urban respondents and 28 percent of rural respondents can recognize at least three danger signs during the post natal period. Around a fifth of rural and a sixth of urban women cannot recognize even one danger sign of the postpartum period. High fever (58 
percent) and lower abdominal pain (42 percent) are the most commonly experienced complications during this period.

More than half of the women were able to recognize jaundice and difficult breathing as danger signs among newborns. High fever or a weak cry are also recognized by around 40 percent of the eligible women.

It appears from the findings that women received most of their health-related information from other people around them, as opposed to health services providers or any kind of mass media. For example, for pregnancy-related information, in-laws, friends, or relatives are the main source. Among the health service providers, TBAs/Dais are most active and are the source of information for delivery, for a third of the women. They were noted by a fifth of women for information on the ante and post natal period.

Almost all respondents were able to recognize at least one family planning method, regardless of their use status. Most women in this regard seem to know about female methods, such as the pill and the injections. Knowledge of natural methods like withdrawal and rhythm were comparatively lower in both rural and urban areas, around half of the women could not identity these methods even after prompting. The overall contraceptive prevalence rate in the district is 17 percent, 26 percent in urban areas and 14 percent in rural areas). Of all the methods, female sterilization (6 percent) is the most popular, followed by injectables ( 4 percent), pills ( 2 percent) and IUD ( 2 percent). These four methods alone account for 80 percent of all family planning users.

We hope that these data may be used by health officials, NGOs, and other concerned stakeholders to improve the situation regarding maternal and newborn health in Rawalpindi. PAIMAN will use this information to guide its own interventions and to monitor its progress. 


\section{References}

Caldwell, J., Routes to Low Mortality in Poor Countries. Population and Development Review, Vol. 12, No. 2. (Jun., 1986), pp. 171-220.

Federal Bureau of Statistics, "Socio-Economic Indicators at District Level, Punjab," Statistics Division, Government of Pakistan, (2002).

Hollander, D., Antenatal Education Helps Turkish Women Adopt Health-Promoting Behaviour. International Family Planning Perspectives, Vol. 30, No. 1. (Mar., 2004), pp. 45-46.

JHPIEGO/Maternal and Neonatal Health Program, "Monitoring Birth Preparedness and Complication Readiness: Tools and Indicators for Maternal and Newborn Health," (2004).

Mahmood, Arshad, Determinants of Neonatal and Post-Neonatal Mortality in Pakistan. The Pakistan Development Review, Vol. 41, No. 4, Part II (Winter 2002), pp. 723-744.

Mahmood, Arshad, Socioeconomic Factors, Personal Illness Control and Infant and Child Mortality in Pakistan. Pakistan Population Review, Vol. 3, No. 1 (1992), pp. 67-86.

Martin, Linda G.; J. Trussell; Florentina Reyes Salvail; Nasra M. Shah, Co-variates of Child Mortality in the Philippines, Indonesia, and Pakistan: An Analysis Based on Hazard Models. Population Studies, Vol. 37, No. 3. (Nov., 1983), pp. 417-432.

Nawaz, Shuja, The Mass Media and Development in Pakistan. Asian Survey, Vol. 23, No. 8. (Aug., 1983), pp. 934-957.

Ringheim, Karin, When the Client is Male: Client-Provider Interaction from a Gender Perspective, International Family Planning Perspectives, Vol. 28, No. 3 (Sept., 2002), pp. 170-175.

Robbins, P.T., Global Approaches to Development. Sociology of Development, University of London, (2001), pp. 29-37.

Sathar, Zeba; Nigel Crook; Christine Callum; Shahnaz Kazi, Women's Status and Fertility Change in Pakistan. Population and Development Review, Vol. 14, No. 3. (Sep., 1988), pp. 415432.

Simmons, George B., Family Planning Programs or Development: How Persuasive is the New Wisdom? International Family Planning Perspectives, Vol. 5, No. 3. (Sep., 1979), pp. 101-110.

Syed, Sabiha H., Communications Channels and Family Planning in Pakistan. Studies in Family Planning, Vol. 10, No. 2. (Feb., 1979), pp. 53-60.

www.unesco.org 